\title{
Review of Seismicity and Ground Motion Studies Related to the Development of Seismic Design Criteria at SRS (U)
}

Date E. Stephenson

Westinghouse Savannah River Cornpany

Savannah River Site

Aiken, SC 29808 


\section{Contents}

Introduction 1

Seismicity Database 3

Regional Seismicity 3

Rates of Occurrence 6

Maximum Magnitude 8

Attenuation Relations 9

Design Basis Earthquake 11

Studies Based Upon Deterministic and Single Model

Probabilistic Methodology 11

Historic Methodology 13

Studies Based on Multiple Model Probabilistic Methodology 14

Ground Motion Response Spectra 19

Housrier Response Spectra 19

URS/Blume Response Spectra 19

Nuclear Regulatory Commission Response Spectra 20

Department of Energy Response Spectra 21

Lawrence Livermore National Laboratory Spectra 21

Electric Power Research Institute Response Spectra 22

SRS Seismic Hazard and PGA for Restart in Relation to Other Similar Facilities in the Region 23

Seismic Instrumentation 27

Current Seismic Instrumentation 27

Planned Seismic Instrumentation 28

Programs for Resolving Outstanding Issues 29

Seismic Programs Associated with Reactor Restart 30

Long Terrn Seismic Programs 30

Conclusions 33

References 35

Tables 39 


\section{List Of Tables}

Table

1 Significant Earthquakes within 300 Kilometers of SRS (pages 41-46)

2 South Carolina Earthquakes, 1986 - 1989 (pages 47-48)

3 Recent Recorded Earthquakes near SRS (page 49)

$4 \quad$ Magnitude Recurrence Relations (page 50)

5 Summary of Dominant LLNL Seismic Sources and their Parameters (pages 51-52)

6 Summary of Dominant EPRI Seismic Sources and their Parameters (page 53)

7 Intensity-Based Peak Ground Acceleration Attenuation Models (page 54)

8 Magnitude-Based Peak Ground Acceleration Attenuation Models (pages 55-56)

$9 \quad$ Seismic Analysis of SRS Non-Reactor Facilities (page 57)

10 Interpreted Peak Ground Motions at the Richard B. Russell Site (page 58) 


\section{List Of Figures}

\section{Figure}

Historical Seismicity in the Southeastern United States, $1698-1977, \mathrm{~m}_{\mathrm{b}} \geq 0$ (page 3)

Historical Seismicity in the Southeastern United States, $1698-1977, \mathrm{~m}_{\mathrm{b}} \geq 3$ (page 4)

SRL Seismic Hazard Curve (page 11)

D'Appolonia Seismic Hazard Curve (page 12)

URS/Blume Seismic Hazard Curves for the Two Postulated Configurations of the Charleston Seismic Zone (page 13)

JBA Seismic Hazard Curves for Vogtle and the Historic Seismicity Assessment (page 13)

JBA Seismic Hazard Curves, One Taking a 200-Year Window and the Preferred Estimate Based on the Period of Completeness for the Catalog (page 14)

LLNL Seismic Hazard Curve (page 15)

LLNL. Best Estimate and Arithmetic Mean Hazard Curves: $M \geq 5$ (page 15)

LLNL Best Estimate and Arithmetic Mean Hazard Curves: $4<M<5$ (page 16)

LLNL Best Estimate and Arithmetic Mean Hazard Curves: $5<M<6$ (page 16)

LLNL Best Estimate and Arithmetic Mean Hazard Curves: $M \geq 6$ (page 16)

JBA Seismic Hazard Curve Using EPRI Data (page 17)

Housner Response Spectra for SRS (page 19)

URS/Blume Response Spectra for SRS (page 20)

NRC Response Spectra for SRS (page 20)

DOE Response Spectra for SRS (page 20)

LLNL Response Spectra for SRS: Velocity Versus Period for Various Recurrence Intervals (page 21)

LLNL Response Spectra for SRS: Velocity Versus Period for 1000 Year

Recurrence Interval: Various Percentile Spectra (page 21)

LLNL Response Spectra for SRS: Velocity Versus Annual Frequency of

Exceedance (page 21)

Uniform Hazard Response Spectra (EPRI) at Annual Frequency of Exceedance of $10^{-4}$ (page 22)

Uniform Hazard Response Spectra (EPRI) at Annual Frequency of Exceedance of $10^{-5}$ (page 22)

Uniform Hazard Response Spectra (EPRI) at Annual Frequency of Exceedance of $10^{-6}$ (page 22)

UBC Seismic Risk Zone Map (page 23)

ATC Seismic Risk Zone Map (page 24)

ANSI Seismic Risk Zone Map (page 24) 
Tri-Service Manuals Seismic Risk Zone Map (page 25)

28

Algermisson Seismic Risk Zone Map (page 26)

29

SRS SEISNET Station Locations (page 27) 


\section{List Of Abbreviations}

\begin{tabular}{|c|c|}
\hline AASHTO & American Association of State Highway and Transportation Officials \\
\hline ANSI & American National Standards Institute \\
\hline ARSZ & Adams Run Seismic Zone \\
\hline A.TC & Applied Technology Council \\
\hline BP & Before Present \\
\hline B: $) \mathrm{Z}$ & Bowman Seismic Zone \\
\hline DBE & Design-basis Earthquake \\
\hline DC)E & Department of Energy \\
\hline EPRI & Electric Power Research Institute \\
\hline GSA & General Services Administration \\
\hline JBA. & Jack Benjamin and Associates, Inc. \\
\hline LLNL & Lawrence Livermore National Laboratory \\
\hline M & Magnitude \\
\hline $\mathrm{m}_{\mathrm{b}}$ & Magnitude - Body Wave \\
\hline $\mathrm{m}_{\mathrm{b}}(\mathrm{L} \xi)$ & Magnitude - Body Wave (Lg) \\
\hline $\mathrm{M}_{\mathrm{D}}$ & Magnitude - Duration \\
\hline$M_{L}$ & Magnitude - Local \\
\hline MMI & Modified Mercalli Intensity \\
\hline MPSS: & Middleton Place - Summerville Seismic Zone \\
\hline $\mathrm{M}_{\mathrm{S}}$ & Magnitude -- Surface Wave \\
\hline NRC & Nuclear Regulatory Commission \\
\hline PGA & Peak Ground Acceleration \\
\hline PRA & Probabilistic Risk Analysis \\
\hline PSHA & Probabilistic Seismic Hazard Analysis \\
\hline PSRV & Pseudo Relative Response Velocity \\
\hline SBC & Southern Building Code \\
\hline SCNET & South Carolina Network \\
\hline SEAOC & Structural Engineers Association of California \\
\hline SEUSSN & Southeastern United States Seismic Network \\
\hline SHCP & Seismic Hazard Characterization Project \\
\hline SRL & Savannah River Laboratory \\
\hline SRS & Savannah River Site \\
\hline SRS SEISN ZT & Savannah River Site Seismic Network \\
\hline $\mathrm{UBC}$ & Uniform Building Code \\
\hline UHS & Uniform Hazard Response Spectra \\
\hline USAEC & United States Atomic Energy Commission \\
\hline USGS & United States Geological Survey \\
\hline VA. & Veterans Administration \\
\hline
\end{tabular}




\section{Introduction}

The seismic design criteria for critical facilities and the studies conducted as a basis for the criteria at the Savannah River Site (SRS) have been ongoing at various levels of intensity since 1968 by a number of organizations and individuals. There have been six studies of seismicity and seismic hazards performed for SRS, and all resulted in similar conclusions with respect to the design basis ground motion and hazard. The purpose of this report is to summarize the database and the results from these investigations into a single document that: (1) details the consistency of the results for SRS; (2) details their coherence with other similar facilities in the region; and (3) demonstrates the logic of the choice of the criteria for the restart of $K, L$, and $P$ Reactors.

Both traditional deterministic and more recent stateof-the-art probabilistic seismic hazard analyses have been performed for SRS to develop seismic design criteria. The original seismic criteria for SRS was defined in DPE 2383, "Earthquake Criteria for the Savannah River Plant" (Housner, 1968). These criteria were developed by G. W. Housner of the California Institute of Technology, an expert in earthquake engineering, J. W. Oliver of Lamont Geological Observatory of Columbia University, an expert in seismology, and V. T. Hurst of the University of Georgia, an expert in geology. The conclusions reached were that a repetition of the August 31, 1886 Charleston, SC earthquake in the meizoseismal area or possibly closer to the site posed the greatest potential for strong ground shaking at SRS. An estimate of $0.05 \mathrm{~g}$ ground motion at the site was developed from the historic data, but with the possibility of a similar event closer to the site, a 0.10 $\mathrm{g}$ ground motion was assigned to the site by Housner. Using these values and applying a safety factor, Housner recommended a design basis of $0.20 \mathrm{~g}$ for the SRS facilities and developed a fixed base foundation response spectra for this value at zero period.

The consulting firm of D'Appolonia, using the Nuclear Regulatory Commission (NRC) guidance, developed a seismic design for the Defense Waste Processing Facility at the site (D'Applolonia, 1979). This study proposed a $0.26 \mathrm{~g}$ horizontal ground motion for the design basis; however, this was refined in 1982 by the URS/Blume study, which updated the seismic design criteria. The results of this study, which was based on the methodology of NRC as outlined in Appendix A 10 CFR 100, is presented in "Update of Seismic Design Criteria for the Savannah River Plant" (DPE 3699, URS/Blume, 1982).
The URS/Blume criteria included a design basis earthquake (DBE) response spectra based on a peak ground acceleration (PGA) of $0.20 \mathrm{~g}$, enveloping two controlling earthquakes; a local event of magnitude 5.0 to 5.5 (MMI VIII); and a recurrence of the 1886 Charleston earthquake with a site intensity of MMI VII.

In the 1970s the Department of Energy (DOE) Headquarters requested the Lawrence Livermore National Laboratory (LLNL) to develop uniform design criteria for critical facilities at DOE sites throughout the United States. The results of these studies were published in 1984 in UCRL-53582, "Natural Phenomena Hazards Modeling Project: Seismic Hazard Models for Department of Energy Sites" (Coats and Murray, 1984). The earthquake hazard presented in this report was developed for a given site from a combination of recorded earthquake data, estimated earthquake magnitudes of known events for which recorded data were not available, review of local geological investigations, and use of expert judgement from seismologists and geologists familiar with the site. The results were presented as a frequency plot that gives the return period or annual probability of exceedance of different PGAs at the site. The results for SRS was $0.19 \mathrm{~g}$ for a return period of 5000 years, the same time period used in the URS/Blume study.

In the 1980s twin state-of-the-art seismic hazard studies were performed for SRS (Savy, 1988). One study, performed by LLNL, used the inputs and methodology developed by LLNL (through support from the U.S. NRC). The other study, performed by the firm of Jack Benjamin and Associates (JBA), used the methodology and inputs developed by the Electric Power Research Institute (EPRI: sponsored by the Seismic Owner's Group, a group of eastern U.S. electric utilities). The results for SRS from the LLNL study was $0.2 \mathrm{~g}$ with an annual probability of exceedance of $4 \times 10^{-4}$ for the best estimate and $2 \times 10^{-3}$ for a mean value. Using the EPRI methodology and input, J. A. Benjamin and Associates determined the annual probability of exceedance of $5 \mathrm{x}$ $10^{-5}$ for a mean value at $0.20 \mathrm{~g}$.

The development of the seismic criteria from the various studies resulted in various response spectra to be used for facilities at SRS. The NRC also developed a response spectrum that could be used by commercial nuclear facilities in lieu of a site specific spectra that was published in Regulatory Guidance (Reg Guide) 1.60 document (U.S. NRC, 1977). The NRC spectra is based 
on an evaluation of actual response spectra from many earthquakes recorded at sites. These response spectra developed for SRS and Regulatory Guide 1.60 are based on 7 percent damping, with the exception of the $\mathrm{H}$ isusner spectrum that was developed for 5 percent damping. The other spectra are normalized to $0.2 \mathrm{~g}$ with the exception of the DOE spectrum, which is normalized to $0.11 \mathrm{~g}$. The Housner and DOE spectra are very similar but considerably below those of URS/Blume and the NRC. Though the shapes of the curves are very sirnilar, the NRC values are somewhat higher at the high frequencies than the URS/Blume values.

The studies performed at SRS that used the deterministic methodology resulted in the selection of $0.2 \mathrm{gPGA}$ as the design basis for critical facilities. The studies that employed single model or multiple model probabilistic seismic hazard analysis have shown that at the $0.2 \mathrm{~g}$ level at SRS, the probability of exceeding this level of ground motion per year is in the range of $10^{-3}$ to $10^{-5}$, the lower probability levels for critical facilities reported by the Panel on Seismic Hazard Analysis of the National Research Council (1988). A review of the values used for other critical critical facilities in the region (SC, NC, and GA) has also shown the SRS design basis to be comparable for both deterministic and probabilistic design values. The range of the PSHA for SRS is consistent with the values of PSHA performed by LLNL and EPRI for many commercial nuclear power facilities. Therefore, the use of $0.2 \mathrm{~g}$ as the design basis earthquake ground motion for existing SRS facilities is appropriate and based on all results of the programs performed for SRS appears justified for use in restart analysis.

The NRC response spectra developed in Regulatory Guide 1.60 is being used in the studies related to the restarting of the existing SRS reactors. Because it envelopes all the other site specific spectra that have been developed for SRS, it provides significant conservatism in the design and analysis of the reactor systems for ground motions of this value or with these probability levels. This spectral shape is also the shape used for the design of the recently licensed Vogtle Nuclear Station, located south of the Savannah River from the SRS.

This report provides a summary of the database used to develop the design basis earthquake. This includes the seismicity, rates of occurrence, magnitudes, and attenuation relationships. The Design Basis Earthquake Section summarizes the studies performed and methodologies used to establish the design basis earthquake for SRS. The ground motion response spectra developed from the various studies are summarized in Ground Motion Response Spectra. The seismic hazard and GPAs developed for other critical facilities in the region are discussed in SRS Seismic Hazard and PGA for Restart in Relation to Other Similar Facilities in the Region. The SRS seismic instrumentation is presented in Seismic Instrumentation and the programs for resolving outstanding issues are discussed in Programs for Resolving Outstanding Issues. 


\section{Seismicity Database}

\section{Regional Seismicity}

The historic record of seismicity for the southeastern United States includes the pre-instrumental database that extends as far back as 1698 and the post-instrumental seismic network database beginning July 1, 1977. The division was determined from the differences in the levels of completeness and accuracy with respect to earthquake size and location. Prior to the mid-1970s, the earthquake catalog consisted primarily of earthquakes large enough to be felt. Following the installation of networks of seismograph stations during the mid to late 1970 s, many small earthquakes were located. The accuracy of epicentral locations for the pre-instrumental events averages in the tens of kilometers, and the depths could not be determined. A higher degree of epicentral location accuracy (within a few kilomete,s) and reliable focal depths (less than 5 kilometer error estimates) have since been obtained with the network data.

\section{Pre-Instrumental Seismicity}

Most of the information on earthquakes in the SRS region before the early 1970 s was derived from intensity data, which chronicle the effects of earthquakes on people, structures, and land forms. Although different intensity scales have been used during various periods of the historical record, the Modified Mercalli Intensity (MMI) Scale of 1931 is used for the descriptive ranking of earthquake effects in this report. Epicenters of earlier earthquakes were set at or near the centers of the maximum intensity of shaking as determined from the observed effects. There is considerable uncertainty (up to several tens of kilometers) in locating the epicenters with this method because it depends upon the population distribution of the region in which the earthquake occurred.

Several intensity-to-magnitude conversion relationships have been developed to relate the size of the earthquake based on observed effects to the size based on instrumental responses. When the local or regional intensity-to-magnitude conversion relationship has been established, it is applied to the historical data for estimation of magnitude. These various magnitude scales $\left[\mathrm{m}_{\mathrm{b}}, \mathrm{m}_{\mathrm{b}}(\mathrm{Lg}), \mathrm{M}_{\mathrm{s}}\right]$ must be related on a common base scale to establish a magnitude recurrence relation. Therefore, the relationship between the magnitude scales used for the historical database and the common base magnitude must also be established. When the intensity to magnitude conversion relationships and the

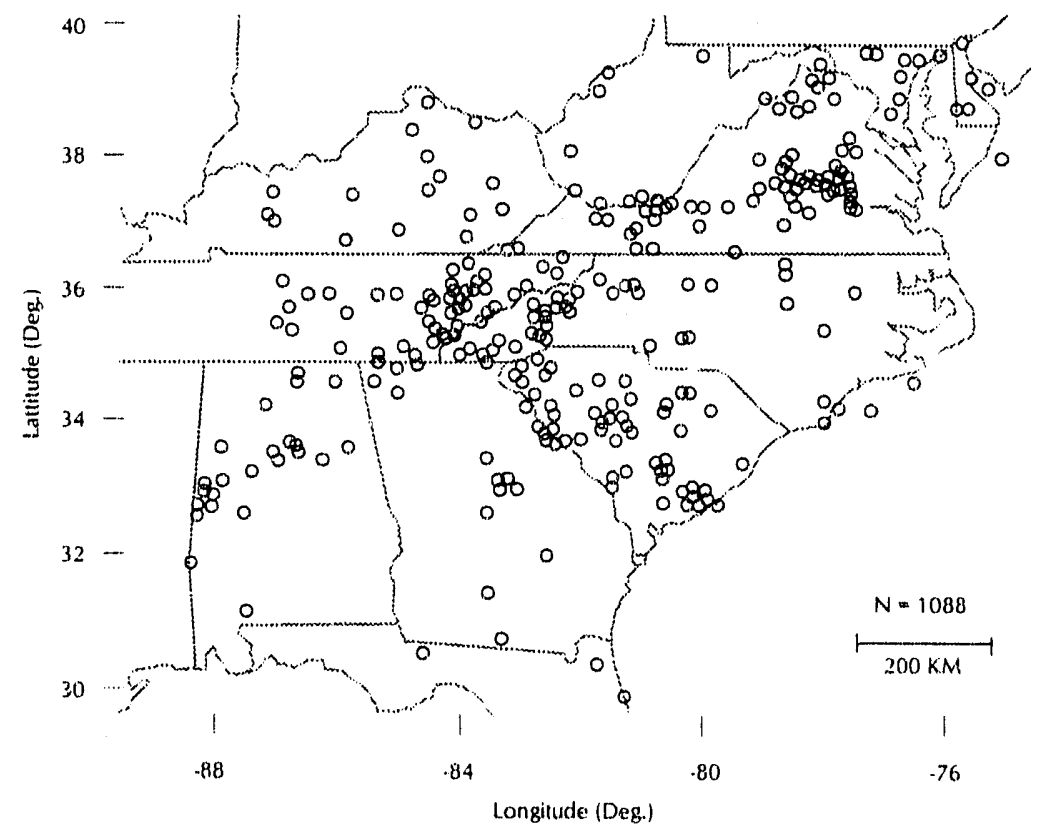

Figure 1. Historical Seismicity in the Southeastern United States, $1698-1977, \mathrm{~m}_{\mathrm{b}} \geq 0$ 


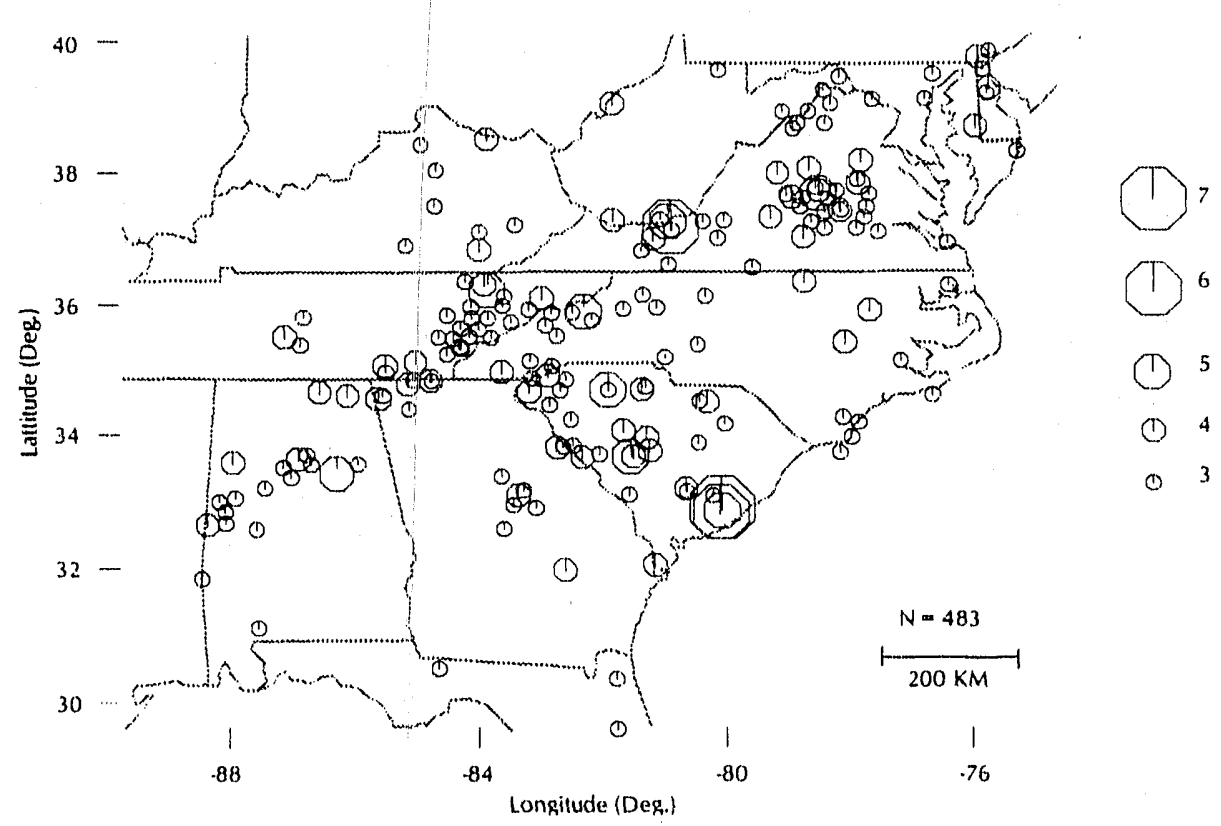

Figure 2. Historical Seismicity in the Southeastern United States, $1698-1977, \mathrm{~m}_{\mathrm{b}} \geq 3$

magnitude scale relationships have been applied to the historical database, the seismicity can be catalogued in terms of a common base magnitude.

The southeastern United States Seismic Network (SEUSSN) earthquake database lists 1088 events for the pre-instrumental network period from 1698 to July $\therefore, 1977$ (Figure 1). A total of 483 events had magnitudes greater than $3.0\left(\mathrm{M}=\mathrm{m}_{\mathrm{b}}, \mathrm{m}_{\mathrm{b}}(\mathrm{Lg}), \mathrm{M}_{\mathrm{D}}\right.$, or $\mathrm{M}_{\mathrm{L}}$; Figure 2). Events with magnitudes less than 3.0 are not considered significant for derivations of recurrence intervals. The catalog was reviewed for significar. earthquakes that may have affected the region within a 300 -kilometer radius of the SRS. Reported earthquakes of MMI IV or greater or magnitude 3.0 or greater that occurred within the region, and earthquakes that occurred outside the region but that may have been felt at the SRS, are included in Table 1.

\section{Post-Instrumental Seismicity}

The SEUSSN earthquake database lists 847 events ( 89 with $M>3.0$ ) for the post-instrumental network period from July 1, 1977 through 1988. Significant earthquakes $(M \geq 3.0)$ that occurred within 300 kilometers of the SRS are included in Table 2. Earthquakes occurring in South Carolina that were located by the University of South Carolina seismological laboratory are listed in Table 2, and a listing of recorded earthquakes near the SRS is presented in Table 3.
Since the installation of the SRS seismic network in 1976, two small earthquakes have been recorded onsite (Stephenson et al., 1985; Talwani et al., 1985; and Stephenson, 1988). A magnitude 2.6 earthquake occurred on June 9, 1985, at a depth of 1.0 kilometer, and a magnitude 2.0 earthquake occurred on August 5, 1988 , at a depth of 3.0 kilometers. The earthquakes occurred approximately 4 kilometers apart in the south-central SRS. The June 1985 event was MMI III and was felt in the central portion of the SRS. The August 1988 event was not felt and was estimated to be MMI I-II. Neither of the two earthquakes triggered seismic alarms in SRS facilities, indicating the ground motion acceleration accompanying the events was less than $0.002 \mathrm{~g}$ (Stephenson et al., 1985; Stephenson, 1988). To date, the instrumental recordings of the low level seismicity occurring at SRS suggest that the peak ground acceleration accompanying the activity is very smal!.

\section{Paleoseismicity}

Recent investigations have extended the hisiorical seismicity record by means of paleoseismicity studies. In the vicinity of Che rleston, South Carolina, Talwani and Cox (1985) and Obermeier et al. (1985) observed cross-cutting relationships in shallow sediments and obtained age dates of organic material trapped in seismically induced liquefaction sites. The observations allowed time constraints to be established for two 
distinct, moderate to large earthquakes occurring before 1886 and after $3740 \pm 110$ years ago, which suggested a recurrence rate of 1500 to 1800 years for destructive earthquakes in the area. Obermeier et al. (1986) discovered multiple generations of prehistoric Holocene earthquake-induced sandblows widespread throughout sites in Coastal South Carolina. These sandblows are more widely distributed than features associated with the 1886 event, suggesting multiple events at various locations or perhaps one shock stronger than the 1886 event, but with approximately the same epicentral location.

Amick (1990) investigated locations from the Chesapeake Bay area of Virginia to the Georgia-Florida border that had shallow subsurface conditions similar to liquefaction sites in the Charleston area. The locations, which were considered to have equivalent paleoliquefaction potential, provided evidence for four large prehistoric earthquakes in South Carolina. Three events, occurring approximately 1230 years before present (BP), 3200 years BP, and 5150 years BP, were attributed to a southern source, probably in the Charleston area. Prehistoric earthquakes in the Char'eston vicinity appearea to have induced soil liquefaction in the area extenting from Myrtle Beach, South Crolina, to Savannah, Georgia.

An earthquake occurring approximately $1800 \pm 200$ years BP was attributed to a northeastern South Carolina source, possibly in the Myrtle Beach-Georgetown area. Amick (1990) postulated the occurrence of two additional prehistoric earthquakes in this region, one approximately 600 years BP, and one prior to 5150 years $\mathrm{B}_{\mathrm{i}}$. However, Arnick indicated that these events were currently uncertain and studies confirming the occurrence of these events are in progress. The confirmed occurrence of these postillated events will affect the magnitude recurrence relation that was estimated for the Charleston area.

\section{Spatial Relationships}

Within the southeastern United States, seismicity generally occurs in distinct zones superimposed on a regional background of very low level seismicity. Bollinger et al. (1987) divided the region into general zones based on clusters of earthquake epicenters corresponding approximately to the axis of the Appalachian Mountains, the Piedmont physiographic province of Virginia, and the South Carolina-Georgia Coastal Plain province. Eastern North Carolina and the area from southern Georgia to Florida are marked by a very low level of seismic activity.
The spatial distribution of earthquake epicenters is non-random in the southeastern United States (Bollinger, 1973a, b; Hadley and Devine, 1974). Patterns of epicentral distributions are parallel and oblique to the northeastern trend of tectonic structures in the region. The Valley and Ridge and the Blue Ridge provinces exhibit seismic activity throughout the region. The Piedmont and Coastal Plain provinces exhibit seismicity in epicentral clusters only in Virginia, South Carolina, and Georgia. The earthquake epicenters located by network monitoring occur in the same general spatial pattern as the historical pre-instrumental earthquakes. Although the instrumentally located events are typically smaller than the historic events, the general pattern of seismically active/inactive areas appears to hold.

Variation to the distribution pattern occurs in the level of seismicity from the historical period until recently. Relative decreases in seismicity were observed in the Appalachian area of Virginia and in the South Carolina Piedmont, and relative increases in seismicity were observed in the northeastern Kentucky Plateau and in the Appalachian area of southeastern Tennessee (Bollinger et al., 1988). Because SRS is located in the Coastal Plain province, close to the Piedmont province, seismicity patterns in these two physiographic provinces are significant.

\section{Piedmont Province}

Most of the seismicity in the Piedmont province of South Carolina since 1979 has been spatially associated with reservoirs, specifically Lakes Jocassee and Keowee in northwestern South Carolina and Monticello Reservoir in central South Carolina. However, the largest earthquake in the Piedmont of South Carolina was the MMI VII to VIII event that occurred in Union County in 1913 (Taber, 1913; Reagor et al., 1980).

Low level seismic activity has occurred and has been monitored at Lake Jocassee since its impoundment in October 1979. The largest earthquake, magnitude 3.9, occurred on August 29,1979. The seismicity is typically shallow, within the top 5 kilometers. Composite focal mechanisn solutions indicated strike slip motion with the axis of maximum horizontal compression oriented approximately $\mathrm{N} 60^{\circ} \mathrm{E}$.

An earthquake of magnitude 3.2 occurred on February 13, 1986, at Lake Keowee, in northwestern South Carolina, a region of prior low level seismicity (Acree et al., 1988). A second main shock followed by a sequence of aftershocks began in June 1986. The events in both sequences were shallow, less than 4 kilometers deep, 
and focal mechanism solutions suggested a slip along a northeast or northwest striking surface.

Seismicity has been monitored at Monticello Reservoir since its impoundment in December 1977. The initial seismic activity through 1985 occurred within the top 6 kilometers in the vicinity of the reservoir and was associated with fractured rocks surrounding granitic plutons. Composite focal mechanism solutions indicated that the seismicity occurred by thrust faulting on pre-existing fractures, and the direction of the maximum compressive stress was oriented northeast.

Major exceptions to the reservoir induced seismicity include the two swarms of earthquakes occurring in the vicinity of Newberry from July to August 1982 and in April 1983 (Rawlins, 1986). The swarms included five felt earthquakes of magnitudes greater than 2.0. The seismicity was shallow (within the top 5 kilometers) and occurred at the flanks of a granitic pluton.

Single event focal mechanism solutions were obtained for three of the larger events, which indicated reverse movement on northwest striking faults. The direction of maximum compressive stress was subhorizontal and oriented in the regional east-northeast direction. Therefore, although the majority of the stress direction determinations within the South Carolina Piedmont province were established on the basis of earthquakes associated with reservoirs, the direction of maximum compressional stress that was determined from tectonic earthquakes indicated agreement within the regional stress regime.

\section{Coastal Plan Province}

Seismicity in the Coastal Plain of South Carolina occurs in three distinct zones. The Middleton Place-Summerville seismic zone (MPSSZ), about 20 kilometers northwest of Charleston; the Bowman seismic zone (BSZ), about 60 kilometers northwest of the MPSSZ; and the Adams Run Seismic zone (A.2SZ), about 30 kilometers southwest of the MPSSZ (Tarr et al., 1981). Additional earthquakes large enough to be felt have also occurred in spatially isolated areas of the Coastal Plain.

The largest earthquake in the southeastern United States occurred in the South Carolina Coastal Plain in $1886\left(m_{b}=6.7, M_{\mathrm{s}}=7.7\right.$, MMI X). The epicenter was probably about 20 to 30 kilometers northwest of Charleston in the MPSSZ, the largest and most active seismic zone. Talwani (1982) inferred the existence of two intersecting subsurface fauits from relocations of instrumentally recorded earthquakes in the MPSSZ, the Ashley River, and the Woodstock faults. The Ashley River fault was interpreted to be shallow, approximately 4 to 8 kilometers, and the Woodstock fault was interpreted to be deeper, approximately 9 to 13 kilometers. Two distinct regions of seismicity were thus interpreted for the MPSSZ. Composite and single event focal mechanism solutions indicated that the seismicity may be occurring on the Ashley River fault, which may be either a steeply dipping thrust fault or a shallow dipping reverse fault striking northwest. Composite focal mechanism solutions indicated strike slip motion on the Woodstock fault, a north-northeast trending fault. The direction of maximum compressive stress was subhorizontal and oriented east-northeast.

A series of felt events $\left(3<M_{L}<4\right)$ occurred near Bowman, SC between 1971 and 1974 (Tarr and King, 1974; Tarr, 1977), which defined the Bowman seismic zone (BSZ). The BSZ has continued to exhibit sporadic shallow ( $<6$ kilometers) seismicity. The seismicity is considered to be associated with the border fault of a buried Triassic basin.

The Adams Run seismic zone was defined on the basis of four small (magnitude <2.5) earthquakes that occurred in December 1977 (Tarr et al., 1981). Relocations o: these events using a revised velocity model led Talwani to interpret the presence of the subsurface, north northeast trending Woodstock fault. No fault plan solutions were obtained for the events, and the absence of recurring seismicity suggests that the earthquakes may constitute a cluster of activity instead of a distinct zone.

A focal mechanism solution for the June 1985 earthquake at SRS suggested strike slip motion and a north-northeast direction of maximum compressive stress (Talwani et al., 1985). Right lateral strike slip motion on a northwest trending fault or left lateral slip on a northeast trending fault were suggested from the focal mechanism solution. Because of the proximity and orientation of the Dunbarton basin (a Triassic basin), slip along the northeast plain was interpreted. The northeast direction of maximum horizontal compressive stress was subsequently confirmed through a series of in-situ stress measurements conducted in deep coreholes at SRS (Zoback and Moos, 1989; Zoback et al., 1989).

\section{Rates of Occurrence}

Recurrence relations were developed for the southeastern United States and for various sub-regions (three physiographic provinces and four seismic zones) 
b.ssed on a combination of historical (1698 through 1977) and instrumental network (1978 through 1986) data (Bollinger et al., 1989). The data were converted to magnitude $\left[\mathrm{m}_{b}(\mathrm{Lg})\right]$ values to provide a database of comparable values. After attempts to perform intensity-magnitude conversion, which were based on relations derived from the New Madrid seismic zone in the cencral United States, failed to converge, an intensitymagnitude conversion was developed specifically for the region (Sibol et al., 1987).

Magnitude recurrence relations are developed from the equation

$\log N=a-b M$

where

$N=$ the number of earthquakes above a given inagnitude and

$M=$ the magnitude under consideration.

As the threshold of earthquake size under consideration in a region is decreased, the number of earthquakes above the magnitude increases. The rate of occurrence of events greater than the given magnitude is measured by the $a$ and $b$ values. The value determined for a is the activity parameter, which is used for comparisons of seismicity levels among regions. To indicate the recurrence rate for a given magnitude earthquake, $b$ values are used. The smaller the $b$ value, the more numerous are the earthquakes within a specific time interval. Earthquakes with magnitudes less than 3.0 are typically not used in establishing recurrence relations for a region. The recurrence relations developed for the southeastern U.S. and the various subregions are listed in Table 4

The sourheastern United States was divided into the Valley and Ridge/Blue Ridge, Piedmont and Coastal Plain physiographic provinces, and the Giles County, Virginia; eastern Tennessee; central Virginia; and Charleston, South Carolina seismic zones. The recurrence rate for the region as a whole indicated a high $b$ value $(0.84)$, which represent; a higher proportion of smaller magnitude earthquakes. The a value normalized for the area (1.15) indicated an intermediate activity level for the region. The cumulative recurrence relation for the southeastern region $\left(\log \mathrm{N}_{c}=3.13-\right.$ $0.84 \mathrm{~m}_{\mathrm{b}}(\mathrm{Lg})$ ) corresponds to the relations derived for other regions of the central and eastern United States, the New Madrid area $\left(\log N_{c}=3.43-0.88 \mathrm{mb}_{\mathrm{b}}\right)$ and the New. England area $\left(\log \mathrm{N}_{\mathrm{c}}=2.87-0.84 \mathrm{M}_{\mathrm{c}}\right)$, and with results obtained by Chinnery (1979).

The Valley and Ridge/Blue Ridge physiographic province includes the Giles County, Virginia and the eastern Tennessee seismic zones. The second largest earthquake of the region occurred at Giles County in 1897 (MMI VIII). Aftershocks from this event were removed from the earthquake database to establish the recurrence rate for the zone and for the region.

Recurrence relations for the province and for the eastern Tennessee seismic zone indicated high $b$ values ( 0.82 and 0.90 , respectively). However, the recurrence relation for Giles County (0.64) indicated an extremely low. b value, which suggests a low proportion of small magnitude events relative to the geologic province and the eastern Tennessee seismic zone. Although the easterii Tennessec seismic zone has been the most seismically active area of the region for the past 10 years, the largest event $\left(m_{b} 4.6\right)$ was smaller than other known events in the southeast. The activity parameter norrualized for the area was highest for eastern Tennessee (2.06) and intermediate for the Valley and Ridge/ Blue Ridge province and for the Giles Cotinty seismic zone.

The Piedmont physiographic province includes the central Virginia seismic zone, which has been characterized by the occurrence of persistent, low-level seismicity. The tecurrence relation established for the Piedmont province indicated an intermediate a value $(0.94)$ and a high $b$ value $(0.81)$ in contrast to the low a and $b$ values ( 0.64 and 0.63 , respectively) established for the central Virginia seismic zone.

Of the distinct seismic zones encompassed by the Coastal Plan province, the Charleston area has been and remains the most seismically active. For the Coastal Plain province, the recurrence relation indicated a low activity parameter (a value $=0.67$ ) and an intermediate $b$ value (0.78). The Charleston seismic zone includes the previously defined zones in the vicinity of Charleston, the Middleton Place-Surnmerville seismic zone (MPSSZ) and the Adams run seismic zone (ARSZ). The largest earthquake of the southeastern United States occurred in the Charleston zone in 1886 (MMI $\mathrm{X}$ ). The aftershocks from this event were removed from the data prior to establishing of the recurrence relation. Although the activity parameters determined from the recurrence relation ranged from 0.67 , a low'value for the Coastal Plain, to 1.99, a high value for the Charleston seismic zone, the b values were comparable. 


\section{Maximum Magnitude}

The historical seismicity record measured earthquakes by intensity, for example, from the observed elfects on people, structures, and landforms, by the decrease of damage with distance, and from the extent of the felt area. The magnitude of an earthquake is defined from the amplitude of motion on a standard instrument normalized to account for the separation of the instrument and the earthquake. In the SRS region, several magnitude scales that are not exactly equivalent are commonly used. The reported magnitudes, however, are approximately equivalent to body wave magnitude. The uncertainty in intensity values is \pm 0.4 to 0.6 intensity units, and the uncertainty of instrumentally determined magnitudes is about \pm 0.3 magnitude units.

The Charleston area is the most significant source of seismicity affecting the SRS, both in terms of maximum historical site intensity and in the number of earthquakes felt in the area including SRS. The greatest intensity felt at SRS has been estimated at MMI VI to VII and was produced by the MMIX earthquake that struck Charleston on August 31, 1886.

The 1913 earthquake that oscurred in Union County, which is about 150 kilometers north of the SRS, is the event closest to SRS outside the Charleston area with an epicentral intensity greater than or equal to VII. This carthquake was felt at Aiken with an intensity of II to III (Taber, 1913). Several other earthquakes, including aitershocks from the 1886 Charleston event, were felt in the area, including SRS, with intensities that were estimated to be less than or equal to IV. Earthquakes that have been reported within 80 kilometers of the SRS include the July 26,1945 , intensity MMI $\mathrm{V}$ to the northeast, and the October 28, 1974, intensity IV earthquake to tire north of the SRS. A survey following the 1974 event indicated that it was felt by a few individuais at SRS.

Two earthquakes of MMI III or less are known to have occurred within the borders of SRS. On June 9, 1985, an intensity III earthquake with a local magnitude of 2.6 occurred at SRS (Stephenson et al., 1985; Talwani et al., 1985). Felt reports were concentrated near the western edge of the central portion of SRS. A more recent event, estimated as an MMI I to II earthquake occurred August 5, 1988, with a local magnitude of 2.0 .

A personnel survey at SRS during the earthquake indicated that it was not felt (Stephenson, 1988). Neither of these earthquakes triggered the seismic alarms at SRS facilities, indicating that the acceleration accompanying the seismicity was less than $0.002 \mathrm{~g}$ (Stephenson et al., 1985; Stephenson, 1988). An $M_{L} 2.6$ earthquake (local magnitude) occurred in Aiken, which is approximately 30 kilometers north of SRS, on February 17, 1988. Felt reports indicated that this event was felt in the Aiken area, at SRS, and the surrounding region. These earthquakes were of similar magnitude and intensity of recent events with epicentral locations southeast of the SRS.

Large events that occurred outside the 300 kilometer radius of SRS include the $\wedge$ Madrid, Missouri sequerise of 1811 and 1812 (abou, 350 kilometers west-northwest of SRS) and the Giles County, Virginia earthquake of May 31, 1897 (about 450 kilometers north of SRS). The intensities at the epicenters of the largest New Madrid earthquakes have been estimated as MMI X to XII. The events may have been felt in the area including SRS with an intensity of MMI V to VI (Nuttli, 1973). The intensity at the epicenter of the Giles County, Virginia, event has been estimated at MMI VIII and may have been felt in the area with an intesisity of MMI III.

The maximum earthouge intensities werc considered in the URS/Blume (1982) report for the three seismic source regions: the Appalachian Mountains, the Coastal Plain, and the Charleston seismic zone. The maximum postulated events for the seismic source regions are as follows:

- Appalachian Mountains: A MMI VIII event along the fall line closest to SRS (45 kilometers from the central SRS area)

- Coastal Plain: A MMI VII event near SRS or a MMI $\mathrm{X}$ event at Bowman (95 kilometers from central SRS

- Charleston seisnic zone: A MMI X event at Middle. ton Place (145 kilometers from central SRS)

LLNL developed seismic hazard calculations for nuclear facilities in the eastern U.S.; this was based on a panel of seismic experts estimation of source, seismicity parameters (i.e., activity rates, b values, and maximum magnitudes), and the degree of uncertainty for each factor (Bernreuter et al., 1989). A summary of the dominant seismic sovices and their parameters is presented in Table 5. The experts who predict the greatest hazard assurne that the Charleston seismic zone, with a maximum of 7.0 or greater, extends to SRS, or that the Charleston source has a maximum magnitude of 7.5, a low b value, and a high activity rate.

The EPRI seismic hazard calculations (McGuire et al, 1989) use the seismic sources and seismicity parameters 
developed by earth-science teams. To characterize uncertainty, each team specified its confidence that the source existed (the probability of activity, $\mathrm{P}^{\mathrm{a}}$ ) and probability distributions for the source's activity parameters. A summary description of the EPRI seismic sources that dominate the calculated hazard at SRS is presented in Table 6 . The activity probability was used to characterize alternative hypotheses about the seismic sources near SRS. For all teams, the major contributor to the seismic hazard is a host zone, a source zone that includes SRS.

Based on the EPRI study of the maximum magnitude issue, Coppersmith and Youngs (1989) concluded the following for the central and eastern U.S.:

- The rate of occurrence of large earthquakes within stable continental crust is very low relative to plate boundary regions. Fewer than 60 earthquakes have occurred in the past 200 years with a magnitude equal to or greater than 6.0 and only 8 of magnitude 7.0 or greater.

- Expressed in terms of moment magnitude per year, about 64 years have passed since the last $M \geq 7$ event in stable continental regions world wide and more than 150 years since the last $M \geq 8$ event.

- Most large events (68 percent) occurred within the location of prior seismicity (stationarity).

- Intra-continental rifts and passive margins (formerly extended continental crust) are significant locations of seismicity within stable continental regions. About 75 percent of earthquakes $(M \geq 5)$ are associated with extended continental crust, 35 percent with passive margins, and 40 percent with imbedded rifts. Rifts with the most recent extensional activity occurring during the Mesozoic are the most seismically active.

- Extended crust is significant from the standpoint of large earthquakes in that 70 percent of the $M \geq 6$ earthquakes and ail eight of the $M \geq 7$ earthquakes are associated with extended crust.

The significance of the conclusions that associate large earthquakes with extended crust pertains to the geologic structures underlying SRS. The Dunbarton basin is a well-researched rift basin formed during the Mesozoic under extensional stress conditions. Although none of the known large earthauakes occurred at SRS, the Charleston area (thought to be an area of extended crust approximately 90 miles from the central SRS) was the location of a moment magnitude 7.5 earthquake in 1886.

\section{Attenuation Relations}

When the seismic activity has been determined within a source region, the effects of the seismicity must then be determined. Attenuation relationships are transfer functions that relate information regarding the seismic source to the site under study in terms of structurally relevant parameters (i.e., acceleration, velocity, and spectral acceleration). The attenuation relationships are inexact because of inherent uncertainties in earthquake triggering mechanisms, variations in travel paths, variable site conditions, and the limited descriptive capability of the parameters used. Because probabilistic models include the spectrum of uncertainties associated with these relationships for any event at any location, all possible outcomes for the site are covered. The outcomes ate expressed in terms of how likely they are to occur.

The attenuation relationships were derived empirically. Models for the attenuation of site intensity were initially developed because of a lack of strong motion data and the availability of intensity data. The site intensities were then converted to ground motion parameters, particularly peak ground acceleration (PGA), by using existing eastern strong motion data in conjunction with data from western stutes. The epicentral intensity as a parameter in the attenuation model was converted to body wave magnitude using an area-specific intensity to magnitude conversion relationship.

The variation of the data around the mean recurrence relationship is a significant property of the ground motion parameter expression. The statistical properties of peak acceleration are characterized by the natural logarithm of acceleration. Dispersions are expressed in terms of the standard derivation of o PGA where PGA is the peak ground acceleration $\left(\mathrm{cm} / \mathrm{sec}^{2}\right)$.

The seismic hazard at the site is generated by one of two types of events: near-field earthquakes of small to moderate magnitude in the host region and large earthquake motion from distant sources. The energy of near-field events is released at the site at high frequencies whereas large distant earthquakes transmit low frequency surface wave motion.

Site-specific and regional ground motion attenuation relationships have been derived by a number of researchers for SRS and presented in reports by Housner (1968), Stephenson and Marine (1978), D'Ap- 
polonia (1980), URS/Blurne (1982), Jack Benjamin and Associates (MicCann, 1986), LLNL (Savy, 1988), and EPRI (McGuire et al., 1989). The intensity-based peak ground acceleration moduls are listed in Table 7 and the magnitude-based attenuation models are listed in Table 8. 


\section{Design Basis Earthquake}

This section describes, in summary form, the studies and methodologies used to establish the design basis earthquake and associated ground motion for the SRS. The original design of SRS facilities in the early 1950s used only the 1946 Uniform Ruilding Code (UBC) for earthquake loading because no nuclear facilities codes, standards, or regulations were established at the time of construction. The SRS facilities have undergone upgradcs over the years to improve seismic resistance. These upgrades have been based upon the studies described in this section; the criteria and methodologies used in performing these studies have been based on NRC regulations.

\section{Studies Based Upon Deterministic and Single Model Probabilistic Methodology}

A deterministic seismic hazard analysis selects one or more earthquakes within tectonic provinces and then assumes them to occur at the site or the closest point within the province to the site. This is the procedure outlined in Appendix A to 10 CFR 100 for nuclear power plants. Ground motions are then obtained by attenuation relations or seismograms either real or synthetic. This is in general the methodology employed by Housner in 1968 .

Housner (1968), using the existing catalog of historic seismic events in the region, the geologic literature, and attenuation relations, developed a design basis earthquake ground motion of $0.20 \mathrm{~g}$ for the SRS facilities. The results of the study were summarized in the report as follows:

"The strongest shaking experienced at the site was that produced by the Charleston earthquake of 31 August 1886. On the basis of the seismicity of the general area and the Hurst geology report, it was concluded that the greatest likelihood of strong shaking in the future is a repetition of the 1886 shock near Charleston, or possibly west of Charleston somewhat closer to the site. In as much as a 5 percent g ground motion at the site was estimated for the 1886 shock, a 10 percent $g$ ground motion might be a possibility if a similar earthquake were located somewhat further west. The plant should, of course, have an appropriate factor of safety over and above such possible expected ground motion to take care of unforeseen contingencies, etc. Accordingly, it is recommended that the plant be checked for safe shutdown using the 20 percent $\mathrm{g}$ design spectrum. These spectrum curves have the same shape as given in TID 7024 (Nuclear Reactors and Earthquakes, published by the USAEC Division of Technical Information) but are reduced to 10 percent $\mathrm{g}$ maximum acceleration at zero period. Alternatively, where appropriate, detailed vibration analyses may be made using the accelerograrns recorded at Taft, California on 21 July 1952, scaled so that the spectrum curves for the ground motion are not below those of design spectrum curves for periods less than one second and for damping of 5 percent of critical or greater."

Studies were conducted using a combination of deterministic and single model probabilistic methodologies for the SRS in 1978 by the Savannah River Laboratory (Stephenson and Marine, 1978) and in 1979 by the consulting firm of D'Appolonia (D'Appolonia, 1979). In the SRL study, the design basis ground motion of $0.20 \mathrm{~g}$ was assumed. D'Appolonia, using deterministic methods, proposed a site intensity of MMI VIII, and using the Trifunac and Brady 1975 attenuation relationships, calculated a site ground motion of $0.26 \mathrm{~g}$. In both studies the methodology of the NRC was used to

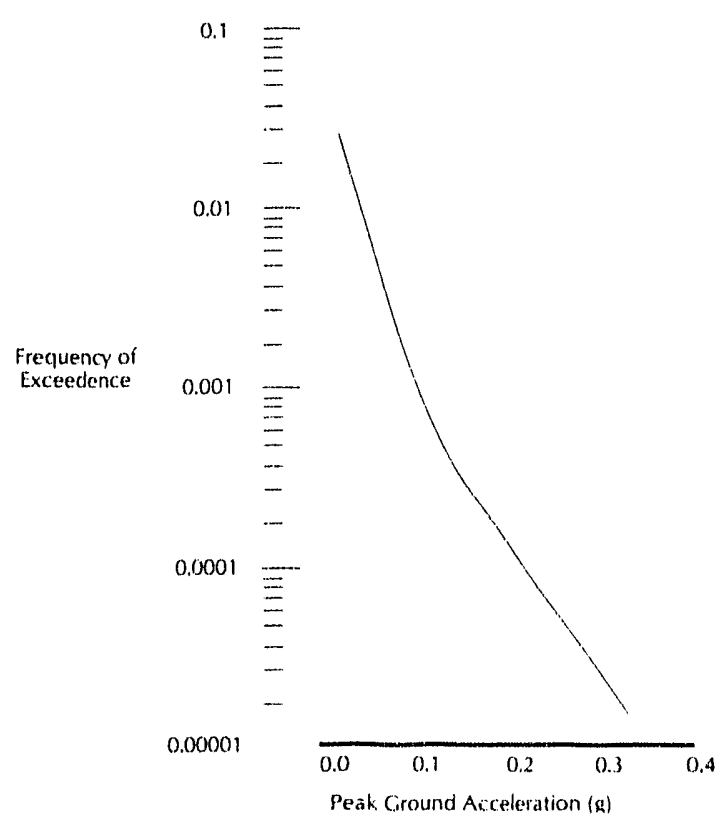

Figure 3. SRL Seismic Hazard Curve 
determine seismic zones though a single model seismic hazard analysis was applied to arrive at the probability of exceeding the ground motion. The SRL study (Figure 3) predicted a value of $1 \times 10^{-4}$ per year probability of exceeding $0.20 \mathrm{~g}$ at SRS (Siephenson and Marine, 1978). The results obtained by D'Appolonia (Figure 4) for the probability of excceding $0.20 \mathrm{~g}$ per year was $5.0 \mathrm{x}$ $10^{-5}$ (D'Appolonia, 1979).

The report by the consulting firm URS/Blume titled "Update of the Seismic Design Criteria for the Savannah River Plant" (DPE 3699) was issued in September. In performing the work to prepare this report, URS/ Blume reviewed large amounts of geologic, seismologic, and seismotectonic data relating to SRS and the surrounding regions. Following the procedure outlined by the NRC in Appendix A 10 CFR 100, the geologic structures in the region within a 200 mile radius of the site were evaluated for possible correlation with seismicity. The local geology and structures were also evaluated. The recent work in the specific vicinity of the 1886 Charleston earthquake performed by the U. S. Geological Survey (USGS) under contract to the NRC was reviewed and interpreted for use in the seismotectonic models. Strong ground motion at the site was evaluated from both deterministic and probabilistic (single model) perspectives.

From this study, URS/Blume determined that no capable faults (movement within the last 35,000 years)

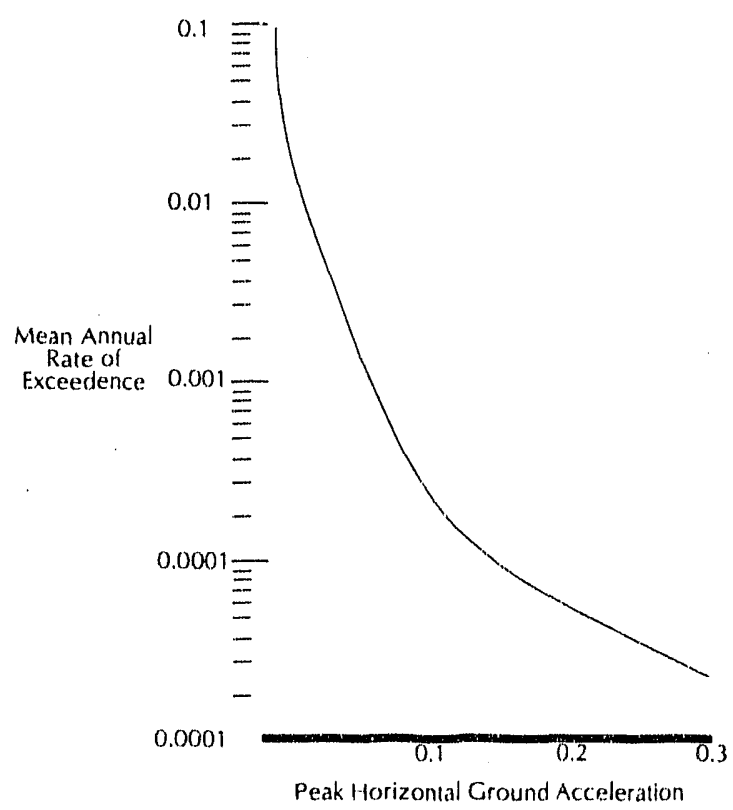

Figure 4. D'Appolonia Seismic Hazard Curve are known to exist in the $S ? S$ region and that the known seismicity cannot be correlated with any well-identified geologic structures. The information in the literature and ongoing studies do not resolve the questions concerning the physical nature or geographic extent of the seismotectonic regime that produced the 1886 Charleston earthquake. The available evidence indicated that the recurrence of that event is more likely in the vicinity of the 1886 meizoseismal area than elsewhere. Yet, URS/Blume considered the possibility that earthquakes of similar magnitude might also occur at other locations where large northeast-trending faults are intersected by large northwestward extrapolated faults or fracture zones. Strengths and weaknesses of several postulated seismotectonic models of the 1886 Charleston earthquake were evaluated and discussed in some detail in the URS/Blume report.

Studies of SRS geology have resulted in identifying Coastal Plain sediments consisting largely of unconsolidated cross-bedded sands, sandy limestones, silts, and clays which vary both vertically and laterally across the site. The Pen Branch fault, recently interpreted through seismic reflection and drill core data, is closely associated with the border fault of the Triassic basin. A crystalline basement exists in the northwestern part of the site, and Triassic rocks exist in the southeastern section. Other high-angle faults were known to exist in the basement, and although none of these faults were considered capable in the sense of NRC regulations, their possible implications were considered.

The strong seismic ground motion at the site was evaluated by URS/Blume from two perspectives. First, an analysis based on an estimate of the maximum earthquake potential of various seismic zones in the region following deterministic methodology was performed. The largest earthquakes were postulated for the zones, and the corresponding intensities at SRS were estimated using intensity attenuation relations.

By using that methodology, we determined the highest intensity at SRS was the result of a local earthquake of MMI VII and a postulated MMI X event similar to the 1886 Charleston earthquake but occurring only 95 kilometers from the site. URS/Blume then used an intensity of MMI VIII ( $M=5.0$ to 5.5$)$ at the site as the design basis earthquake. In URS/Blume's judgment, this intensity represented a ground motion, which at one standard deviation would not be exceeded by an event producing a site intensity of MMI VII. With this as the SRS intensity for design-basis criteria, URS/ Blume specified a peak free-field ground acceleration of $0.20 \mathrm{~g}$. For a MMI VII earthquake, the highest 


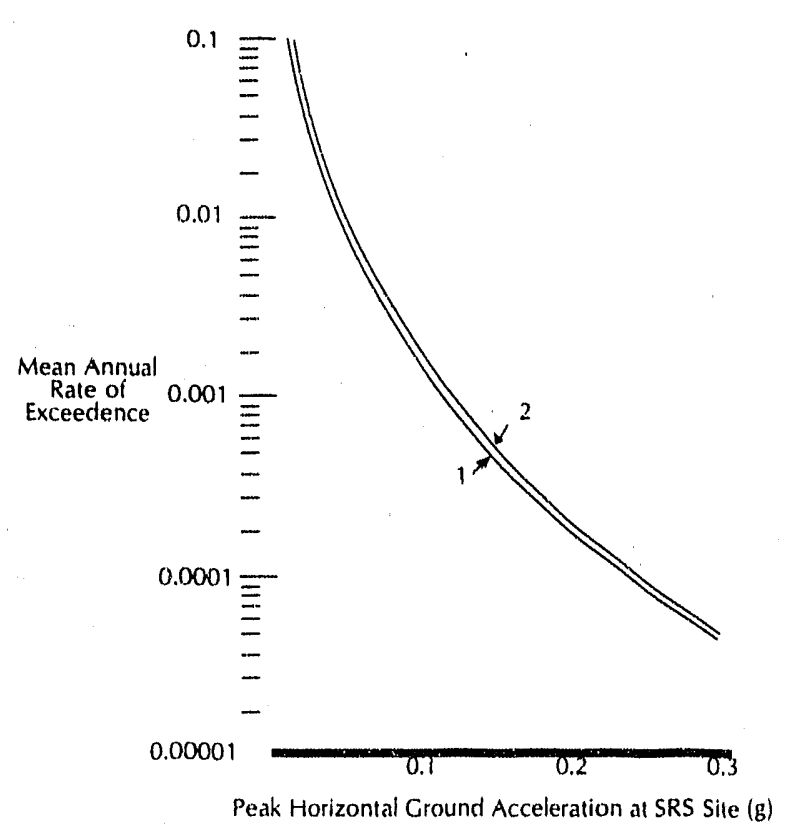

Figure 5. URS/Blume Seismic Hazard Curves for the Two Postulated Configurations of the Charleston Seismic Zone

intensity postulater for the site, a peak acceleration of $0.10 \mathrm{~g}$ was obtain $\mathrm{d}$.

The second analysis performed by URS/Blume used a single-model type probabilistic seismic hazard analysis. They concluded that the results were relatively insensitive to variations in the postulated configurations of the Charleston seismic zone. From the model (Figure 5) the estimated mean annual rate of exceedance for a peak ground acceleration of $0.20 \mathrm{~g}$ was $2 \times 10^{-4}$. This value, URS/Blume stated, "is comparable with exceedance rates of peak ground accelerations of the operating basis and safe-shutdown earthquakes for commercial nuclear power plants regulated by the U.S. Nuclear Regulatory Commission." This value is also in the range of $10^{-3}$ to $10^{-6}$ for critical facilities reported by the National Research Council Panel on Seismic Hazard Analysis (1988).

\section{Historic Methodology}

In 1986 the consulting firm of Jack R. Benjamin and Associates, Inc. (JBA) performed a historic seismicity analysis for SRS (McCann, 1986). This type of analysis differs from conventional probabilistic seismic hazard analysis (PSHA) in that it used the catalog of historical earthquake location snd size to generate a catalog of estimated ground motion at the site. These results are then used to generate an empirical estimate of the seismic hazard curve at the site. The estimate does not require that assumptions be made regarding the seismic source and intensity (or magnitude) distributions, but does require assumptions as to ground motion predictions and a correction for the completeness of the earthquake catalog (the catalog should be 200 to 300 years long).

To evaluate the historic ground motion at SRS for the earthquakes contained in the catalog (JBA used the EPRI catalog), ground motion attenuation models describing the PGA as a function of earthquake size and distances from the site were used. In this study JBA used seven Modified-Mercalli-Intensity-distance models and seven magnitude-distance models for attenuation. Each model represents an alternative to predicting ground motion and provides a measure of the uncertainty in the data. The result of this analysis of historic ground motion at SRS is a probability distribution on the frequency of ground shaking at the site. This result is the same as that obtained in a standard PSHA.

The JBA study considered two cases for SRS using the historic methodology. The first used the ground motion models used in the LLNL Seismic Hazard Characterization Project (SHCP). This provided a relative comparison (because it is not same methodology) of the results of the SRS historic analysis with the LLNL SHCP results for the Vogtle plant across the Savarnah River in Georgia. The results of the historic seismic analysis for

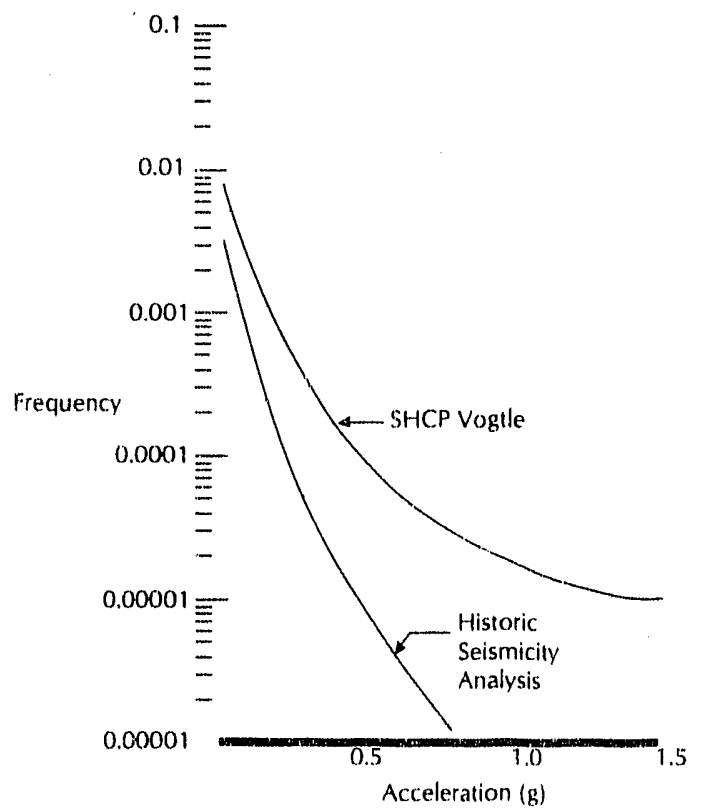

Figure 6. JBA Seismic Hazard Curves for Vogtle and the Historic Seismicity Assessment 


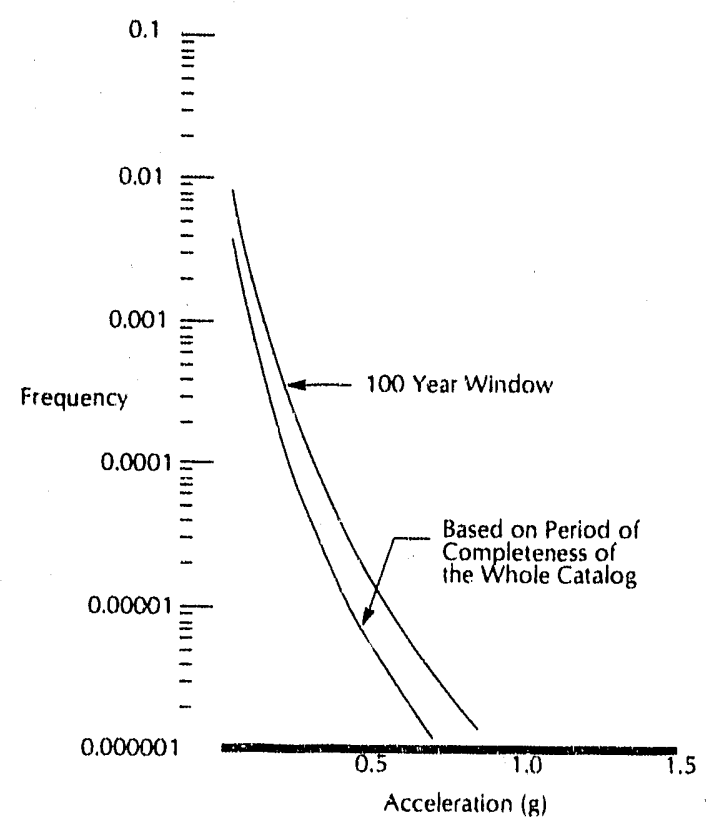

Figure 7. JBA Seismic Hazard Curves, One Taking a 200-Year Window and the Preferred Estirnate

SRS (Figure 6) was a mean probability of exceeding the design basis of $0.20 \mathrm{~g}$ of $1.94 \times 10^{-4}$ per year. The SHCP for Vogtle resulted in a mean value of the probability of exceedance at $0.20 \mathrm{~g}$ of $6.75 \times 10^{-4}$ per year. It was also noted that the difference between the two results became greater at higher PGA levels.

In the second case investigated by IBA, corrections for - the period of completeness of the earthquake catalog were made and attenuation relation models developed specifically for South Carolina were used in the historic analysis. Consideration was also given to alternative intensity magnitude conversion methods. JBA considered this case the preferred estimate for the historic hazard analysis of SRS, which gave a mean probability of exceeding the $0.20 \mathrm{~g}$ design basis of critical facilities to be $1.83 \times 10^{-4}$ per year (Figure 7).

\section{Studies Based on Multiple Model Probabilistic Methodology}

In performing a seismic hazard analysis for a site, there is a certain amount of uncertainty associated with the available data. This is very true in the eastern United States. The scientific community expresses large uncertainty as to the spatial distribution, occurrence rates, and maximum magnitude of earthquakes and for the attenuation of ground motion with distance in the area east of the Rocky Mountains. For this reason, the multiple model probabilistic method was developed.
This methodology allows consideration of any number of alternatives to calculate the hazard. To quantify the uncertainty on the hazard, a probability is assigned to each model typically based on subjective judgment. Examples of this PSHA methodology are the methods developed by the electric utilities group (Seismic Owner Group), EPRI (McGuire et al., 1989), and LLNL (Coats and Murray, 1984; Bernreuter et al., 1989).

In the 1980s LLNL performed two PSHAs of SRS. The first study was performed for the office on Nuclear Safety of DOE to develop uniform design criteria for critical facilities at DOE sites throughout the U.S. subjected to hazards posed by natural phenomena such as earthquakes, floods, and wind. The methodology followed in this study was basically the same used in the later study performed by LLNL for SRS. In summary it included the following:

- specify the geometry of seismic source regions

- establish a recurrence relationship for the seismic zones and the maximum magnitude

- select attenuation relations to transfer the ground motion from the epicenter to the site

- establish the uncertainty associated with these data

- combine the potential activity of all sources for all earthquakes to determine the probability that a certain acceleration will not be exceeded in a defined time frame

A panel of ten seismologists was assembled to provide their expert opinions and confidence in the seismic zonation, recurrence, magnitude, and attenuation, which were to be used in the evaluation. The estimates of the probability of exceedance of ground motion obtained from this study represent the weighted results from all experts to establish a base case and the uncertainty on the parameter about this base. The results obtained in this study for SRS was a probability of exceedance per year of $1.7 \times 10^{-4}$ for the design basis of $0.20 \mathrm{~g}$. The upper and lower limits obtained in this study due to the uncertainty in the input parameters were defined loosely as one standard deviation with respect to the best estimate (Figure 8).

LLNL, also during the 1980 s, under contract to the NRC, expanded their original PSHA to provide the data and methodology with which the seismic hazard at commercial nuclear power plants east of the Rocky Mountains could be estimated. While doing this, LLNL included both the random (physical) uncertainty and the modeling (knowledge) uncertainty and provided for various foundation conditions in a generic fashion. There were also two groups of experts used, one in 


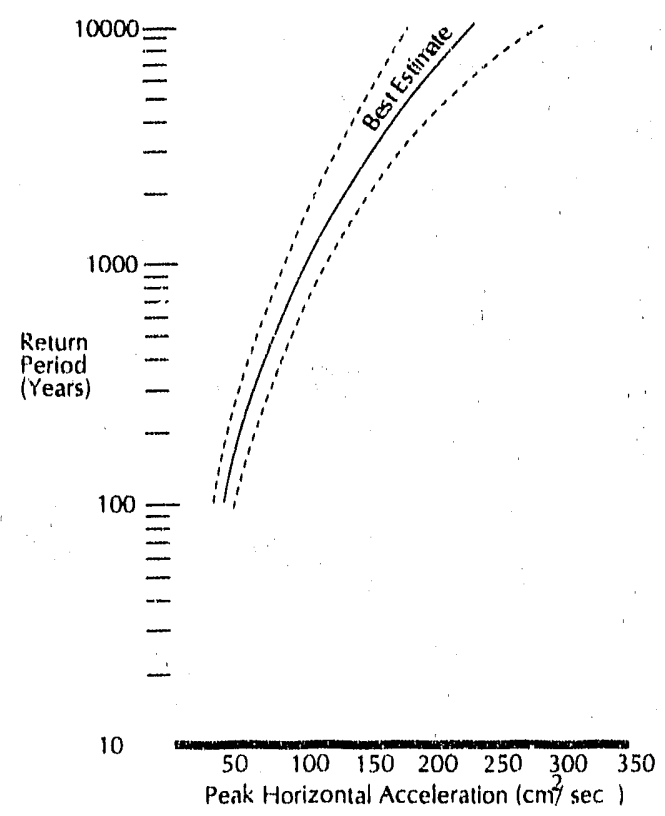

Figure 8. LLNL Seismic Hazard Curve

seismicity and tectonics and the other in groundmotion modeling. The basic methodology used in the previous LLNL study was followed in this investigation. Upon completion of this investigation for the NRC, it was LLNL's conclusion that databases of zonation seismicity models of the eastern U.S. and of groundmotion attenuation models for predicting PGA on pseudo-velocity response spectra (PSRV) were available for general use. In these databases: (1) site-specific foundation conditions were not included, (2) models of seismicity did not concentrate on specific regions but were for the entire eastern U.S., and (3) the attenuation models were for regions. However, the databases were considered accurate to provide preliminary types of PSHA of any site in the eastern U.S.

In their final report (Bernreuter et al., 1989) LLNL also had some general conclusions. These were that there is substantial uncertainty in the estimate of the hazard, that generally earthquakes below a magnitude 5 significantly increase the seismic hazard if included but they pose no threat to critical facilities, and that the site soil category (rock, shallow soil, deep soil) has an important effect on the estimated hazard. They also concluded that the 50th percentile (constant percentile hazard curve) appeared to be a stable estimator of the seismic hazard being least sensitive to changes in the parameters.

In 1988 the SRS requestud LLNL to perform the same type calculation of the PSHA at the site as performed for the NRC at commercial nuclear power plant sites in the eastern U.S. using the latest methodology and data.

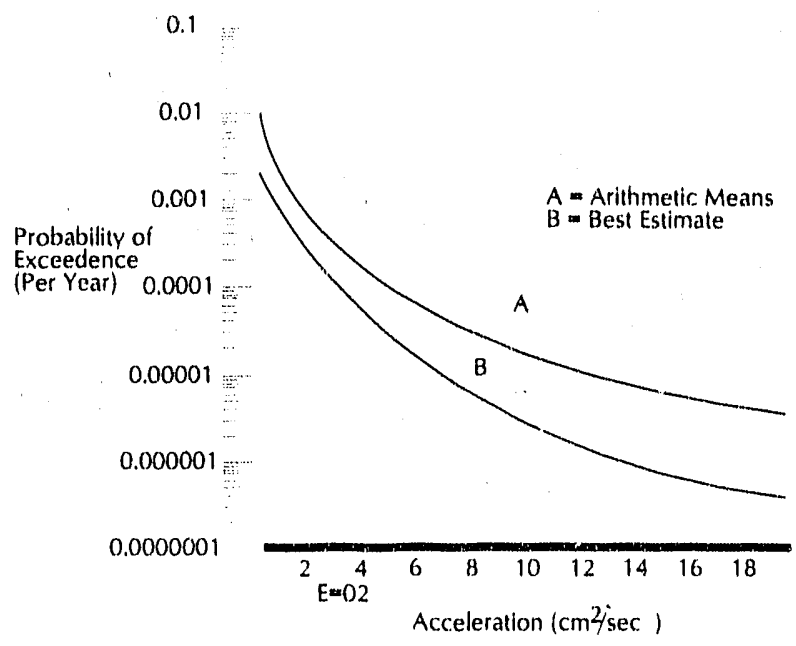

Figure 9. LLNL Best Estimate and Arithmetic Mean Hazard Curves: $M \geq 5$

The parameters requested by SRS were the free-field PGA in probability of exceedance per year as a function of magnitude and PSRV in the free field for 5 percent critical damping at five frequencies. Several cases were run to produce output that allowed evaluation regarding the size earthquakes contributing to the seismic hazard at the site. The base case consisted of earthquakes of magnitude 5 and greater, contributing earthquakes between magnitude 4 and 5 , between magnitude 5 and 6 , and equal to or greater than magnitude 6 . The site location used was latitude $33.22^{\circ}$ $N$ longitude $81.62^{\circ} \mathrm{W}$, which is approximately the center of SRS. In the central portion of the site, the depth to basement is about 300 meters; therefore, in the analysis SRS was considered a deep-soil site. For the upper 60 meters of the sediments, a shear wave velocity in the range of 300 to 350 meters per second was estimated. This is a category 5 as defined in the LLNL site soil classification.

The results of the study performed for SRS by LLNL (Savy, 1988) and presented as the best estimate (B) and arithmetic mean $(\mathrm{A})$ hazard curves were as follows:

- all earthquakes of magnitudes $\geq 5.0$, probability of exceeding 0.20 per year for A $2.0 \times 10^{-3}$ and B $4 \times 10^{-4}$ (Figure 9)

- earthquakes of magnitude 4.0 to 5.0 , probability of exceeding 0.20 g per year for $\mathrm{A} 3 \times 10^{-4}$ and $\mathrm{B} 4 \times 10^{-5}$ (Figure 10) 
- earthquakes of magnitude 5.0 to 6.0 , probability of exceeding $0.20 \mathrm{~g}$ per year for A $3.5 \times 10^{-4}$ and B $1 \times$ $10^{-4}$ (Figure 11)

- earthquakes of magnitude $\geq 6.0$, probability of exceeding $0.20 \mathrm{~g}$ per year for a $2.0 \times 10^{-3}$ and B $2.5 \times 10^{-4}$ (Figure 12)

These results show that it is the earthquakes with a magnitude of 6.0 and greater that dominate the seismic hazard at SRS. The seismic hazard calculated by LLNL are at the upper end of the National Research Council panel on seismic hazard analysis recommended values of probability of exceedance per year for critical facilities. Using more rite-specific data in the analysis and regional seismicity parameters may change these values.

In 1988 SRS also contracted the consulting firm of Jack Benjamin and Associates (JBA) to perform a probabilistic seismic hazard analysir of the site using the inputs and methodology developed by the Electric Power Research Institute (EPRI) for the group of eastern U.S. Electric utilities owning nuclear power plants called the Seismic Owners' Group. The EPRI study paralleled the LLNL study of the same area that was performed to provide another viewpoint. The EPRI and LLNL methodologies differ in how the inputs are parametered and in using event free or Monte Carlo computational schemes, but the two methodologies are the same. This has been demontrated-by using the same input data

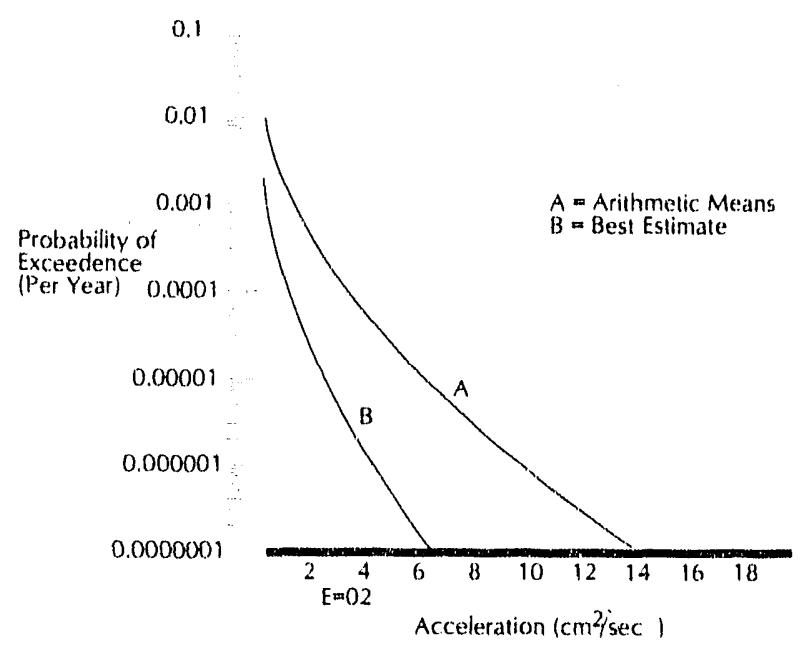

Figure 10. LLNL Best Estimate and Arithmetic Mean Hazard Curves: $4<M<5$

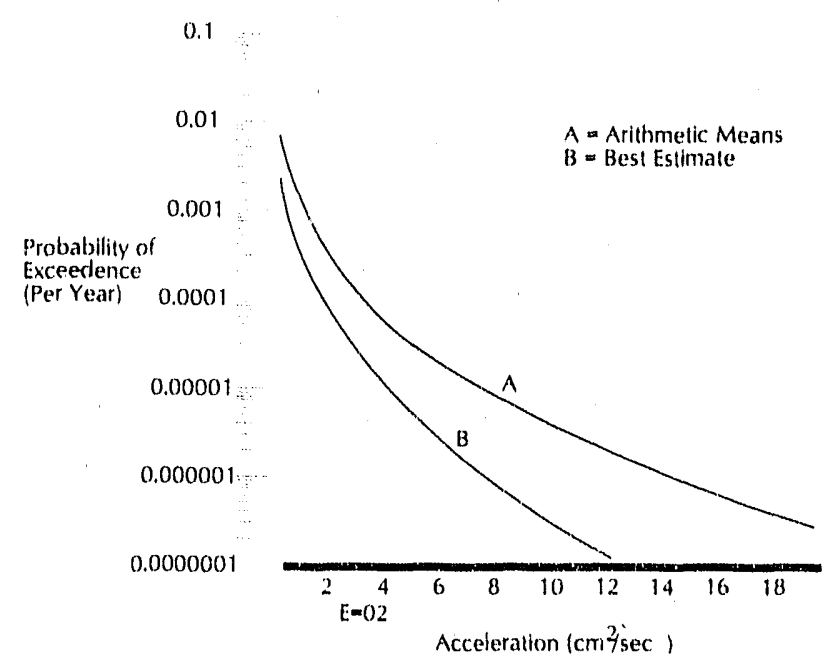

Figure 11. LLNL Best Estimate and Arithmetic Mean Hazard Curves: $5<\mathrm{M}<6$

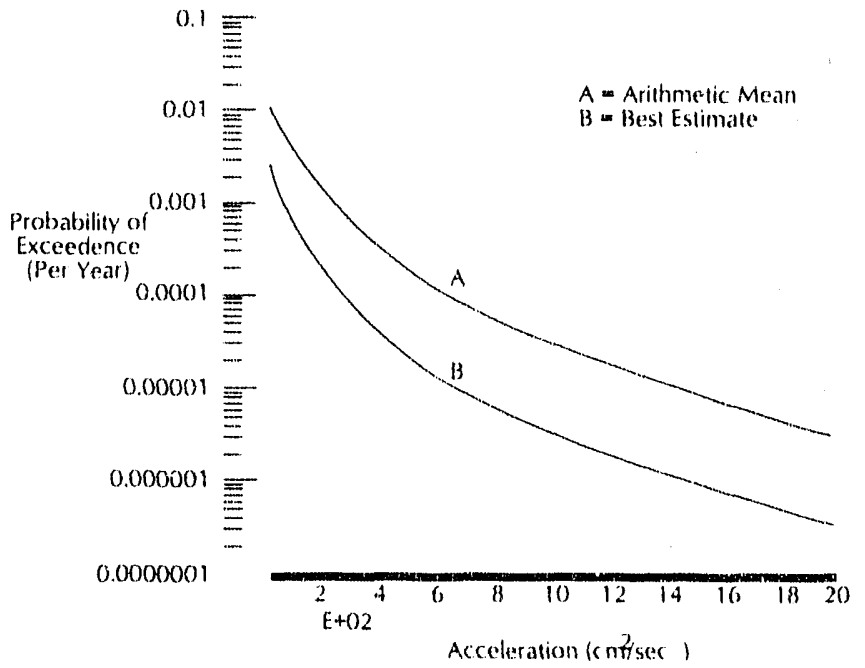

Figure 12. LLNL Best Estimate and Arithmetic Mean Hazard Curves: $M \geq 6$ 
they produce essentially the the same output. The input for the EPRI study of eastern U.S. seismic hazards was developed by expert geoscience teams rather than individual experts with some experts participating in both studies.

JBA, for the calculations of seismic hazards at SRS, used the seismic source and seismicity parameters developed by the six ea:th-science teams of the EPRI study. Each team characterized the uncertainty on the existence and parameters of the source zones and their confidence in the existence of the source, as well as providing specified probability distributions for the source's seismicity parameters.

The results obtained by JBA using the EPRI data developed for the study of seismic hazards of commercial nuclear power plants located east of the Rocky Mountains and calculational techniques with the same SRS data used by LLNL for a design basis of $0.20 \mathrm{~g}$ were a probability of exceedance of $5 \times 10^{-5}$ per year (Figure 13). This value corresponds to the mean value from the results of the six teams.

Although the LLNL and EPRI methodologies differ somewhat in computational details, the two are equivalent. That is, with identical input, they should produce about the same output. Therefore, the difference seen in the probability of exceedance between the two studies is the result of differences in the assumptions used to generate the input by the LLNL experts and the
EPRI teams. A review of the causes in the differences in the PSHA results suggests that the differences in the seismological interpretations were a large contributor to the difference, as well as one ground motion attenuation model (Risk Engineering, 1990).

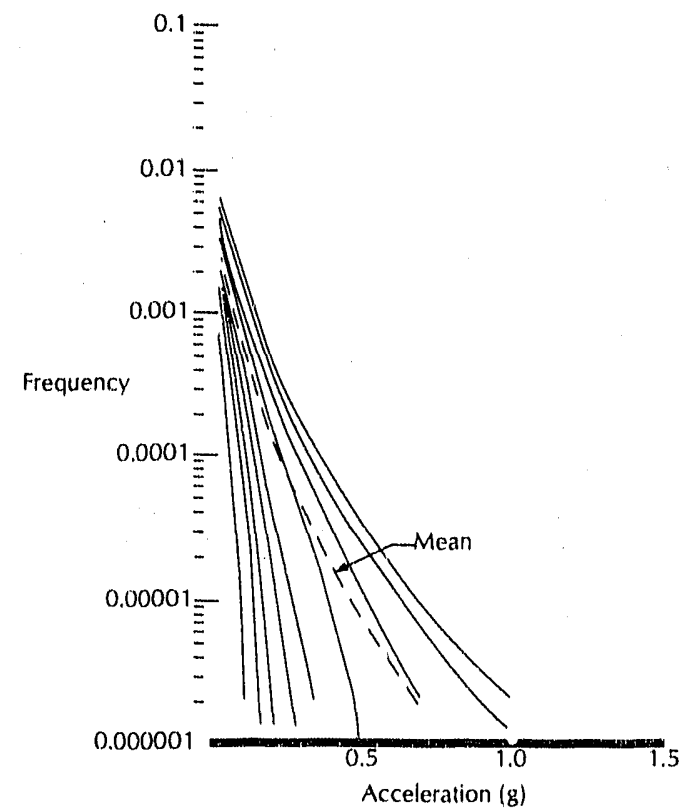

Figure 13. JBA Seismic Hazard Curve Using EPRI Data 


\section{Ground Motion Response Spectra}

Following the determination of the PGA of a site, it is necessary to characterize the temporal variation of the resulting ground motion. This is due to the fact that engineered structures respond to excitation caused by earthquakes based upon the PGA, frequency characteristics of the structure relative to the frequency of the ground motion, and the duration of the motion. The response spectra provide the seismic engineering information on the frequency characteristics of the ground motion due to various earthquakes. Response spectra developed from the existing database of recorded ground motions show considerable variation from one record to the next and from site to site. These differences are due to the characteristics of the source parameters and the geologic character of the sites. In practice, thesc differences are accounted for by statistical techniques. The response spectra can display spectral accelerations, velocities, or displacements for a given damping value in terms of natural frequencies. The developed ground motion design spectra represents the "free-field" responses and serves as the basis for seismic engineering design and evaluation.

From the various studies conducted for SRS to determine the design-basis earthquake, a number of response spectra have been developed to aid the seismic engineering of the design and analysis of critical facilities.

\section{Housner Response Spectra}

In the development of a response spectra for the critical facilities at SRS, Housner (1968) used the 1952 'Taft California earthquake accelerograph records and the recommended peak horizontal ground-motion acceleration for the site of $0.20 \mathrm{~g}$ at zero period. Housner also used a damping value of 5 percent in cieveloping the spectra. Housner's response spectra (Figure 14) was developed to be applied at the base of the structures eliminating any consideration of soil-structure interaction, as was the practice at that time.

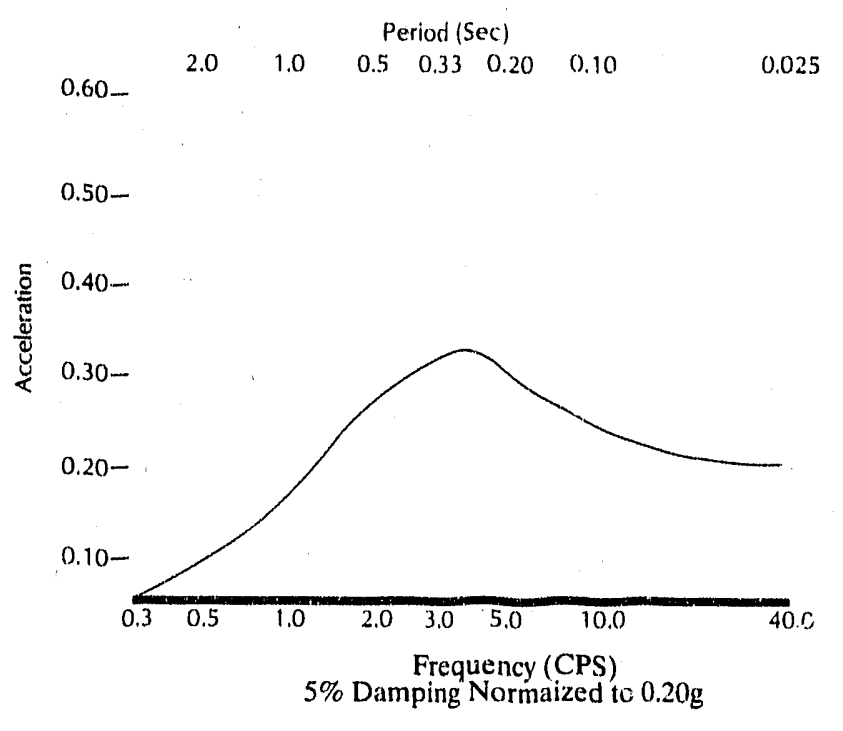

Figure 14. Housner Response Spectra for SRS

\section{URS/Blume Response Spectra}

In the 1982 update of the SRS seismic criteria the URS/Blume "free-field" response spectra were developed from a statistical analysis of the selected sets of recorded western U.S. accelerograph data, which best represented the site conditions to be modeled. Knowledge has been obtained in recent years of the spectra of moderate eastern U.S. earthquakes, but available strong motion accelerograph data were insufficient to develop response spectra for this investigation. The analysis performed by URS/Blume determined response spectra shapes rather than absolute amplitudes. URS/Blume developed spectra to envelop the mean spectra determined for the postulated SRS near $(10 \mathrm{~km})$ event of magnitude 5 and for a Charleston 1886-type event $\left(M_{t}=6.6\right)$ occurring in the range of distances of 95 to $145 \mathrm{~km}$ from SRS.

Standard statistical procedures were used to develop the site-specific spectra. The data were normalized to $1.0 \mathrm{~g}$ and pseudo-relative response velocity (PSRV) amplitudes for damping values of 0 percent, 2 percent, 5 percent, and 10 percent were obtained. The PSRV at the specified period was treated as a normally distributed random variable. These data were then used to derive the SRS ground response spectra at the specified damping values for both the local and distant earthquake. The smooth spectra shapes enveloping the 


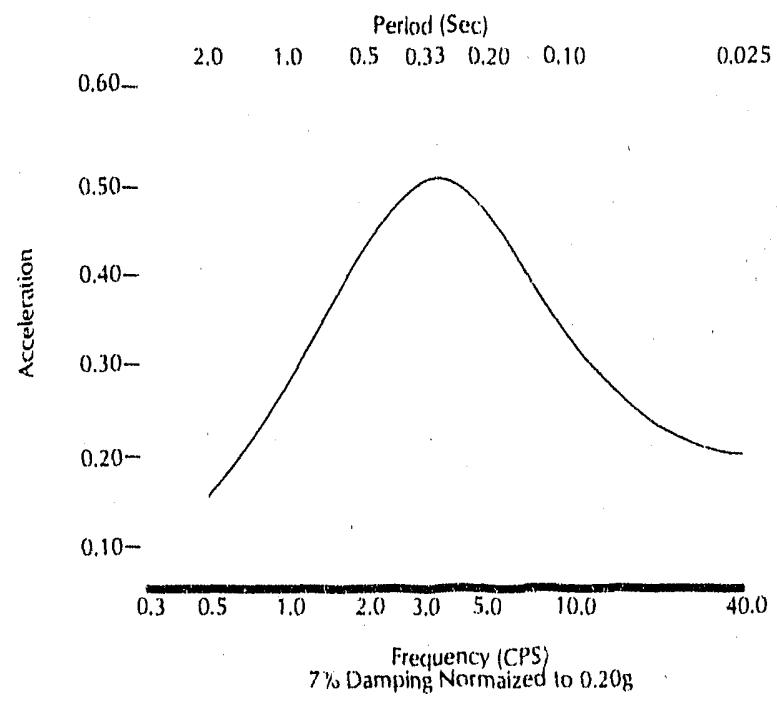

Figure 15. URS/Blume Response Spectra for SRS

mean of the spectra for both events are shown in Figure 15. The spectra were scaled to the peak ground acceleration of $0.2 \mathrm{~g}$.

\section{Nuclear Regulatory Commission Response Spectra}

In 1977 , the NRC formalized and presented response spectra for commercial nuclear power plants, which are presented in Regulatory Guidance 1.60. These response spectra were developed using statistical techniques from accelerograph data of many large western earthquakes recorded at sites with varying geologic conditions. These statistical spectra take into consideration the variation in the nature of the geology and founciation properties, near-field and far-field effects, and duration. Since these NRC spectra take into account all the variables affecting ground motion, they were presented for use at all sites regardless of the nature of the site. The deterministic approach used by the NRC encourages a site-specific response spectra to determine the effects of a given magnitude earthquake at the site. The NRC spectra as provided in Regulatory Guide 1.60, is shown in Figure 16.

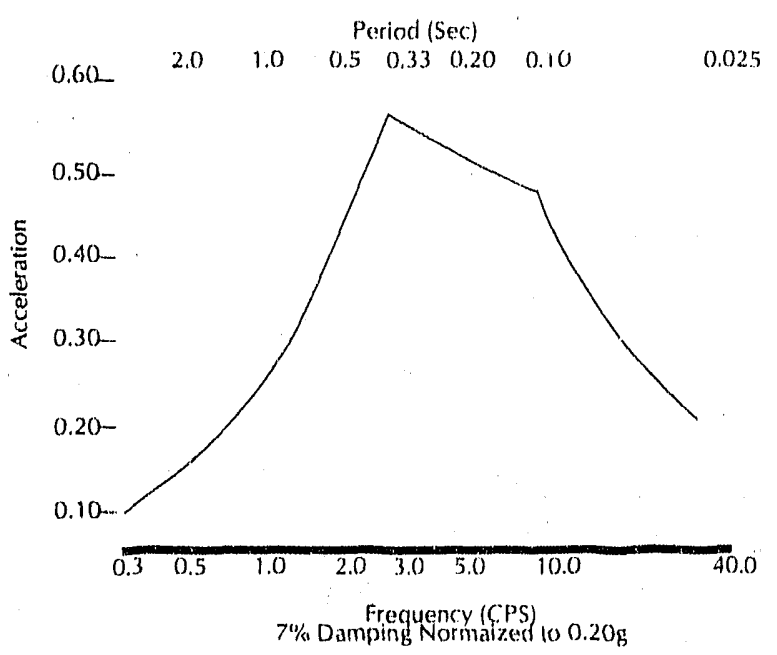

Figure 16. NRC Response Spectra for SRS

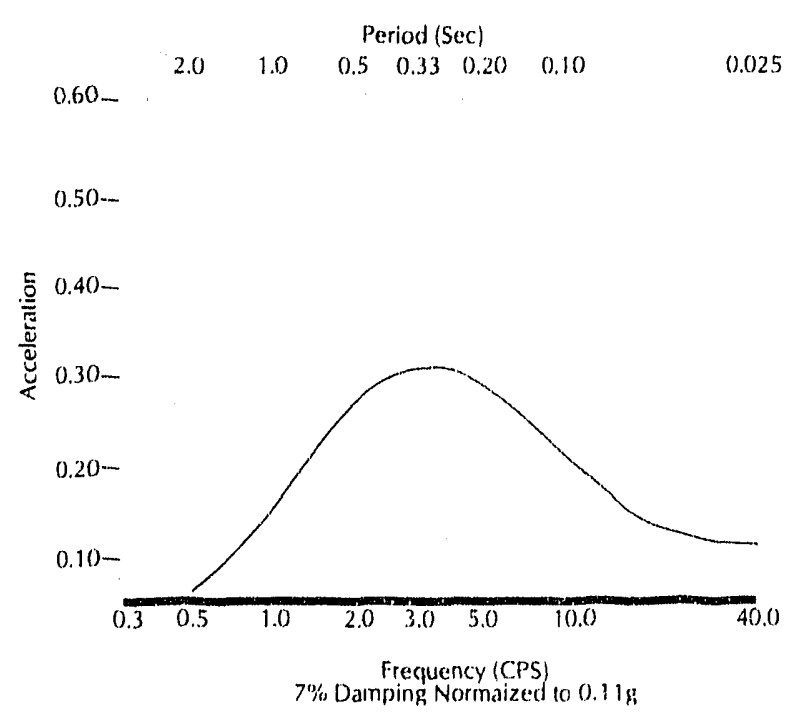

Figure 17. DOE Response Spectra for SRS 


\section{Department of Energy Response Spectra}

The study performed for DOE by LLNL (Coats and Murray, 1984) of seismic hazards at all DOE sites as part of the Natural Phenomena Hazards program developed response spectra for each site. The general methodology followed in the development of sitespecific response spectra was the same as in the other studies. Accelerograph data from near-field smaller magnitude earthquakes and far-field large earthquakes representing both high-frequency body wave response and low-frequency surface wives were combined statistically to develop the spectra. Site soil conditions were also used in an elementary fashion to develop the response spectra for each site. The spectra developed should be considered as median-centered spectra for purposes of analysis. The smoothed spectra scaled to $0.11 \mathrm{~g}$ are shown in Figure 1".

\section{Lawrence Livermore National Laboratory Spectra}

When using multiple model PSHA, as LLNL did in their 1988 (Savy, 1988) study of SRS, complexities arise with a single response spectra because not enough information can be displayed. Plots are provided of velocity versus period for different recurrence intervals. for given recurrence intervals various percentiles providing information on the uncertainty, and velocity versus annual frequency of exceedance for various period (frequency) at a vesignated percentile. Examples of each type of plot for SRS are show'n in Figures 18-20. These spectra are different from those discussed

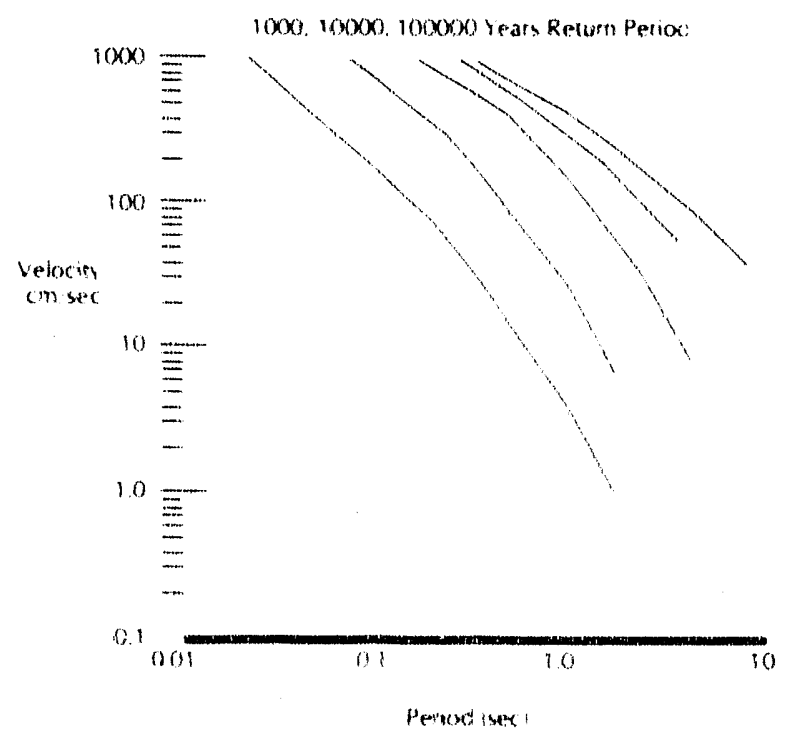

Figure 18. LLNL. Response Spectra for SRS: Velocity Versus Period for Various Recurrence Intervals

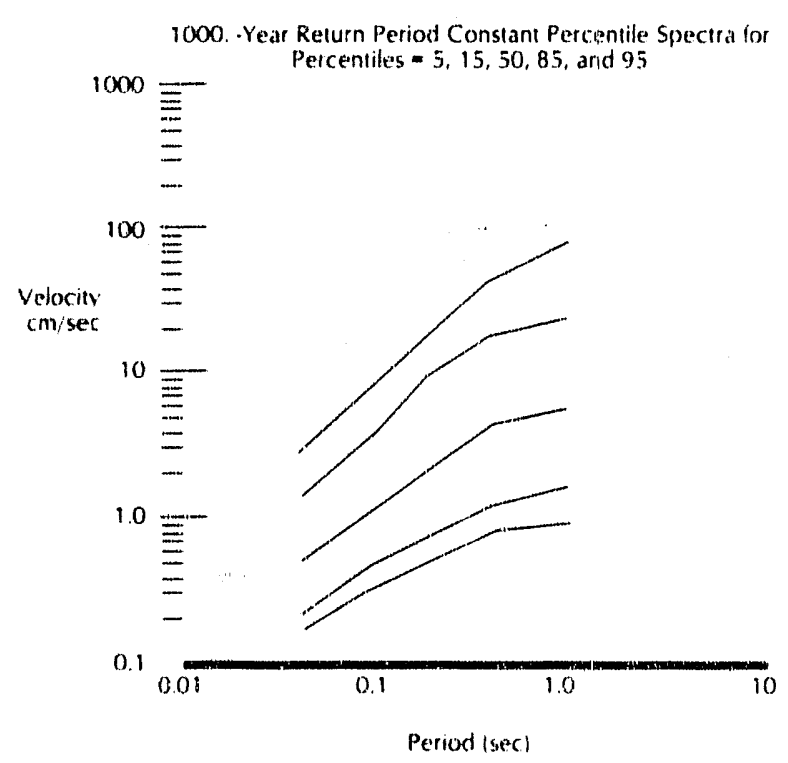

Figure 19. LLNL Response Spectra for SRS: Velocity Versus Period for 1000 Year Recurrence Interval: Various Percentile Spectra

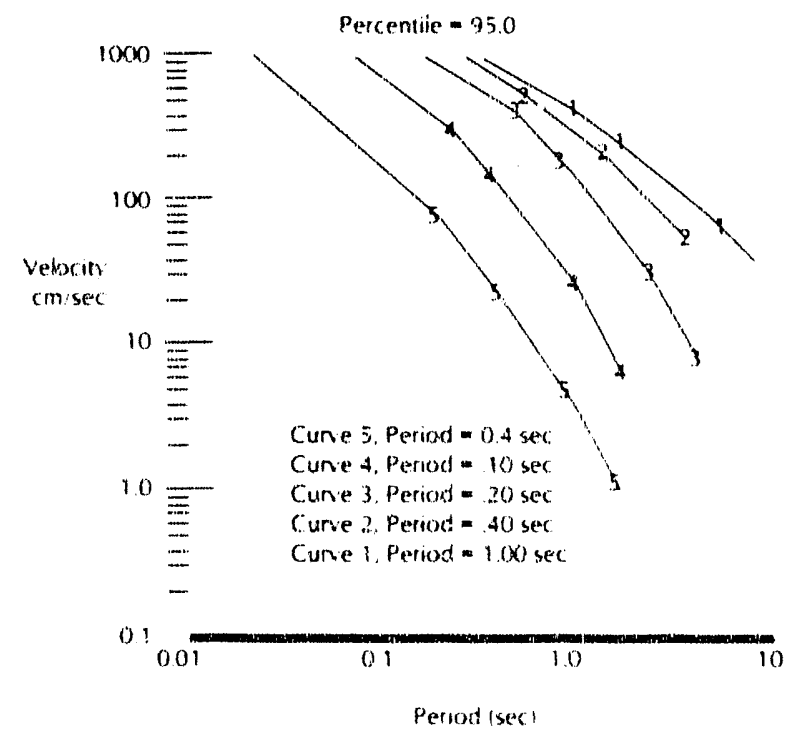

Figure 20. LLNL Response Spectra for SRS: Velocity Versus Ansual Frequency of Exceedance 


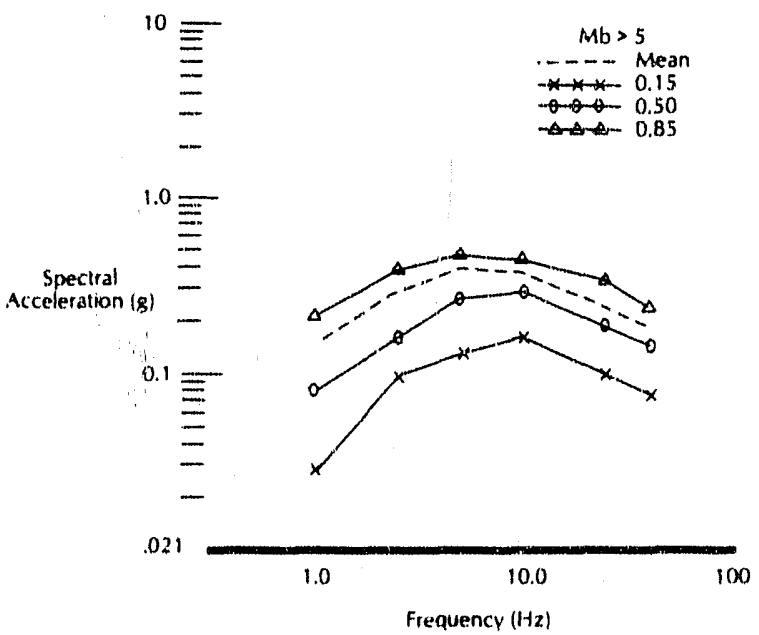

Figure 21. Uniform Hazard Response Spectra (EPRI) at Annual Frequency of Exceedance of $10^{-4}$

previously in that they are not earthquake or groundmotion specific.

\section{Electric Power Research Institute Response Spectra}

The EPRI model of the PSHA for SRS was a multiple model as was the LLNL model. The model was used to estimate six measures of the ground motion at SRS, peak ground acceleration, and pseudo-relative velocity response spectra at five frequencies $(1.0,2.5,5.0,10.0$, and $25.0 \mathrm{~Hz}$ ). J. Benjamin and Associates (1990) performed the PSHA for SRS using the EPRI method. ology and presented the results in terms of uniform hazard response spectra (UHS) at annual frequencies of exceedance of $10^{-4}, 10^{-5}$, and $10^{-6}$. The UHS, which are given in Figures 21,22, and 23, are presented in terms of spectral acceleration (Sa), whereSa(f) $=2 \pi f$ $\operatorname{PSRV}(f)$, andf is in hertz.

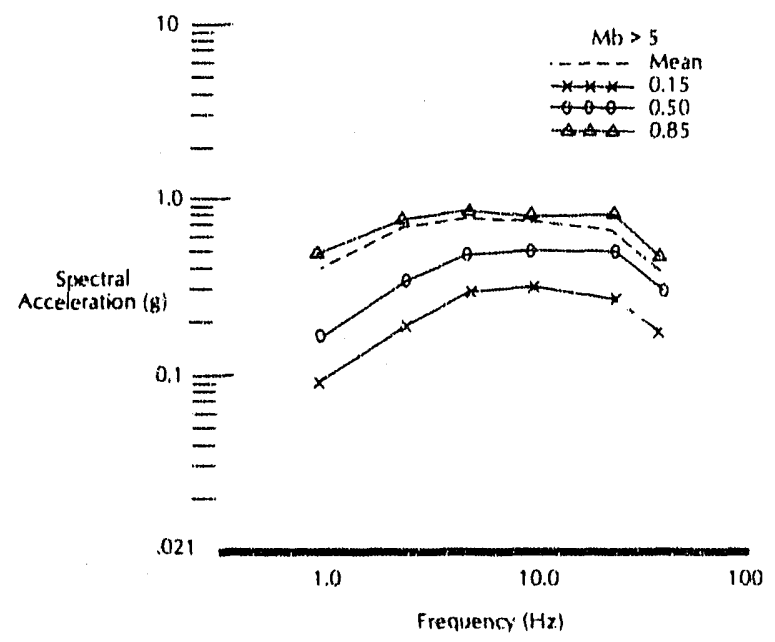

Figure 22. Uniform Hazard Response Spectra (EPRI) at Annual Frequency of Exceedance of $10^{-5}$

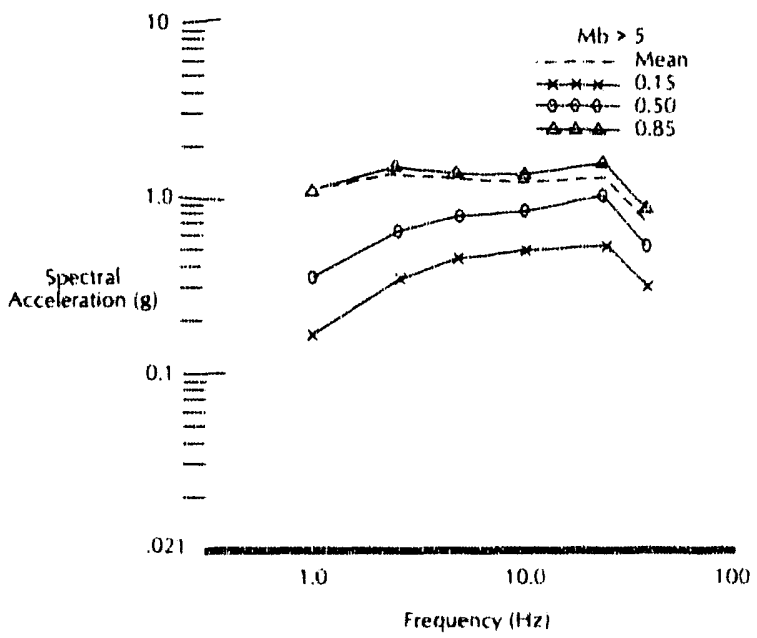

Figure 23. Uniform Hazard Response Spectra (EPRI) at Annual Frequency of Exceedance of $10^{-6}$ 


\section{SRS Seismic Hazard and PGA for Restart in Relation to Other Similar Facilities in the Region}

Seismic design criteria for critical facilities and public buildings in earthquake-prone areas typically rely on seismic-risk maps to identify regions of the country or state in which various intensities of ground motion may have occurred or are anticipated. These seismic-risk maps, which may be relative or probabilistic, have been developed for use in building code applications, land use planning, insurance analysis, and emergency preparedness. This section discusses the values determined for the southeastern U.S. and the SRS area to show the consistency between these values and the design bases used for the reactors.

The more recent seismic-risk maps have been developed using probabilistic techniques and give the ex. pected ground motion in terms of expected peak acceleration and for velocity for specific time periods such as 10,50 , and 250 years with about 90 percent probability of being exceeded.

The Uniform Building Code (UBC) provided a seismicrisk map for the design of buildings. The seismic-risk map (Figure 24) developed for the UBC (International Conference of Busiting Officials, 1982) was based on the maximum earthquake that had occurred in the region. According to the map, SRS is located in Zone 2, where moderate damage corresponding to an earthquake of MMI VIII ( $0.11 \mathrm{~g} \mathrm{PGA})$ could be anticipated.

The Applied Technology Council (ATC) developed "Tentative Provisions for Development of Seismic Regulations for Buildings" (ATC, 1978) published by the National Bureau of Standards with National Science Foundation participation. The ATC Provisions were considered a state-of-the-art document for seismic design and provided acceleration maps for determination of the seismic intensity factor. The effective peak, or maximum, acceleration map is presented as Figure 25. SRS is located within the $0.10 \mathrm{-g}$ contour interval, which indicates a 90 percent probability that the peak ground acceleration will not be exceeded within a 50 year period. The Provisions divide buildings into seismic hazard exposure groups depending on their use. The building rating is combined with the seismicity index determined from the map to establish the applicable seismic performance category for the structure. The seismic performance category is used to determine design and detail requirements, such that the

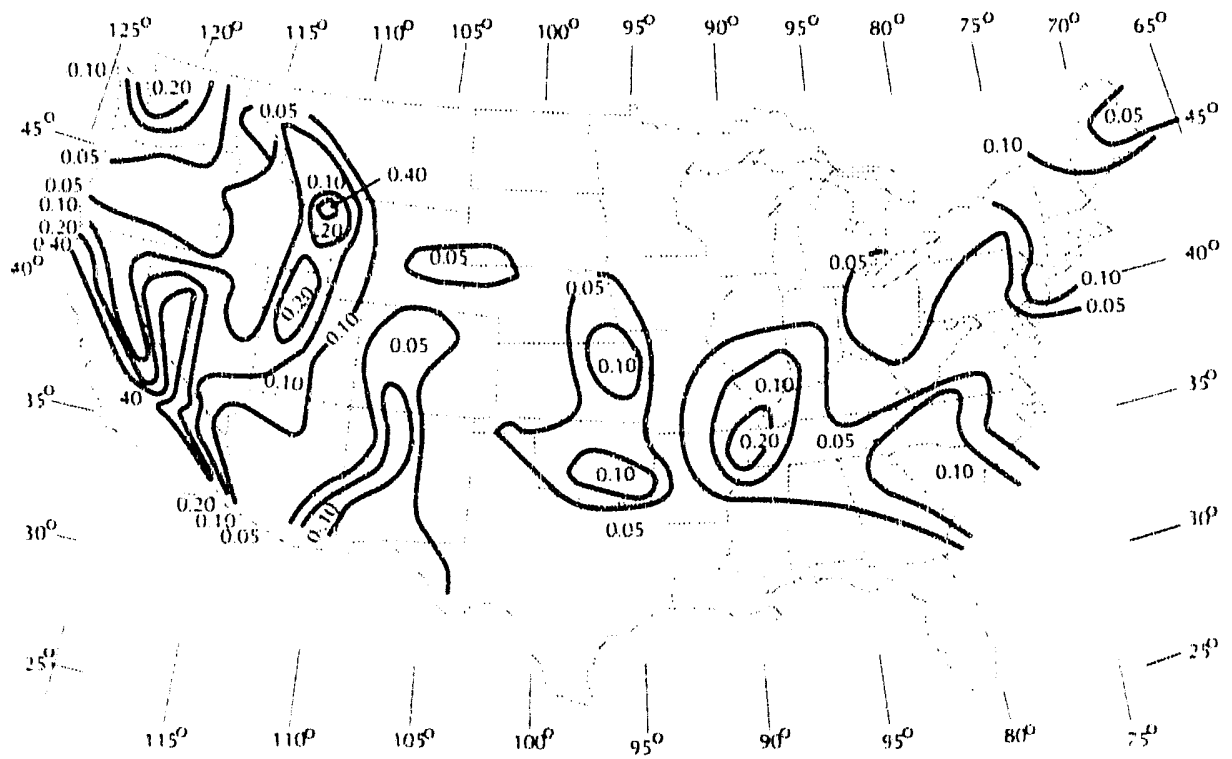

Figure 24. UBC Seismic Risk Zone Map 


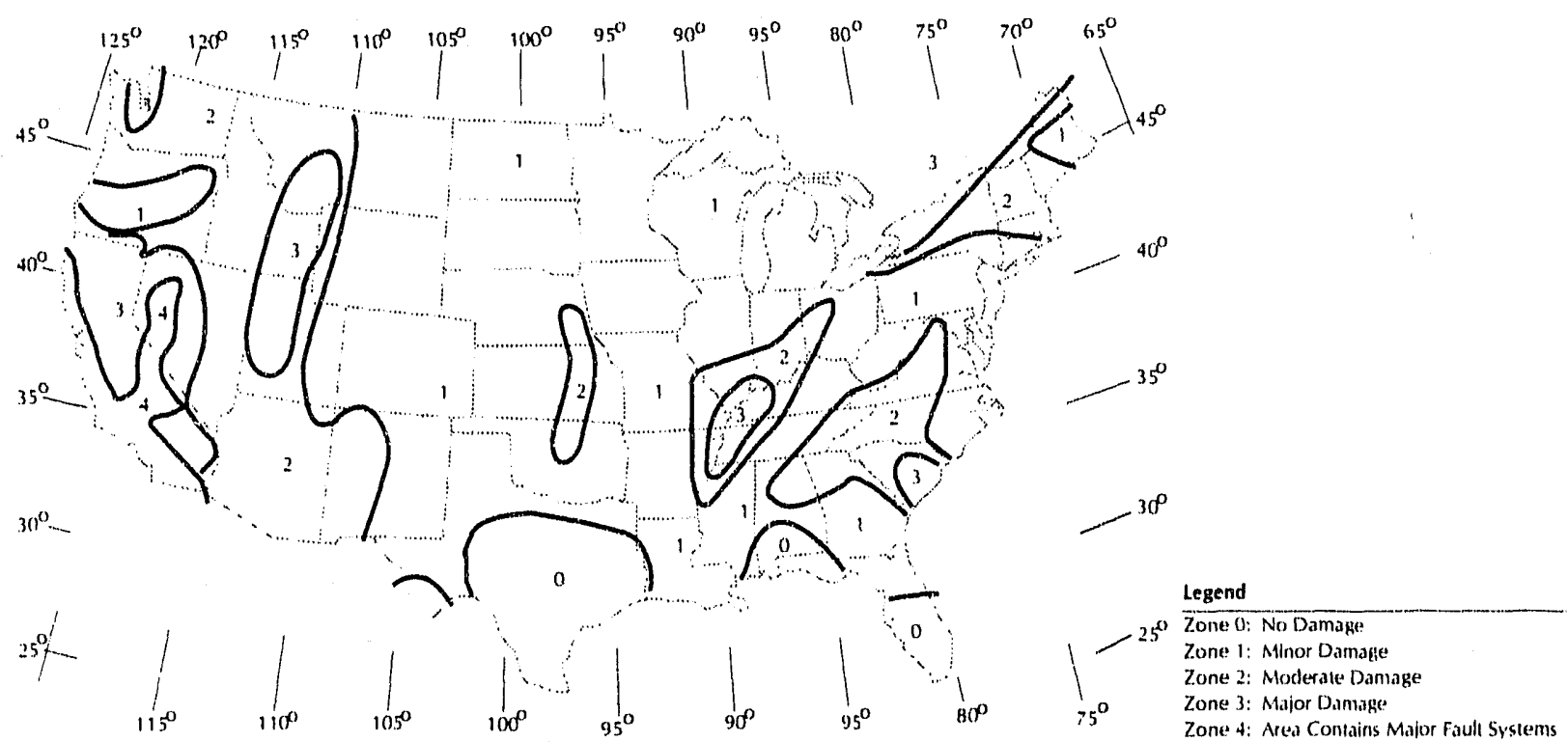

Fighire 25. ATC Seismic Risk Zone Map

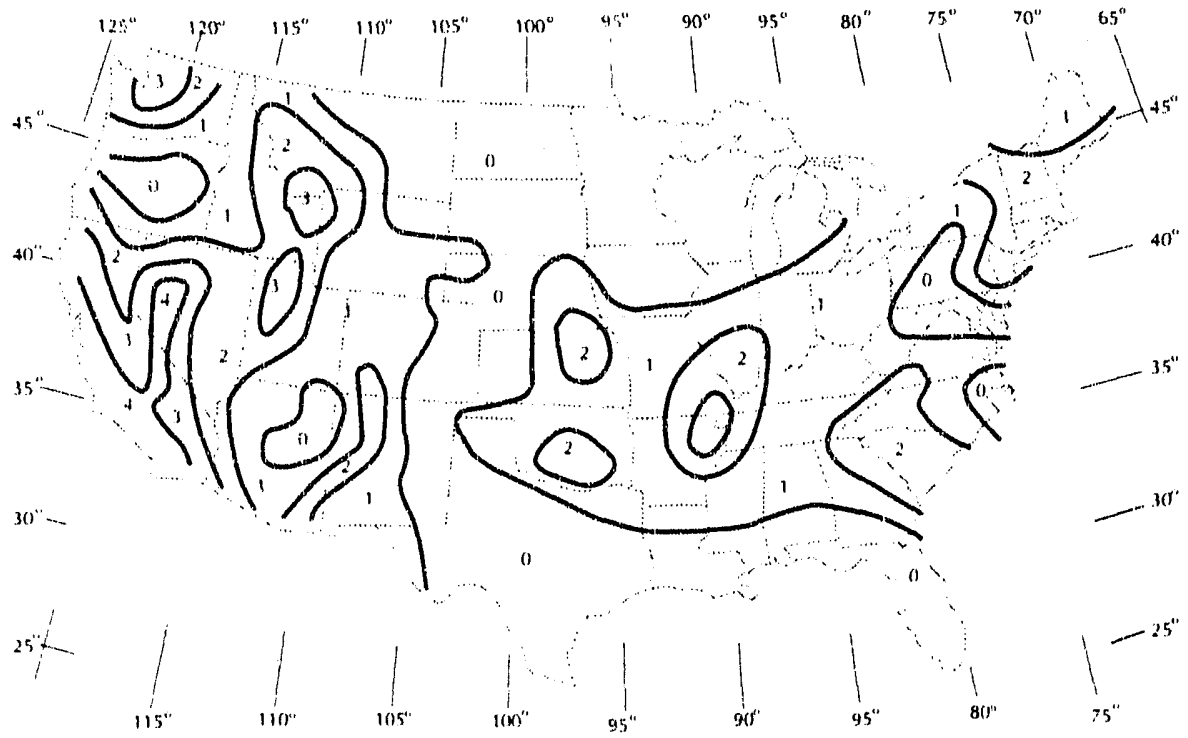

Legend

Zone 0: No Damuase

Zone 1: Minor Danlage

Zone 2: Moderate Damage

Zone 3: Major Damage

Zone 4: Area Contains Major Foull Systems

Figure 26. ANSI Seismic Risk Zone Map 


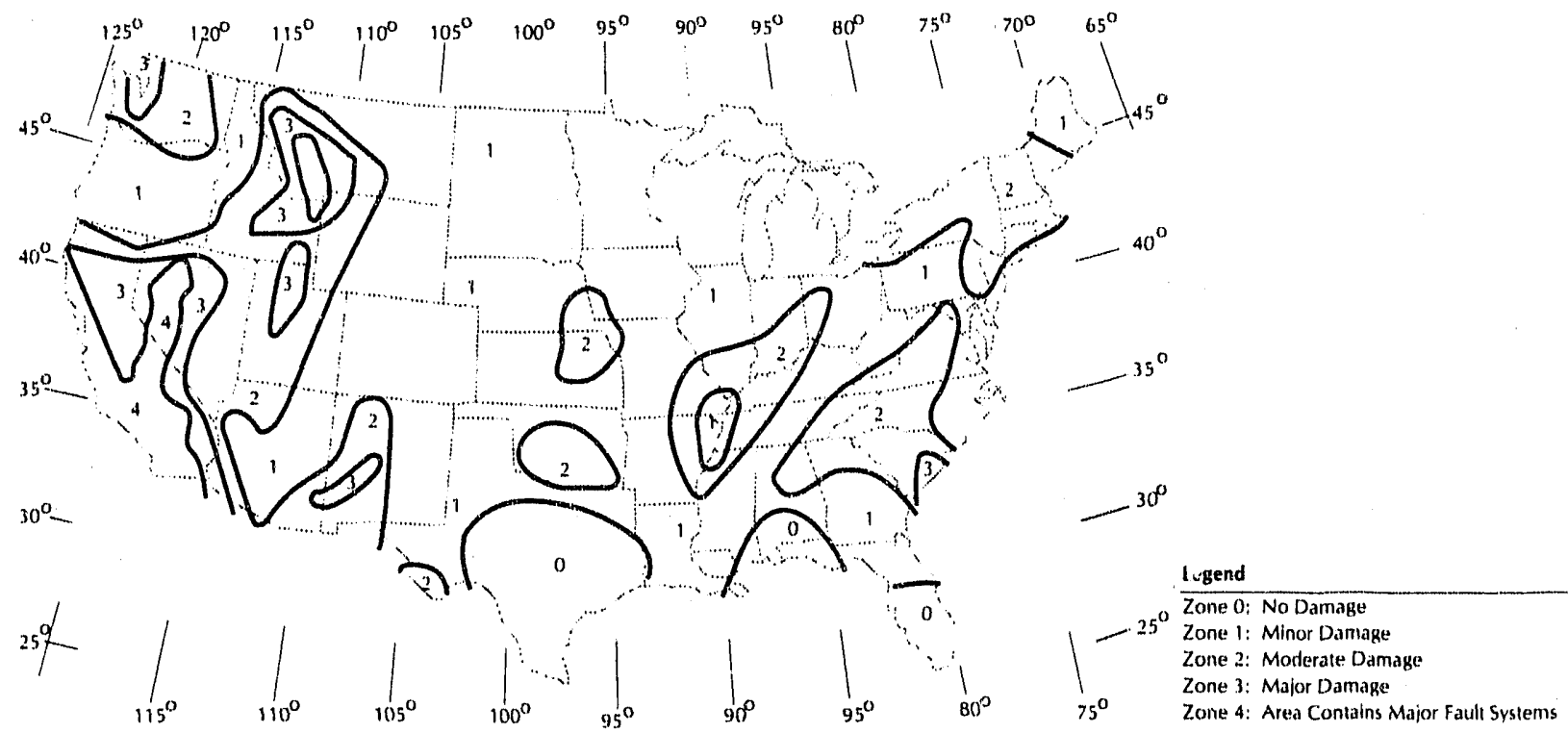

Figure 27. Tri-Service Manuals Seismic Risk Zone Map

more important the structure and the higher the seismicity, the more stringent the design and detailing requirements.

The American National Standards Institute (ANSI) published "Minimum Design Loads for Buildings and Other Structures" (ANSIA58.1-1982), the only voluntary national loading standard in the United States. The ANSI Standard contains requirements for earthquake loads that are suitable for inclusion in building codes and other design documents. The seismic design requirements contained in the ANSI Standard are similar to those contained in the SEAOC recommendations, the UBC, and parts of the ATC Provisions. The seismic-risk map (Figure 26) used in the ANSI Standard was based on work performed in developing the ATC Provisions and was based upon seismic risk instead of the maximum earthquake. According to the map, the SRS is located in seismic-risk zone 2 , a zone of moderate risk.

The design and construction of Army, Navy, and Air Force facilities are governed by the document "Seismic Design for Buildings" (U.S. Dept. of Army, Navy, and Air Force, 1982), commonly referred to as the Tri-Service manual. The manual contains specific guidelines for procedures and details providing seismic resistance of buildings and is based on recommendations of the Structural Engineers Association of California (SEAOC, 1975). The seismic-zone map used by the Tri-Service Manual (Figure 27) illustrates that the SRS is located in Zone 2, the zone of probability of moderate damage.

Algermisson et al. (1982) published seismic-zone maps for the U.S. based on probabilistic estimates of maximum acceleration and velocity. The map of horizontal acceleration (expressed as percent of gravity) in rock with 90 percent probability of not being exceeded in 250 years is presented in Figure 28. Algermisson et al. considered the unresolved question regarding the origin of the Charleston earthquakes as a basis for delineating the northwest-trending zone of $0.23 \mathrm{~g}$, which includes the larger events of the zone. The SRS is located within the 0.10 to $0.20 \mathrm{~g}$ interval, indicating a 90 percent probability of not being exceeded in 250 years.

Seismic design criteria have been established for a number of non-reactor facilities at SRS (Table 9) and analysis of their seismic response calculated. The PGA used for design and in the analysis as the zero period PGA ranged from $0.12 \mathrm{~g}$ to $0.20 \mathrm{~g}$ with the exception of the New Production Reactor (NPR), which used $0.30 \mathrm{~g}$ in the preliminary design phase. This preliminary design value used for the NPR was developed by LLNL using their probabilistic methodology and database created for the eastern U.S. All the other values used by SRS were deterministic values. In determining the final design value for the NPR, site and regional data will be used by LLNL. 


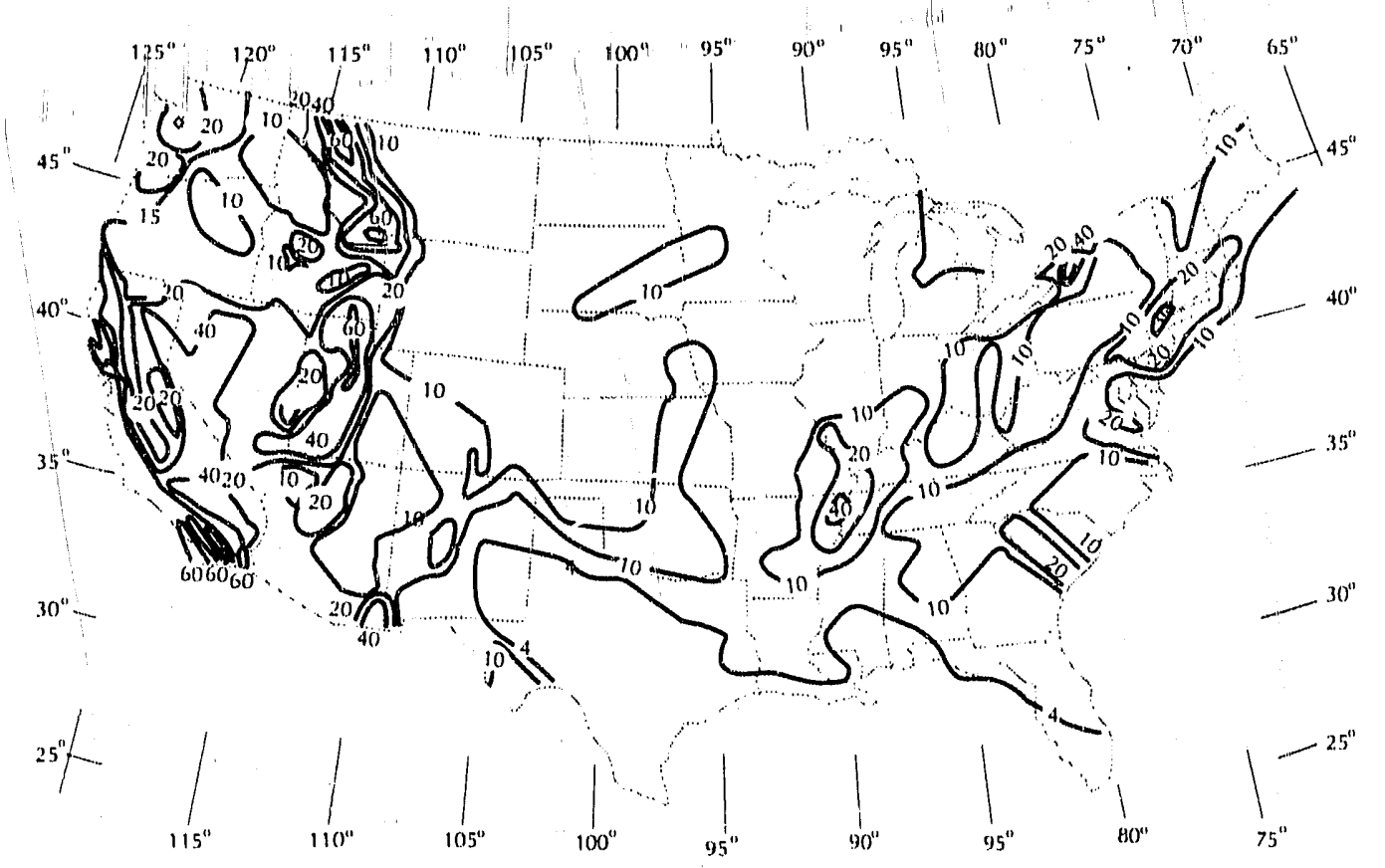

Figure 28. Algermisson Seismic Risk Zone Map

In the majority of the seismic analyses performed for the non-reactor facilities, the 1982 URS/Blume response spectra was used. This spectra was developed for a free-ficld response scaled to a $0.20 \mathrm{~g} \mathrm{PGA}$ with a mean annual rate of exceedance of about $2 \times 10^{-4}$. For the preliminary design of the NPR, a response spectra was developed from the probabilistic results and engineering judgment.

The exception was the Richard B. Russell Dam, which was designed for a peak ground acceleration at $0.50 \mathrm{~g}$. The U.S. Army Corps of Engineers (Titcomb and Hancock, 1981) consulted with a panel of seismicity experts to establish a maximum earthquake and an operating basis earthquake for the dam. The panel utilized probabilistic methods based on the historical seismicity record to develop seismic risk zones and the interpreted peak ground motion at the dam (Table 10). The Corps interpreted the annual probability of exceedance for an MMI VII earthquake at the dam to be $5 \mathrm{x}$ $10^{-4}$. According to Titcomb and Hancock (1981), the dam was designed to withstand an earthquake several times stronger than would be expected to occur during its useful life.

The annual probability of exceedance of the specific PGA was also estimated for each of the nuclear power production facilities by LLNL and for the Richard B. Russell Dam by the U.S. Army Corps of Engineers (Table 9).

The LLNL determined two probabilities of exceedance for each facility, the arithmetic mean and the best estimate hazard curves. The arithmetic mean (A) was the average of all input from the panel of experts involved in the study, whereas the best estimate (B) was obtained frorn the most likely values for the seismic parameters determined by the seismic experts and the most likely ground motion models determined by the ground motion experts. The best estimate hazard curve, therefore, does not represent the relative contributions when all possible alternatives and all uncertainties are used. The estimates of the probability of exceedance for the nuclear production plants were generally in the $10^{-3}$ range.

The values estimated for the Vogtle Nuclear Station, the nearest and most recently constructed facility, were generally the lowest probabilities, with the arithmetic mean $(A)=1.5 \times 10^{-3}$ and the best estimate $(B)=3 x$ $10^{-4}$. 


\section{Seismic Instrumentation}

In an effort to identify and understand the seismicity in the region of SRS, a small network of short-period vertical seismometers was placed in operation in 1976. The SRS Seismic Network (SRS Seisnet) was located in remote areas of the site with the data transmitted to a central recording site in SRL. The SRS Seisnet was expanded and upgraded in 1988 to its present configuration.

\section{Current Seismic Instrumentation}

The SRS Seisnet at this time consists of five short-period vertical seismometers and two horizontal seismometers located within the SRS site (Figure 29). The signals are transmitted to the central recording station in Building 735-11A where four visual records are ob- tained. These data and the three remaining channels of data are sent to the computer for analysis. If an earthquake in the region is detected by the computer, the records are written to tape for storaging and for recording permanently the event. The paper copies of records from the four sites are also kept as a permanent record.

SRL also has three portable units, which can be placed in service as required. Two of these are digital recording units, which will support both seismometers and accelerometers. The units allow the performance of time and frequency series analysis on the individual data channels.

A strong motion accelerograph has been located at SRS since the facility was constructed in the 1950s. However,

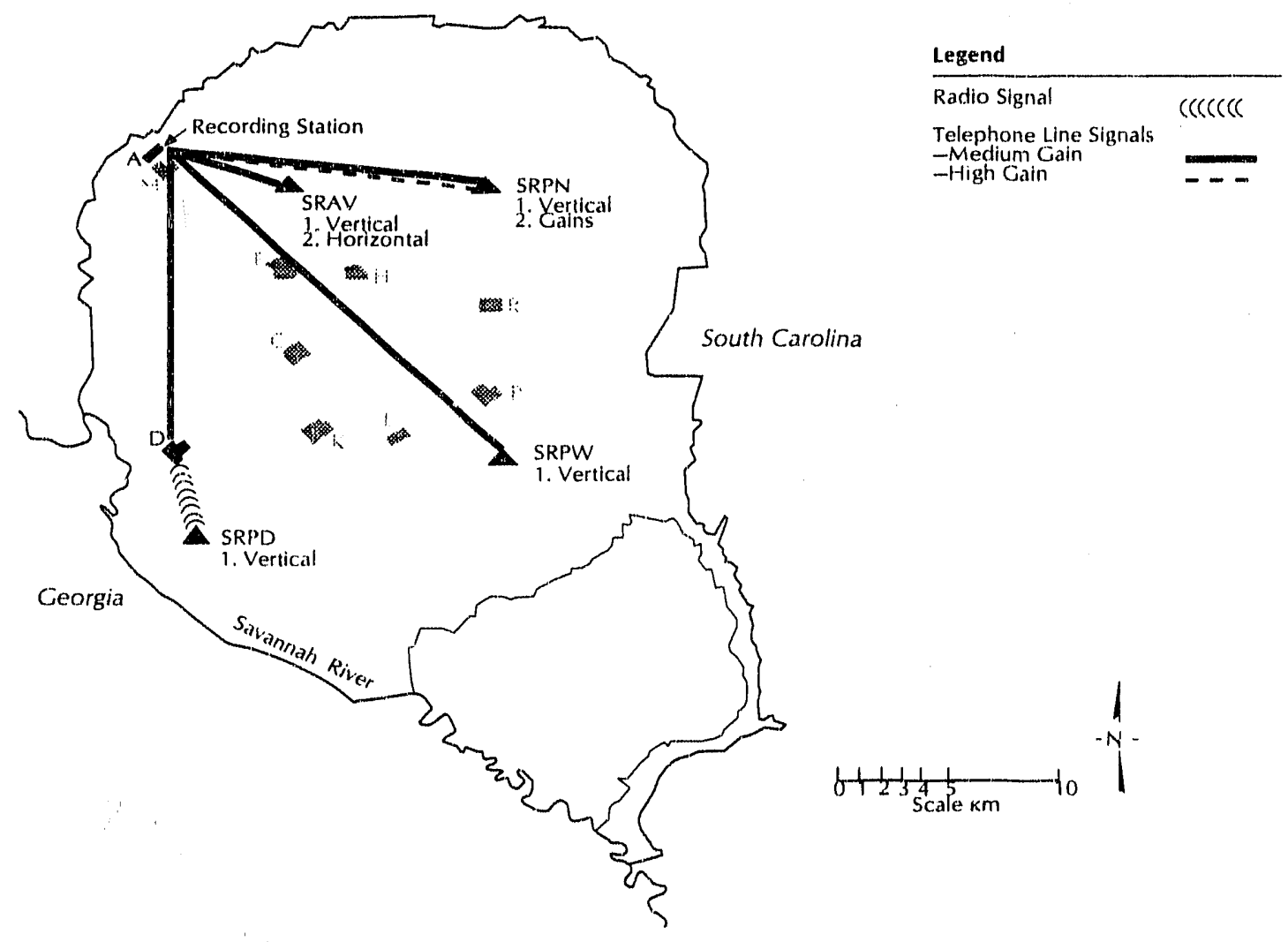

Figure 29. SRS SEISNET Station Locations 
it is not operational at the present time, and a pendulum system designed to trigger at $0.002 \mathrm{~g}$ has been used to monitor ground motion at SRS.

\section{Planned Seismic Instrumentation}

The SRS Seisnet is to be expanded within the next two years to include six, three-component sites located about 10 to $20 \mathrm{~km}$ from the center of SRS with two locations in Georgia and the others in South Carolina. A borehole seismometer will also be placed at about 900-meters depth in a borehole on SRS. These added stations to the SRS Seisnet will allow for better location of earthquake in the site region and constrain the depths that may occur within SRS.

There are also efforts underway at the present time to exchange data from the SRS Seisnet with the USGS SCNET. This will provide SRS with station data at some distance from the site and provide additional data for use in the statistical analysis of location and depth.

SRS purchased a Model SSA3 Solid State Accelerograph system, which consists of a central recording unit and multi-sensor triaxial accelerometers developed for the reactor industry generally following ANSI 2-2/1978 Guidelines. This state-of-the-art instrumentation, which will be placed in one of the reactors, offers the following:

- rapid analysis of earthquake data using the systems computer (including a response spectra)

- computer control of all data acquisitions functions

- direct digital recording at 2.00 samples per second

- high dynamic range

In the event of an earthquake, the SSA3 will digitally store the acceleration time history for each recorder. The data can then be retrieved, the time history and peak acceleration determined, and a response spectra calculated.

A Model SSA1 has also been purchased for placement at one of the short-period seismometer sites to obtain free-field data on ground motion at the site. 


\section{Programs for Resolving Outstanding Issues}

The Savannah River Laboratory (SRL), in April of 1988, developed a seismic program to provide technical data to improve the understanding of the seismic risk, seismicity, and potential hazards because of earthquakes at SRS facilities. An important element of this program was the establishment of the SRS Seismic Advisory Committee, which was chartered to provide independent overview and advise on seismic issues as they relate to seismic risk, seismicity, and earthquake hazard evaluation. From reviews by the SRS Seismic Advisory Committee, the SRL Seismic Program has been expanded and modified.

In 1987, the SRL implemented a seismic program to develop an understanding in the areas of seismicity and earthquake hazards at SRS and the surrounding region. The original program included the upgrading of the SRS Seismic Network, a detailed gravity survey of the site, and a modern reflection seismic survey of the site. The purpose of the program was to obtain better detail of the structural features beneath the site (especially within the basement) and to provide more and modern coverage of seismicity within the site and the surrounding area. The program objective was to establish a level of confidence in the safety of existing or proposed SRS facilities with respect to seismic activity by providing the basic data required for design and analysis. Elements of the program included the following:

- monitor site and regional seismicity through the SRS seismic network to identify source parameters, such as location, magnitude, depth, and mechanisms

- monitor free-field (ground) and structural response to earthquake motions through the establishment of a site strong-motion network

- review existing data and combine with new data on the geology and seismicity of the region to establish seismic source zones and earthquake source mechanisms

- describe the seismicity in terms of occurrence and magnitude in the seismic zones

- develop an earthquake recurrence model for the region for specific seismic zones

- derive or select a transfer function (attenuation relationship) to mathematically carry information from the epicenter to the site in terrns of structurally relevant parameters

- integrate the data to determine the potential seismic activity of all sources for all earthquake magnitudes to determine the probability that a certain acceleration will not be exceeded within a given time period

The program was planned to confirm the design of the design basis earthquake and ground response parameters for SRS, which could be translated into seismic loading and response spectra used in seismic engineering analysis of site facilities.

The upgrading of the SRS Seismic Network consisted of the addition of one vertical and two horizontal shortperiod seismometers to the three existing stations on site. A digital data acquisition system was also added to the system to provide real time preliminary location of events in the region of SRS. The older seismometers were also replaced with modern instruments.

The University of South Carolina was subcontracted to perform a detailed gravity study of the site. The purpose of the study was to provide detailed information on the character of the rocks below the Coastal Plain and structural features, such as faults, within these rocks (Anderson, 1990). A reflection seismic survey was also performed by Conoco, Inc., which included about 100 line miles of seismic lines within the plant boundaries (Chapman and DiStefano, 1989).

Following the February 1988 Aiken earthquake $(M=2.6)$ the SRL seismic program w'as expanded and formalized in DPST-88-470, Savannah River Laboratory's Seismic Program. This program plan outlined four major elements:

- expand SRS Seisnet

- form Seismic Advisory Cormmittee

- define potential for intraplate seismicity in region of SRS

- integrate SRS into regional seismotectonic framework

All four items were initiated in 1988, with some of the specific tasks outlined in the program plan completed during FY 88. The Seismic Advisory Committee was formed with the following membership:

- G. A. Bollinger, Virginia Polytechnic and State University

- M. D. Zoback, Stanford University

- J. Fletcher, U.S. Geological Survey 
- P. Talwani, University of South Carolina

- D. E. Stephenson, Savannah River Laboratory

This group met in October 1988 and reviewed the SRS seismic program and the results obtained to date. From that review, recommendations were made to expand the program. They included the following:

- install modern strong motion instrumentation

- locate seismometers of the SRS Seisnet offsite, especially toward the west in Georgia

- reprocess the Conoco seismic reflection data

- perform deep in-situ stress measurements and investigate possible wedge-edge effects to explain high-intensity along the fall line from the 1886 Charleston event

\section{Seismic Programs Associated with Reactor Restart}

In 1989 a cooperative effort was established between the SRL seismic program and the Seismic Qualification Program developed by the Seismic Engineering Section of SRS for seismic evaluation and qualification of the SRS reactors, as well as with the group performing PRA studies. In support of the reactor restart program, studies were undertaken to provide information on the seismic hazards at SRS and the associated ground motion. The specific tasks, which were recommended by the SRS Seismic Advisory Committee, are as follows:

1. Evaluate the cause and potential effect on SRS of the increased, intensity levels along the fall line reported in the original study of the 1886 Charleston earthquake (Dutton, 1889).

2. Determine the cause of the large difference in the mean values of the PSHA of SRS as determined by LLNL and EPRI.

3. Develop a site-specific response spectra.

The result of the first two tasks may influence the sitespecific response spectra; therefore, the tasks were performed sequentially.

Task 1 was performed by the Seismological Observatory of Virginia Polytechnic Institute and State University and completed in October 1989. The intensity database of the 1886 Charleston event and most recent earthquakes in the region was evaluated to determine if anomalous intensity amplification occurred along the fall line (Piedmont-Coastal Plain contact) in the vicinity of SRS. The results presented in Chapman et al. (1989) concluded that there was no anomalous increase in Modified Mercalli Intensity at the fall line. But, there was a relatively higher attenuation of intensity in the thicker sections of the Coastal Plain sediments near the coastline as documented by Dutton (1889), which has a relative effect to stronger inelastic absorption. However, because of the strong near-surface velocity and density contrasts, frequency-dependent local effects could be a dominant factor in determining response at some sites near the Piedmont-Coastal Plain contact. SRS, it appears, is far enough down dip to not be afiected, but a site-specific response spectra should be determined.

Because the LLNL and EPRI PSHA for SRS represent the current state-of-the-art analysis methods and the results appear to provide an upper and lower bound on the seismic hazard and effects, the PGA, and spectra, a study was performed to document the reasons for the difference in the values obtained. This study was performed by Risk Engineering, Inc. (1990). The primary differences in the results of the two studies appears to be in the seismological interpretations developed by the two groups.

A site-specific response spectra is being developed using the recent data obtained from the various SRS programs.

\section{Long-Term Seismic Programs}

There are a number of studies under way or planned to provide data for the determination of the potential seismic hazard for SRS and to support the long-term seismic qualification of facilities. These include the following:

- The installation of modern strong motion instrumentation within facilities and at several far-field sites will be completed this calendar year, and the expansion of the SRS seismic network and calibration of the network is in the design phase.

- VPI is reprocessing the Conoco reflection seismic data to allow interpretation of the deeper portion of the recorded interval to determine the underlying structure associated with the Triassic basin and the intermediate crustal zone.

- Regional studies of the tectonics are being performed to determine how the site fits the regional seismotectonic framework.

- In-situ stress regime determinations at depth are being completed to evaluate the potential faulting mechanisms that are possible on existing structures.

- Studies are being performed to confirm that the Pen Branch fault is not capable as defined by the NRC. 
With these data, the potential maximum magnitude site earthquake and recurrence interval, the potential for local seismicity, and the site-specific effects of regional seismicity can be estimated. An updated seismic hazard analysis can then be performed. 


\section{Conclusions}

Studies to evaluate the seismicity, ground motion, seismic design bases, and seismic hazards for the SRS facilities have been ongoing since the late 1960s (Housner, 1968, Stephenson and Marine, 1978; D'Appolonia, 1979; URS/Blume, 1982; Coats and Murray, 1984; McCann, 1986; Savy, 1988; and McCann, 1989). These studies have been performed by individuals and organizations recognized for their experience and expertise in seismicity, hazard analysis, and earthquake engineering. The studies have employed several methodologies; each could be considered state-of-theart at the time it was used and recognized by the regulatory agencies. The more recent studies have used probabilistic methods that provide an idea of the statistical uncertainty with the seismic hazard at SRS.

The study by Housner in 1968 using a deterministic approach, determined the design basis for the SRS reactors to be $0.2 \mathrm{~g}$ peak horizontal ground acceleration due to a repeat of the 1885 Charleston earthquake. In 1979 D'Appolonia considired the Charleston 1886 event and selected a peak ground acceleration attenuated to SRS using the Trifunac and Brady relation of $0.26 \mathrm{~g}$ for the Defense Waste Processing Facility. The design basis also established by deterministic methods, which URS/Blume obtained, was $0.20 \mathrm{~g}$ resulting from the recurrence of the 1886 Charleston earthquake. Housner's study was performed prior to the establishment of regulatory guidance; however, both the studies by D'Appolonia and URS/Blume followed the guidelines presented in Appendix A to 10 CFR 100. The design-basis ground motion of $0.20 \mathrm{~g}$ for the SRS reactors is comparable to the highest value to which commercial nuclear reactors in the region, which are licensed by the NRC, are designed.

Probabilistic seismic hazard analysis of SRS have been conducted using both single and multiple model meth" ods. The early PSHA studies of Stephenson and Marine (1978), D'Appolonia (1979), and URS/Blume (1982) employed single models and resulted in probabilities of exceeding $0.20 \mathrm{~g}$ at SRS of $5 \times 10^{-5}$ to $2 \times 10^{-4}$ per year. J. Benjamin and Associates (McCann, 1986) performed a PSHA using the historic methodology and determined a probability of exceeding $0.20 \mathrm{~g}$ of $1.83 \times 10^{-4}$ per year for SRS. In 1984 for the DOE, LLNL performed a PSHA for critical facilities and DOE sites. For SRS, a value of $1.5 \times 10^{-4}$ probability per year of exceeding $0.20 \mathrm{~g}$ was established (Coats and Murray, 1984).
In the late 1980s LLNL calculated a PSHA for SRS using the methodology developed for the NRC and applied to commercial nuclear power plants east of the Rocky Mountains. This was performed using a multiple model and the probability of exceeding $0.20 \mathrm{~g}$ at SRS per year was determined to be $2.0 \times 10^{-3}$. In the same time period, J. Benjamin and Associates, using the method developed for DPRI, calculated a probability of exceeding the $0.20 \mathrm{~g}$ design basis at SRS to be $5 \times 10^{-5}$ per year. These values of the probability of exceedance are within the general range of $10^{-3}$ to $10^{-6}$ reported by the Panel of Seismic Hazard Analysis of the National Research Council. These values are also comparable to the commercial nuclear facilities in the region of SRS (EPRI, 1986; Bernreuter et al., 1989).

Seismic risk maps, which have been developed for zoning, design, and site evaluations, so that the designers can read expected ground accelerations directly from the maps, were also evaluated to determine what values were considered appropriate for SRS from this source. These seismic risk maps were developed by seismologists and organizations such as ATC and then incorporated into codes and regulations to attempt to standardize design. For the SRS site, the ground acceleration provided by the seismic risk maps ranged from 0.11 to $0.22 \mathrm{~g}$. The higher value from the USGS study by Algermission (1980) was based on a probabilistic analysis and predicts a 10 percent probability of being exceeded in 250 years. This shows that the $0.20 \mathrm{~g}$ horizontal ground acceleration used by the design basis for the SRS reactors is in the upper range of values specified by seismic-risk maps of the region.

By comparing the $0.20 \mathrm{~g}$ design basis of the SRS reactors with values used for commercial nuclear facilities in the southeastern U.S. with values of acceleration suggested by seismic risk maps and with the PSHA determined for critical facilities and other nuclear facilities, it compares very favorably, providing strong support for the use of this value for the restart of the SRS reactors.

Response spectra have been developed for the SRS site beginning with that constructed by Housner in 1968. Housner's spectra was normalized to $0.20 \mathrm{~g}$ at zero period with 5 percent damping. It was applied to the base of the structure and did not consider soil-structure interaction. In 1982, URS/Blume developed a site-specific resporise spectra for SRS with an allowable 
damping of 7 percent as per NRC Reg Guide 1.60, normalized to $0.20 \mathrm{~g}$, and soil-structure interaction was considered. In 1984, LLNL, for DOE, developed a sitespecific response spectra with 7 percent damping. In Regulatory Guide 1.60, the NRC presented a generic response spectra for commercial nuclear facilities; however, the Regulatory Guide suggested a site-specific response spectra be determined if appropriate. The NRC spectra envelops all the other site-specific response spectra that have been developed for SRS and is similar in shape to the generic spectra. However, at frequencies below $2 \mathrm{~Hz}$, the SRS spectra is lower than the URS/Blume spectra.

Because the PGA and response spectra that are being used in the design and analysis of the SRS reactors for restart compare to those used for commercial nuclear facilities, and because the PSHA results are also similar to the facilities, as well as being within the range of all critical facilities, there is a high level of confidence that it is justified for use in the SRS restart program. 


\section{References}

Acree, S. D., J. R. Acree, and P. Talwani, 1988, "The Lake Keowee. South Carolina Earthquakes of February Through July 1986", Seismological Research Letters, 1: 59, n. 2, pp 63-70

Algermission, S. T., 1980, "Some Aspects of the Seismic Hazard Associated with Radioactive Waste Disposal", U. S. Geol Sun: Open File Report 80-2017, $33 \mathrm{pp}$

Algermission, S. T.. D. M. Perkins, F C. Thenhaus. S. L. Hanson, and B. L. Bender 1982. "Probabilistic Estimates of Maximum Accel: ation and Velocity in Rock in the Contiguous United States", U. S. Geol. Sun: Open File Report. 82-1033, 99 pp

Amick. D. et. a!, Palioliquefaction Features Along the Atlantic Seaboard. NUREG/CR 5613, Prepared by Ebasco Services Incorporated for the USNRC, Washington. October 1990

American National Standards Institute. Inc., 1982, "Minimurn Design Loads for Buildings and Other Structures: ANSI". New York, NY.

Anderson, E. E., 1990. "Resuits of a Detailed Gravity Survey of the Savannah River Plant Area", $M . S$. Thesis (unpublished). Universin of South Carolina. Columbia. SC

Applied Technology Council, 1978. "Tentative Provisions for the Development of Seismic Regulations for Buildings", National Bureau of Standards, $S P, 510$. Washington. DC

Bernreuter, D. L., J. B. Savy, R. W. Mensing, and J. C. Chen. 1989. "Scismic Hazard Characterization of 69 Plant Sites East of the Rocky Mountains". "Me-nodology', Input Data and Comparisons to Previous Results for Ten Test Sites", Lastrence Livermore National Laboraton. Technical Reparr, UCID-21517. U. S. Nucl. Reg. Comm. Report. NU. REGICR5250

Bollinger, G. A.. 1973a. "Seismicity of the Southeastern United States". Bulletin Seismol. Society Am., v: 6.3.pp $1785-1808$

Bollinger, G. A., 1973b, "Seismicity and Crustal Uplift in the Southeastem United States". Am. Jour. Sci. 1: 273.4. pp $396-408$
Bollinger, G. A., F. C. Davison, Jr., M. S. Sibol, and J. B. Birch, 1989, "Magnitude Recurrence Relations for the Southeastern United States and Its Subdivisions", Joumal of Geophys. Res., v. 94, n. B3, pp $2857-2873$

Bollinger, G. A., E. G. Ehlers, Jr., and M. J. Moses, 1987, "Intraplate Seismicity in the Easte-n United States", U. S. Nucl. Reg. Comm. Repo' \& NUREG/ $C R-4974,19 \mathrm{pp}$

Bollinger, G. A., A. C. Johnsion, P. Talwani, L. T. Long, K. M. Shedlock, M. S. Sibol, and M. C. Chapman, 1988, "Seismicity of the Southeastern United States, 1698 to 1986", Decade of North American Geology Volume, in press

Chapman, W. L., and M. P. DiStefano, 1989, "Savannah River Plant Seismic Survey, 1987.1988", Conoco, Inc., Consulting Report 1809-005-006-89, 110 pp

Chaprnen, M. C., M. C. Sitol, and G. A. Bollinger, 1989, "Investigation of Anomalous Earthquake Intensity Levels Along the Coastal Plain - Piedmont Boundary in South Carolina and Georgia", Vir. ginia Polytechnic Institute and State Universin;, Blacksburg, VA, Consulting Repon pripared for Westinghouse Savannah River Company

Chinnery, M. A.., 1979, "A Comparison of the Seismicity of Three Regions of the Eastern United States". Bull. Seismol. Soc. Am., v. 69, pp 757-772

Coats, D. W., and R. C. Murray, 1984, "Natural Phenomena Hazards Modeling Project", "Seismic Hazard Models of Department of Energy Sites", Lawrence Livermore National Laboraton UCRL. 53582 R.1., University of Califomia. Liver. more, CA, $91 \mathrm{pp}$

Coppersmith. K. J., and R. R. Youngs, 1989, "Kheeping Pace with the Science", "Seismic Hazard Analysis in the Central and Eastern United States", Second DOE Narural Phenomena Hazards Mitigation Conference Proceedings, sponssored by U. S. Department of Energy Headquarters of Nuclear Safer, Knoxville. TN, $436 \mathrm{pp}$ 
D’Appolonia Consulting Engineers, Inc., 1979, "Draft Pieliminary Safety Analysis for Defense Waste Processing Facility", Secrion 3, submitted to E. I. du Pont de Nemours and Company

Dutton, C. E., 1889, "The Charleston Earthquake of August 31, 1886", U. S. Geoi. Sun: Annual Report, 1887-1888, pp 203-528

Electric Power Research Institute, 1986, "Seismic Hazard Methodology for the Central and Eastern United States", EPRI Technical Report $N P-4726-A, 11$ volumes

Hadley, J. B., and J. F. Devine, 1974, "Seismotectonic Map of the Eastern United States", U. S. Geol. Sun: Misc. Field Sudies Map MF-620

Housner, G. W., 1968, "Earthquake Criteria for the Savannah River Plant", E. I. du Pont de Nemours and Company DPE-2383,13 pp

Inter.ational Conference of Building Officials, Inc., 1982, "Uniform Building Code", ICBO, Inc., Whittier, CA

McCann, M. W., 1989, Probabilistic Seismic Hazard Evaluation for Savannah River Site, Aiken, SC, by Jack Benjamin \& Associates

McCann, M. W., Jr., 1986, "Historic Seismicity Analysis for the Savannah River Plant", Jack R. Benjamin and Assoc., Inc., Consulting Repon JBA-153-010-2, prepared for E. I. du Poni de Nemours and Company

McGuire, R. K., G. R. Toro, J. P. Jacobson, T. F. O'Hara, and W. J. Silva, 1989, "Probabilistic Seismic Hazard Evaluations in the Central and Eastern United States", "Resolution of the Charleston Earthquake Issue", Eleciric Power Research Institute Special Report NP-6395-D

Nuttli, O. W., 1973, "The Mississippi Valley Earthquakes of 1811 and 1812", "Intensities, Ground Motions, and Magnitudes", Bull. Seismol. Soc. Am.. v. 6.3, pp 2.27-248

Nuttli, O. W., 1974, "Magnitude-Recurrence Relation for Central Mississippi Valley Earthquakes", Bull. Seismol. Soc. Am., 1: 64, pp 1189-1207
Obermeier, S. F, G. S. Gohn, R. E. Weens, R. L. Gelinas, and M. Rubin, 1985, "Geologic Evidence for Recurrent Moderate to Large Earthquakes Near Charleston, South Carolina", Science, v. 227, pp 408.411

Obermeier, S. F., R. B. Jacobson, G. S. Gohn, and R. E. Weems, 1986, "Holocene and Late-Pleistocene (?) Earthquake-induced Sandblows in Coastal South Carolina (abs.)", Earthquake Notes, 1. 57, p 17

Obermeier, S. F., R. E. Weems, and R. B. Jarobson, 1987. "Earthquake-Induced Liquefaction Features in the Coastal South Carolina Region", U.S. Geol. Sun. Open File Report 87-504, 20 pp

Ra:viins, J., 1986, "Seismotectonics of Newberry Country, South Carolina", M. S. Thesis, Univ of South Carolina, Columbia, SC, $60 \mathrm{pp}$

Reagor, B. G., S. W. Sotver, and S. T. Algermission, 1980, "Seismicity Map of the State of South Carolina”, U. S. Geol. Sun. Misc. Field Studies Map MF-1060

Risk Engineering, Inc., 1990, "Comparison and Analysis of Assumptions in LLNL and EPRI Seismic Hazard Studies for the Savannah River Site", Risk Engineering, Inc., consulting Report prepared for Westinghouse Savannah River Company

Savy, J., 1988, "Seismic Hazard Characterization of the Savannah River Plant Site (SRP)", Lawrence Livermore National Laboratory Technical Report UCID-21596, University of California, Livermore, $\mathrm{CA}$

Sibol, M. S., G. A. Bollinger, and J. B. Birch, 1987, "Estimation of Magnitudes in Central and Eastern North America Using Intensity and Felt Area", Bull. Seismol. Soc. Am., v. 7\%, pp 1635-1654

Stephenson, D. E., 1988, "Augusta 1988 Savannah River Plant Earthquake", E.I. du Pont de Nemours and Company, DPST-88-841, $12 \mathrm{pp}$

Stephersson, D. E., and I. W. Marine, 1978, "Parametric Study of the Effect of Southeastern Earthquakes on the SRP Site", E. I. du Pont de Ne. mours and Company, Savannah River Laboratory, DPST: $78 \cdot 424,24 \mathrm{pp}$ 
Stephenson, D. E., P. Talwani, and J. Rawlins, 1985, "Savannah River Plant Earthquake of June 1985", E. I. du Pont de Nemours and Company, DPST-85-583

Structural Engineers Association of California, 1975, "Recornmended Lateral Force Requirements and Commentary", SEAOC, San Francisco, CA

Taber, S., 1913, "The South Carolina Earthquake of January 1, 1913", Bull. Seismol. Soc. Am., v. 3, pp 6-13

Talwani, P., 1982, "Internally Consistent Pattern of Seismicity Near Charleston, South Carolina", Geolo. gy, v: 10, pp 654-658

Talwani, P., and J. Cox, 1985, "Paleoseismic Evidence for Recurrence of Earthquakes Near Charleston, South Carolina", Science. v. 229, pp 379-381

Talwani, P., J. Rawlins, and D. E. Stephenson, 1985, "The Savannah River Plant, South Carolina, Earthquake of June 9, 1985 and Its Tectonic Setting", Earthquake Notes, v. 56, n. 4, pp 101-106

Tarr, A. C., 1977, "Recent Seismicity Near Charleston, South Carolina, and Its Relationship to the August 31, 1886, Earthquake", U. S. Geol. Sun: Prof. Paper 1028-D, pp 43-57

Tarr, A. C., and K. W. King, 1974, "South Carolina Seismic Program", U. S. Geol. Sun: Open File Report $74-58,15 \mathrm{pp}$

Tarr, S. C., P. Talwani, S. Rhea, D. Carver, and D. Amick. 1981, "Results of Recent South Carolina Seismological Studies", Bull. Seismol. Soc. Am., v. 71, pp 1883-1902

Titbomb, E. F., Jr., and W. E. Hancock, 1981, "Earthquake Investigations for the Richard B. Russell Dam, Savannah Fiver, Georgia and South Carolina". Earthquakes and Earhquake Engineering; Eastem U. S., Ann Arbor Science Publishers, Inc., Ann Arbor, MI, $576 \mathrm{pp}$
U. S. Department of the Army, Navy, and Air Force, 1982, "Seismic Design for Buildings", TM 5-809-10, NVA FAC P-355, AFM 88-3, U. S. Govermment Printing Office, Washington, DC

U. S. Nuclear Regulatory Commission, Regulatory Guide 1.60 Design Response Spectra for Seismic Design of Nuclear Power Plants, Washington, DC, 1977

URS/John A. Blume and Associates, Engineers, 1982, "Update of Seismic Criteria for the Savannah River Plant, V. 1 of 2", Geotechnical: URS/JAB 8144, San Francisco, CA, prepared for E. I. du Pont de Nemours and Company, DPE 3699, $293 \mathrm{pp}$

Veterans Administration, 1974, "Lateral Force Design Requirements for VA Hospitals", VA, Washington, DC

Zoback, M. D., and D. Moos, 1989, "In-Situ Stress and Geophysical Measurements in Boreholes SSW-1, SSW-2, SSW-3, DRB-8, DRB-11, Savannah River Plant", Stanford Univ. Dept. of Geophysics, 2 vol. umes

Zoback, M. D., D. Moos, and D. E. Stephenson, 1989, "State of Stress and the Relation to Tectonics in the Central Savannah River Area of South Carolina", in Rock Mechanics as a Guide for Efficient Utilization of Natural Resources, Khair. A. W., ed., A. A. Balkema Publ., Rotterdam, Netherlands, pp $553-560$ 
9103037.TPS 


\section{List of Tables}

\section{Table}

Significant Earthquakes within 300 Kilometers of SRS (pages 41-46)

South Carolina Earthquakes, 1986-1989 (pages 47-48)

Recent Recorded Earthquakes near SRS (page 49)

Magnitude Recurrence Relations (page 50)

Summary of Dominant LLNL Seismic Sources and their Parameters (pages 51-52)

Summary of Dominant EPRI Seismic Sources and their Parameters (page 53)

Intensity-Based Peak Ground Acceleration Attenuation Models (page 54)

Magnitude-Based Peak Ground Acceleration Attenuation Models (pages 55-56)

Seismic Analysis of SRS Non-Reactor Facilities (page 57)

Interpreted Peak Ground Motions at the Richard B. Russell Site (page 58) 
Table 1. Significant Earthquakes within 300 Kilometers of SRS 1698-1988 (page 1 of 6) (Intensity > IV or Magnitude $>3$ )

\begin{tabular}{|c|c|c|c|c|c|c|c|c|c|c|c|c|}
\hline \multicolumn{2}{|c|}{ Date } & \multirow[b]{2}{*}{$\begin{array}{l}\text { UTC } \\
\text { Day }\end{array}$} & \multirow[b]{2}{*}{ Hour } & \multicolumn{2}{|l|}{ Time } & \multicolumn{2}{|c|}{ Location } & \multirow{2}{*}{$\begin{array}{l}\text { Depth } \\
\text { KMI }\end{array}$} & \multirow{2}{*}{$\begin{array}{l}\text { Inten. } \\
\text { MMI }\end{array}$} & \multirow[t]{2}{*}{ Mag } & \multirow{2}{*}{$\begin{array}{l}\text { Site } \\
\text { Dist. } \\
\text { KM }\end{array}$} & \multirow{2}{*}{$\begin{array}{l}\text { Data } \\
\text { Source }\end{array}$} \\
\hline Year & Month & & & Min. & Sec. & DEG $\mathrm{N}$ & DEG W & & & & & \\
\hline 1776 & 11 & 5 & & & & 35.3 & 83.2 & -- & IV & -- & 272 & $\mathrm{BOL}$ \\
\hline 1799 & 4 & 4 & & & & 32.9 & 80.0 & -- & $\mathrm{V}$ & -- & 168 & STR \\
\hline 1799 & 4 & 11 & 8 & 20 & & 32.9 & 80.0 & -- & V & -- & 168 & STR \\
\hline 1799 & 4 & 11 & 14 & 55 & & 34.3 & 80.6 & -- & V & -- & 168 & BOL \\
\hline 1817 & 1 & 8 & 4 & & & 32.8 & 79.8 & -- & V & -- & 184 & BOL \\
\hline 1820 & 9 & 3 & 8 & 30 & & 33.4 & 79.3 & -- & IV & -- & 232 & STR \\
\hline 1851 & 8 & 11 & 1 & 55 & & 35.6 & 82.6 & -- & V & -- & 280 & STR \\
\hline 1853 & 5 & 20 & & & & 34.0 & 81.2 & -- & VI & -- & 112 & STR \\
\hline 1857 & 12 & 19 & 9 & 4 & & 32.8 & 79.8 & -- & V & -- & 184 & BOL \\
\hline 1860 & 1 & 16 & 18 & & & 32.8 & 79.8 & -- & V & -- & 184. & BOL \\
\hline 1869 & 0 & 0 & & & & 32.9 & 80.0 & -- & IV & -- & 168 & STR \\
\hline 1872 & 6 & 17 & 20 & & & 33.1 & 83.3 & -- & $\mathrm{V}$ & -- & 144 & $\mathrm{EQH}$ \\
\hline 1874 & 2 & 10 & & & & 35.7 & 82.1 & -- & VI & -- & 280 & $\mathrm{BOL}$ \\
\hline 1874 & 2 & 22 & & & & 35.7 & 82.1 & -- & IV & -- & 280 & EUS \\
\hline 1874 & 3 & 17 & & & & 35.7 & 82.1 & -- & IV & -- & 280 & EUS \\
\hline 1874 & 3 & 26 & & & & 35.7 & 82.1 & -- & VI & -- & 280 & EUS \\
\hline 1874 & 4 & 14 & & & & 35.7 & 82.1 & -- & IV & -- & 280 & EUS \\
\hline 1874 & 4 & 17 & & & & 35.7 & 82.1 & -- & IV & -- & 280 & EUS \\
\hline 1875 & 11 & 2 & 2 & 55 & & 33.8 & 82.5 & -- & VI & -- & 96 & EUS \\
\hline 1876 & 12 & 12 & & & & 32.9 & 80.0 & -- & IV & -- & 168 & STR \\
\hline 1879 & 12 & 13 & & & & 35.0 & 80.9 & -- & V & -- & 224 & EUS \\
\hline 1885 & 10 & 17 & 17 & 30 & & 33.0 & 83.0 & -- & IV & -- & 112 & BOL \\
\hline 1886 & 8 & 27 & 8 & 30 & & 33.0 & 80.2 & -- & V & -- & 144 & BOL \\
\hline 1886 & 8 & 28 & 8 & 45 & & 32.9 & 80.0 & -- & VI & -- & 168 & STR \\
\hline 1886 & 8 & 28 & 9 & 40 & & 32.9 & 80.0 & -- & IV & -- & 168 & STR \\
\hline 1886 & 8 & 28 & 18 & 20 & & 32.9 & 80.0 & -- & IV & -- & 168 & STR \\
\hline 1886 & 9 & 1 & 2 & 51 & & 32.9 & 80.0 & $-\cdots$ & $\mathrm{X}$ & -- & 168 & $\mathrm{EQH}$ \\
\hline 1886 & 9 & 1 & 6 & 5 & & 32.9 & 80.0 & -- & VI & -- & 168 & STR \\
\hline 1886 & 9 & 2 & 4 & 55 & & 32.9 & 80.0 & -- & V & -- & 168 & STR \\
\hline 1886 & 9 & 4 & 4 & 1 & & 32.9 & 80.0 & -- & VI & -- & 168 & STR \\
\hline 1886 & 9 & 6 & 4 & 6 & & 32.9 & 80.0 & -- & VI & -- & 168 & STR \\
\hline 1886 & 9 & 6 & 16 & 35 & & 32.9 & 80.0 & -- & IV & $\cdots$ & 168 & STR \\
\hline 1886 & 9 & 17 & 6 & 29 & & 32.9 & 80.0 & -- & VI & -- & 168 & STR \\
\hline 1886 & 9 & 21 & 10 & 15 & & 32.9 & 80.0 & -- & VI & -- & 168 & STr \\
\hline 1886 & 9 & 21 & 10 & 30 & & 32.9 & 80.0 & -- & V & -- & 168 & STR \\
\hline 1886 & 9 & 27 & 19 & 2 & & 32.9 & 80.0 & -- & VI & -- & 168 & STR \\
\hline 1886 & 9 & 27 & 32 & 2 & & 32.9 & 80.0 & $-\cdots$ & V & -- & 168 & STR \\
\hline 1886 & 10 & 9 & 3 & 40 & & 32.9 & 80.0 & -- & IV & -- & 168 & STR \\
\hline 1886 & 10 & 9 & 6 & 48 & & 32.9 & 80.0 & -- & VI & -- & 168 & STR \\
\hline 1886 & 10 & 22 & 10 & 20 & & 32.9 & 80.0 & -- & VI & -- & 168 & $\mathrm{EQH}$ \\
\hline 1886 & 10 & 22 & 19 & 45 & & 32.9 & 80.0 & -- & VII & $\ldots$ & 168 & $\mathrm{EQH}$ \\
\hline 1886 & 11 & 5 & 17 & 20 & & 32.9 & 80.0 & -- & VI & -- & 168 & $\mathrm{EQH}$ \\
\hline 1886 & 11 & 28 & 20 & $13^{6}$ & & 32.9 & 80.0 & -- & IV & -- & 168 & STR \\
\hline
\end{tabular}


Table 1. Significant Earthquakes within 300 Kilometers of SRS 1698-1988 (page 2 of 6)

(Intensity > IV or Magnitude > 3)

\begin{tabular}{|c|c|c|c|c|c|c|c|c|c|c|c|c|}
\hline \multirow[t]{2}{*}{ Date } & \multirow[b]{2}{*}{ Month } & \multirow[b]{2}{*}{$\begin{array}{l}\text { UTC } \\
\text { Day }\end{array}$} & \multirow[b]{2}{*}{ Hour } & \multicolumn{2}{|c|}{ Time } & \multicolumn{2}{|c|}{ Location } & \multirow{2}{*}{$\begin{array}{l}\text { Depth } \\
\text { KM }\end{array}$} & \multirow{2}{*}{$\begin{array}{l}\text { Inten, } \\
\text { MMI }\end{array}$} & \multirow[t]{2}{*}{ Mag } & \multirow{2}{*}{$\begin{array}{l}\text { Site } \\
\text { Dist. } \\
\text { KM }\end{array}$} & \multirow{2}{*}{$\begin{array}{l}\text { Data } \\
\text { Source }\end{array}$} \\
\hline & & & & Min. & Sec. & DEG N & DEG W & & & & & \\
\hline 1887 & 1 & 4 & 11 & 44 & & 32.9 & 80.0 & -- & VI & -- & 168 & STR \\
\hline 1887 & 3 & 4 & 7 & & & 32.9 & 80.0 & -- & IV & -- & 168 & STR \\
\hline 1887 & 3 & 17 & 14 & 9 & & 32.9 & 80.0 & -- & V & -- & 168 & STR \\
\hline 1887 & 3 & 18 & 23 & 10 & & 32.9 & 80.0 & -- & IV & -- & 168 & STR \\
\hline 1887 & 3 & 19 & & & & 32.9 & 80.0 & -- & IV & -- & 168 & STR \\
\hline 1887 & 3 & 24 & & & & 32.9 & 80.0 & -- & IV & -- & 168 & STR \\
\hline 1887 & 3 & 24 & 4 & 5 & & 32.9 & 80.0 & -- & IV & -- & 168 & STR \\
\hline 1887 & 3 & 28 & & & & 32.9 & 80.0 & $\cdots$ & IV & -- & 168 & STR \\
\hline 1887 & 4 & 7 & 4 & & & 32.9 & 80.0 & -- & IV & -- & 168 & STR \\
\hline 1887 & 4 & 8 & 9 & & & 32.9 & 80.0 & - & IV & - & 168 & STR \\
\hline 1887 & 4 & 20 & 22 & 30 & & 32.9 & 80.0 & -- & IV & -- & 168 & STR \\
\hline 1887 & 4 & 14 & 7 & 25 & & 32.9 & 80.0 & -- & IV & -- & 168 & STR \\
\hline 1887 & 4 & 26 & 10 & & & 32.9 & 80.0 & -- & IV & -- & 168 & STR \\
\hline 1887 & 4 & 28 & 8 & & & 32.9 & 80.0 & -- & V & -- & 168 & STR \\
\hline 1887 & 5 & 6 & & & & 32.9 & 80.0 & -- & IV & -- & 168 & STR \\
\hline 1887 & 6 & 3 & 12 & & & 32.9 & 80.0 & -- & IV & -- & 168 & STR \\
\hline 1887 & 7 & 10 & 18 & & & 32.9 & 80.0 & -- & IV & -- & 168 & STR \\
\hline 1887 & 8 & 27 & 4 & 30 & & 32.9 & 80.0 & -- & V & -- & 168 & STR \\
\hline 1887 & 8 & 27 & 9 & 20 & & 32.9 & 80.0 & 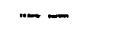 & IV & -- & 168 & STR \\
\hline 1888 & 1 & 12 & 15 & 54 & & 32.9 & 80.0 & -- & VI & -- & 168 & STR \\
\hline 1888 & 1 & 16 & 17 & 52 & & 32.9 & 80.0 & -- & VI & -- & 168 & STR \\
\hline 1888 & 2 & 29 & 11 & & & 32.9 & 80.0 & -- & $\mathrm{V}$ & -- & 168 & STR \\
\hline 1888 & 3 & 3 & & & & 32.9 & 80.0 & - & IV & $-\cdots$ & 168 & STR \\
\hline 1888 & 3 & 3 & 4 & 30 & & 32.9 & 80.0 & -- & IV & -- & 168 & STR \\
\hline 1888 & 3 & 4 & & & & 32.9 & 80.0 & -- & IV & -- & 168 & STR \\
\hline 1888 & 3 & 14 & 5 & & & 32.9 & 80.0 & -- & V & $\cdots$ & 168 & STR \\
\hline 1888 & 3 & 20 & 5 & & & 32.9 & 80.0 & -- & IV & -- & 168 & STR \\
\hline 1888 & 3 & 25 & & & & 32.9 & 80.0 & -- & IV & -- & 168 & STR \\
\hline 1888 & 4 & 16 & & & & 32.9 & 80.0 & -- & IV & -- & 168 & STR \\
\hline 1888 & 4 & 16 & & & & 32.9 & 80.0 & -- & IV & -- & 168 & STR \\
\hline 1888 & 4 & 16 & & & & 32.9 & 80.0 & -- & IV & -- & 168 & STR \\
\hline 1888 & 5 & 2 & & & & 32.9 & 80.0 & -- & IV & -- & 168 & STR \\
\hline 1889 & 2 & 10 & & 31 & & 32.9 & 80.0 & -- & IV & -- & 168 & STR \\
\hline 1889 & 7 & 12 & 2 & 54 & & 32.9 & 80.0 & -- & IV & -- & 168 & STR \\
\hline 1891 & 10 & 13 & 5 & 55 & & 32.9 & 80.0 & -- & IV & -- & 168 & STR \\
\hline 1893 & 6 & 21 & 4 & 5 & & 32.9 & 80.0 & -- & V & -- & 168 & STR \\
\hline 1893 & 7 & 5 & 8 & 10 & & 32.9 & 80.0 & -- & IV & $-\cdots$ & 168 & STR \\
\hline 1893 & 7 & 6 & 9 & 5 & & 32.9 & 80.0 & -- & IV & -- & 168 & STR \\
\hline 1893 & 7 & 8 & 7 & 48 & & 32.9 & 80.0 & $-\cdots$ & IV & -- & 168 & STR \\
\hline 1893 & 7 & 8 & 15 & 25 & & 32.9 & 80.0 & -- & IV & -- & 168 & STR \\
\hline 1893 & 9 & 19 & 7 & 5 & & 32.9 & 80.0 & -- & IV & $\cdots$ & 168 & STR \\
\hline 1893 & 9 & 19 & 7 & 40 & & 32.9 & 80.0 & -- & IV & -- & 168 & STR \\
\hline 1893 & 9 & 19 & 8 & 55 & & 32.9 & 80.0 & -- & IV & -- & 168 & STR \\
\hline 1893 & 11 & 8 & 4 & 40 & & 32.9 & 80.0 & -- & IV & -- & 168 & STR \\
\hline 1893 & 11 & 8 & 6 & 5 & & 32.9 & 80.0 & -- & IV & -- & 168 & STR \\
\hline
\end{tabular}


Table 1. Signii_cant Earthquakes within 300 Kilometers of SRS 1698-1988 (page 3 of 6) (Intensity $>$ IV or Magnitude $>3$ )

\begin{tabular}{|c|c|c|c|c|c|c|c|c|c|c|c|c|}
\hline \multicolumn{2}{|l|}{ Date } & \multirow[b]{2}{*}{ UTC } & \multirow[b]{2}{*}{ Hour } & \multicolumn{2}{|l|}{ Time } & \multicolumn{2}{|c|}{ Location } & \multirow{2}{*}{$\begin{array}{l}\text { Depth } \\
\text { KM }\end{array}$} & \multirow{2}{*}{$\begin{array}{l}\text { Inten. } \\
\text { MMI }\end{array}$} & \multirow[t]{2}{*}{ Mag } & \multirow{2}{*}{$\begin{array}{l}\text { Site } \\
\text { Dist. } \\
\text { KM }\end{array}$} & \multirow{2}{*}{$\begin{array}{l}\text { Data } \\
\text { Source }\end{array}$} \\
\hline Year & Month & & & Min. & Sec. & DEG N & DEG W & & & & & \\
\hline 1893 & 12 & 27 & 6 & 51 & & 32.9 & 80.0 & -- & IV & -- & 168 & STR \\
\hline 1893 & 12 & 27 & 7 & 17 & & 32.9 & 80.0 & -- & IV & -- & 168 & STR \\
\hline 1893 & 12 & 27 & 9 & 9 & & 32.9 & 80.0 & -- & IV & -- & 168 & STR \\
\hline 1893 & 12 & 27 & 9 & 56 & & 32.9 & $8 \mathrm{C} .0$ & -- & IV & -- & 168 & STR \\
\hline 1893 & 12 & 28 & 2 & 20 & & 32.9 & 80.0 & -- & IV & -- & 168 & STR \\
\hline 1894 & 1 & 10 & 8 & 5 & & 32.9 & 80.0 & -- & IV & -- & 168 & STR \\
\hline 1894 & 1 & 10 & 8 & 49 & & 32.9 & 80.0 & -- & IV & -- & 168 & STR \\
\hline 1894 & 1 & 10 & 9 & 15 & & 32.9 & 80.0 & -- & IV & -- & 168 & STR \\
\hline 1894 & 1 & 30 & 4 & 5 & & 32.9 & 80.0 & -- & IV & -- & 168 & STR \\
\hline 1894 & 2 & 1 & 5 & 21 & & 32.9 & 80.0 & -- & IV & -- & 168 & STR \\
\hline 1894 & 6 & 16 & 2 & 16 & & 32.9 & 80.0 & -- & IV & -- & 168 & STR \\
\hline 1894 & 12 & 11 & 5 & 27 & & 32.9 & 80.0 & -- & IV & -- & 168 & STR \\
\hline 1895 & 1 & 8 & 5 & 40 & & 32.9 & 80.0 & -- & IV & -- & 168 & STR \\
\hline 1895 & 1 & 8 & 5 & 58 & & 32.9 & 80.0 & -- & IV & -- & 168 & STR \\
\hline 1895 & 1 & 8 & 7 & 29 & & 32.9 & 80.0 & -- & IV & -- & 168 & STR \\
\hline 1895 & 4 & 27 & 7 & 40 & & 32.9 & 80.0 & $\cdots$ & IV & -- & 168 & STR \\
\hline 1895 & 7 & 25 & 4 & 1 & & 32.9 & 80.0 & $\cdots$ & IV & -- & 168 & STR \\
\hline 1895 & 10 & 6 & 6 & 25 & & 32.9 & 80.0 & -- & IV & -- & 168 & STR \\
\hline 1895 & 10 & 20 & 17 & 8 & & 32.9 & 80.0 & -- & IV & -- & 168 & STR \\
\hline 1895 & 11 & 12 & 23 & 33 & & 32.9 & 80.0 & -- & IV & -- & 168 & STR \\
\hline 1896 & 3 & 19 & 8 & 22 & & 32.9 & 80.0 & -- & IV & -- & 168 & STR \\
\hline 1896 & 8 & 11 & 5 & 58 & & 32.9 & 80.0 & -- & IV & -- & 168 & STR \\
\hline 1896 & 8 & 11 & 6 & 14 & & 32.9 & 80.0 & -- & IV & -- & 168 & STR \\
\hline 1896 & 8 & 11 & 8 & 15 & & 32.9 & 80.0 & -- & IV & -- & 168 & STR \\
\hline 1896 & 8 & 11 & 9 & 24 & & 32.9 & 80.0 & -- & IV & -- & 168 & STR \\
\hline 1896 & 8 & 12 & 7 & 42 & & 32.9 & 80.0 & -- & IV & -- & 168 & STR \\
\hline 1896 & 8 & 14 & 5 & 43 & & 32.9 & 80.0 & -- & IV & -- & 168 & STR \\
\hline 1896 & 8 & 30 & 3 & 24 & & 32.9 & 80.0 & -- & IV & -- & 168 & STR \\
\hline 1896 & 9 & 8 & 18 & 16 & & 32.9 & 80.0 & -- & IV & -- & 168 & STR \\
\hline 1896 & 11 & 14 & 8 & 15 & & 32.9 & 80.0 & -- & IV & -- & 168 & STR \\
\hline 1899 & 3 & 10 & 5 & 43 & & 32.9 & 80.0 & -- & IV & $\cdots$ & 168 & STR \\
\hline 1899 & 12 & 4 & 12 & 48 & & 32.9 & 80.0 & -- & IV & -- & 168 & STR \\
\hline 1901 & 12 & 2 & 0 & 26 & & 32.9 & 80.0 & -- & IV & -- & 168 & STR \\
\hline 1903 & 1 & 24 & 1 & & & 32.9 & 80.0 & -- & IV & -- & 168 & STR \\
\hline 1903 & 1 & 24 & 1 & 15 & & 32.1 & 81.1 & -- & VI & -- & 128 & $\mathrm{EQH}$ \\
\hline 1903 & 1 & 31 & 10 & 54 & & 32.9 & 80.0 & -- & VI & -- & 168 & STR \\
\hline 1903 & 2 & 3 & 10 & 6 & & 32.9 & 80.0 & -- & IV & -- & 168 & STR \\
\hline 1907 & 4 & 29 & 8 & 30 & & 32.9 & 80.0 & -- & V & -- & 168 & EUS \\
\hline 1911 & 4 & 20 & 22 & & & 35.2 & 82.7 & -- & V & -- & 240 & $\mathrm{BOL}$ \\
\hline 1911 & 4 & 21 & 3 & & & 35.2 & 82.7 & -- & V & -- & 240 & EUS \\
\hline 1912 & 6 & 12 & 10 & 30 & & 32.9 & 80.0 & -- & VII & -- & 168 & EUS \\
\hline 1912 & 6 & 20 & & & & 32.0 & 81.0 & -- & V & -- & 144 & EUS \\
\hline 1912 & 9 & 29 & 8 & 6 & & 32.9 & 80.0 & -- & IV & -- & 168 & STR \\
\hline 1912 & 10 & 23 & 1 & 15 & & 32.7 & 83.5 & -- & IV & -- & 168 & STR \\
\hline 1912 & 12 & 7 & 19 & 10 & & 34.7 & 81.7 & -- & IV & -- & 168 & STR \\
\hline
\end{tabular}


Table 1. Significant Earthquakes within 300 Kilometers of SRS 1698-1988 (page 4 of 6) (lntensity > IV or Magnitude > 3)

\begin{tabular}{|c|c|c|c|c|c|c|c|c|c|c|c|c|}
\hline \multicolumn{2}{|l|}{ Date } & \multirow[b]{2}{*}{$\begin{array}{l}\text { UTC } \\
\text { Day }\end{array}$} & \multirow[b]{2}{*}{ Hour } & \multicolumn{2}{|l|}{ Time } & \multicolumn{2}{|c|}{ Location } & \multirow{2}{*}{$\begin{array}{l}\text { Depth } \\
\text { KM }\end{array}$} & \multirow{2}{*}{$\begin{array}{l}\text { Inten. } \\
\text { MMI }\end{array}$} & \multirow[t]{2}{*}{ Mag } & \multirow{2}{*}{$\begin{array}{l}\text { Site } \\
\text { Dist. } \\
\text { KM }\end{array}$} & \multirow{2}{*}{$\begin{array}{l}\text { Data } \\
\text { Source }\end{array}$} \\
\hline Year & Month & & & Min. & Sec, & DEG $\mathrm{N}$ & DEG W & & & & & \\
\hline 1913 & 1 & 1 & 18 & 28 & & 34.7 & 81.7 & -- & VII & -- & 168 & $\mathrm{EQH}$ \\
\hline 1914 & 3 & 5 & 20 & 5 & & 33.5 & 83.5 & -- & VI & -- & 160 & $\mathrm{EQH}$ \\
\hline 1914 & 3 & 7 & 1 & 20 & & 34.2 & 79.8 & -- & IV & -- & 2.16 & STR \\
\hline 1914 & 7 & 13 & 20 & 53 & & 33.0 & 80.2 & $-\cdots$ & IV & -- & 144 & $\mathrm{BOL}$ \\
\hline 1914 & 9 & 22 & 2 & 4 & & 33.0 & 80.2 & -- & V & -- & 144 & $\mathrm{BOL}$ \\
\hline 1916 & 2 & 21 & 17 & 39 & & 35.5 & 82.5 & -- & VII & -- & 272 & BOL \\
\hline 1916 & 3 & 2 & 5 & 2 & & 34.5 & 82.7 & -- & IV & -- & 168 & EUS \\
\hline 1923 & 12 & 31 & 20 & 6 & & 34.8 & 82.5 & $-\cdots$ & IV & -- & 192 & BOL \\
\hline 1924 & 10 & 20 & 8 & 30 & & 35.0 & 82.6 & -- & V & -- & 216 & $\mathrm{EQH}$ \\
\hline 1928 & 11 & 20 & 3 & 45 & & 35.8 & 82.3 & -- & IV & -- & 296 & STR \\
\hline 1928 & 12 & 23 & 2 & 30 & & 35.3 & 80.3 & -- & IV & -- & 272 & STR \\
\hline 1929 & 1 & 3 & 12 & 5 & & 33.9 & 80.3 & -- & IV & -- & 160 & STR \\
\hline 1929 & 10 & 28 & 2 & 15 & & 34.3 & 82.4 & $\cdots$ & IV & -- & 136 & STR \\
\hline 1930 & 12 & 10 & 0 & 2 & & 34.3 & 82.4 & -- & IV & -- & 136 & STR \\
\hline 1930 & 12 & 26 & 3 & & & 34.5 & 80.3 & -- & IV & -- & 200 & STR \\
\hline 1931 & 5 & 6 & 12 & 18 & & 34.3 & 82.4 & -- & IV & -- & 136 & STR \\
\hline 1933 & 6 & 9 & 11 & 30 & & 33.3 & 83.5 & -- & IV & -- & 160 & STR \\
\hline 1933 & 12 & 19 & 14 & 12 & & 33.0 & 80.2 & -- & IV & -- & 144 & EUS \\
\hline 1933 & 12 & 23 & 9 & 40 & & 32.9 & 80.0 & -- & V & -- & 168 & STR \\
\hline 1933 & 12 & 23 & 9 & 55 & & 32.9 & 80.0 & -- & IV & -- & 168 & STR \\
\hline 1934 & 12 & 9 & 5 & & & 33.0 & 80.2 & -- & IV & -- & 144 & BOL \\
\hline 1935 & 1 & 1 & 3 & 15 & & 35.1 & 83.6 & -- & V & -- & 272 & BOL \\
\hline 1941 & 5 & 10 & 11 & 12 & & 35.6 & 82.6 & -- & IV & -- & 280 & STR \\
\hline 1943 & 12 & 28 & 10 & 25 & & 33.0 & 80.2 & -- & IV & -- & 144 & BOL \\
\hline 1944 & 1 & 28 & 17 & 30 & & 32.9 & 80.0 & -- & IV & -- & 168 & STR \\
\hline 1945 & 1 & 30 & 20 & 20 & & 32.9 & 80.0 & -- & IV & -- & 168 & STR \\
\hline 1945 & 7 & 26 & 10 & 32 & 16.4 & 33.75 & 81.38 & 5 & V & 4.4 & 77 & $D \& G$ \\
\hline 1947 & 11 & 2 & 4 & 30 & & 32.9 & 80.0 & -- & IV & -- & 168 & STR \\
\hline 1949 & 2 & 2 & 10 & 52 & & 32.9 & 80.0 & -- & IV & -- & 168 & STR \\
\hline 1949 & 6 & 27 & 6 & 53 & & 32.9 & 80.0 & -- & IV & -- & 168 & STR \\
\hline 1951 & 3 & 4 & 2 & 55 & & 32.9 & 80.0 & -- & IV & -- & 168 & STR \\
\hline 1951 & 12 & 30 & 7 & 55 & & 32.9 & 80.0 & $\cdots$ & IV & -- & 168 & STR \\
\hline 1952 & 11 & 19 & & & & 32.8 & 80.0 & -- & V & -- & 168 & BOL \\
\hline 1956 & 1 & 5 & 3 & & & 34.3 & 82.4 & -- & IV & -- & 136 & BOL \\
\hline 1956 & 5 & 19 & 14 & & & 34.3 & 82.4 & -- & IV & -- & 136 & BOL \\
\hline 1956 & 5 & 27 & 18 & 25 & & 34.3 & 82.4 & -- & IV & -- & 136 & BOL \\
\hline 1957 & 5 & 13 & 14 & 24 & 51.1 & 35.8 & 82.14 & $5 *$ & VI & 4.1 & 296 & $D \& G$ \\
\hline 1957 & 7 & 2 & 9 & 33 & 1.0 & 35.6 & 82.6 & -- & VI & 4.6 & 280 & EUS \\
\hline 1957 & 11 & 24 & 20 & 6 & 17.0 & 35.0 & 83.5 & -- & VI & -- & 256 & BOL \\
\hline 1958 & 5 & 16 & 22 & 30 & & 35.6 & 82.6 & -- & IV & -- & 280 & EUS \\
\hline 1958 & 10 & 20 & 1 & 16 & & 34.5 & 82.8 & -- & $\mathrm{V}$ & $-\cdots$ & 176 & BOL \\
\hline 1959 & 8 & 3 & 6 & 8 & 36.8 & 33.05 & 80.13 & 2 & VI & 4.4 & 154 & $\mathrm{D} \& \mathrm{G}$ \\
\hline 1959 & 8 & 8 & 6 & 8 & 30.0 & 33.0 & 79.5 & -- & VI & -- & 216 & $\mathrm{BOL}$ \\
\hline 1959 & 10 & 27 & 2 & 7 & 28.0 & 34.5 & 80.2 & -- & VI & -- & 208 & EUS \\
\hline 1960 & 3 & 12 & 12 & 47 & 44.0 & 33.07 & 80.12 & 10 & V & 4.0 & 154 & $D \& G$ \\
\hline
\end{tabular}


Table 1. Significant Earthquakes within 300 Kilometers of SRS 1698-1988 (page 5 of 6)

(Intensity > IV or Magnitude > 3)

\begin{tabular}{|c|c|c|c|c|c|c|c|c|c|c|c|c|}
\hline \multicolumn{2}{|l|}{ Date } & \multirow[b]{2}{*}{$\begin{array}{l}\text { UTC } \\
\text { Day }\end{array}$} & \multirow[b]{2}{*}{ Hour } & \multicolumn{2}{|c|}{ Time } & \multicolumn{2}{|c|}{ Location } & \multirow{2}{*}{$\begin{array}{l}\text { Depth } \\
\text { KM }\end{array}$} & \multirow{2}{*}{$\begin{array}{l}\text { Inten. } \\
\text { MMI }\end{array}$} & \multirow[t]{2}{*}{ Mag } & \multirow{2}{*}{$\begin{array}{l}\text { Site } \\
\text { Dist. } \\
\text { KM }\end{array}$} & \multirow{2}{*}{$\begin{array}{l}\text { Data } \\
\text { Source }\end{array}$} \\
\hline Year & Month & & & Min. & Sec. & DEG N & DEG W & & & & & \\
\hline 1960 & 7 & 23 & & & & 33.0 & 80.0 & -- & V & -- & 168 & USE \\
\hline 1960 & 7 & 28 & 3 & 37 & 30.0 & 32.8 & 82.7 & -- & V & -- & 96 & EUS \\
\hline 1963 & 4 & 11 & 17 & 45 & & 34.9 & 82.4 & -- & IV & -- & 200 & EUS \\
\hline 1963 & 5 & 4 & 21 & 1 & 50.3 & 32.97 & 80.19 & $5^{*}$ & IV & 3.3 & 149 & $D \& G$ \\
\hline 1964 & 3 & 7 & 18 & 2 & 58.6 & 33.72 & 82.39 & 5 & -- & 3.3 & 85 & $D \& G$ \\
\hline 1964 & 3 & 13 & 1 & 20 & 17.5 & 33.19 & 83.31 & 2 & V & 3.9 & 142 & $D \& G$ \\
\hline 1964 & 4 & 20 & 19 & 4 & 44.1 & 33.84 & 81.10 & 3 & V & 3.5 & 99 & $D \& G$ \\
\hline 1965 & 9 & 9 & 14 & 42 & 20.0 & 34.7 & 81.2 & -- & -- & 3.9 & 176 & STR \\
\hline 1967 & 10 & 23 & 9 & 4 & 2.5 & 32.8 & 80.22 & 19 & V & 3.4 & 150 & $D \& G$ \\
\hline 1968 & 7 & 12 & 1 & 12 & & 32.8 & 79.7 & -- & IV & -- & 200 & STR \\
\hline 1968 & 9 & 22 & 21 & 41 & 18.2 & 34.11 & 81.48 & $2^{*}$ & IV & 3.5 & 110 & $D \& G$ \\
\hline 1969 & 5 & 18 & & & & 34.0 & 82.6 & -- & -- & $3.5 \mathrm{ML}$ & 120 & STR \\
\hline 1969 & 12 & 13 & 10 & 19 & 29.7 & 35.04 & 82.85 & 6 & V & 3.7 & 232 & $D \& G$ \\
\hline 1971 & 5 & 19 & 12 & 54 & 3.6 & 33.36 & 80.65 & $2^{*}$ & IV & 3.7 & 107 & $D \& G$ \\
\hline 1971 & 7 & 13 & 6 & 42 & 26.0 & 34.8 & 83.0 & $\cdots$ & IV & 3.8 & 216 & $\mathrm{BOL}$ \\
\hline 1971 & 7 & 31 & 20 & 16 & 55.0 & 33.34 & 80.63 & 3 & III & 3.8 & 109 & $D \& G$ \\
\hline 1971 & 8 & 11 & 3 & 50 & & 33.4 & 80.7 & -- & -- & 3.5 & 104 & BOL \\
\hline 1972 & 2 & 3 & 23 & 11 & 9.7 & 33.31 & 80.58 & 2 & V & 4.5 & 114 & $D \& G$ \\
\hline 1972 & 8 & 14 & 15 & 5 & & 33.2 & 81.4 & -- & -- & 3.0 & 16 & GS \\
\hline 1973 & 12 & 19 & 10 & 16 & 8.7 & 32.97 & 80.27 & 16 & -- & 3.0 & 141 & $D \& G$ \\
\hline 1974 & 8 & 2 & 8 & 52 & 11.1 & 33.91 & 82.53 & 3 & VI & 4.1 & 109 & $D \& G$ \\
\hline 1974 & 10 & 28 & 11 & 33 & & 33.79 & 81.92 & -- & IV & 3.0 & 72 & $\mathrm{CSC}$ \\
\hline 1974 & 11 & 5 & 3 & & & 33.73 & 82.22 & -- & III & 3.7 & 77 & $\mathrm{CSC}$ \\
\hline 1974 & 11 & 22 & 5 & 25 & 56.2 & 32.92 & 80.14 & 8 & VI & 4.3 & 154 & $\mathrm{D} \& \mathrm{G} / \mathrm{BOL}$ \\
\hline 1974 & 12 & 3 & 8 & 25 & & 33.95 & 82.5 & -- & III & 3.6 & 110 & $\mathrm{CSC}$ \\
\hline 1975 & 4 & 1 & 21 & 9 & & 33.2 & 83.2 & -- & -- & $3.9 \mathrm{ML}$ & 131 & STR \\
\hline 1975 & 4 & 28 & 5 & 46 & 52.6 & 33.0 & 80.22 & 10 & IV & $3.0 \mathrm{ML}$ & 146 & STR \\
\hline 1975 & 10 & 18 & 4 & 31 & & 34.9 & 83.0 & -- & IV & -- & 224 & STR \\
\hline 1975 & 11 & 25 & 15 & 17 & 34.8 & 34.93 & 82.93 & 2 & IV & 3,2 & 224 & $\mathrm{D \& G} / \mathrm{GS}$ \\
\hline 1976 & 12 & 27 & 6 & 57 & 15.2 & 32.06 & 82.5 & 14 & V & 3.7 & 138 & $D \& G / G S$ \\
\hline 1977 & 1 & 18 & 18 & 29 & 14.2 & 33.04 & 80.21 & 11 & VI & $3.0 \mathrm{ML}$ & 146 & STR \\
\hline 1977 & 3 & 30 & 8 & 27 & 47.8 & 32.95 & 80.18 & 8 & V & $2.9 \mathrm{Ms}$ & 150 & STR \\
\hline 1977 & 8 & 25 & 4 & 20 & 7.0 & 33.39 & 80.69 & -- & V & 3.1 & 104 & GS \\
\hline 1977 & 12 & 15 & 19 & 16 & 43.1 & 32.92 & 80.22 & -- & V & 3.0 & 147 & GS \\
\hline 1979 & 9 & 6 & 20 & 38 & 16.3 & 35.3 & 83.24 & 10 & -- & $3.2 \mathrm{ML}$ & 274 & VPI \\
\hline 1980 & 6 & 10 & 23 & 47 & 32.1 & 35.46 & 82.81 & $2^{*}$ & -- & 3.0 & 272 & VPI \\
\hline 1981 & 4 & 9 & 7 & 10 & 31.2 & 35.51 & 82.05 & $-\div$ & -- & 3.0 & 262 & VPI \\
\hline 1981 & 5 & 5 & 21 & 21 & 56.7 & 35.33 & 82.42 & 10 & -- & 3.5 & 248 & VPI \\
\hline 1982 & 1 & 28 & 5 & 52 & 52.01 & 32.98 & 81.39 & -- & -- & 3.4 & 20 & GS \\
\hline 1982 & 10 & 31 & 3 & 12 & 12.2 & 32.64 & 84.90 & $0^{*}$ & -- & 3.1 & 294 & VPI \\
\hline 1982 & 12 & 11 & & 25 & 6.7 & 32.71 & 83.47 & & -- & $3.0 \mathrm{M} 1$ & 165 & VPI \\
\hline 1985 & 6 & 9 & & 38 & 42.93 & 33.22 & 81.69 & 1 & III & $2.6 \mathrm{ML}$ & & SRL \\
\hline 1986 & 1 & 7 & & 26 & 43.3 & 35.61 & 84.76 & 23.1 & -- & 3.1 & & BOL \\
\hline 1986 & 2 & 13 & 11 & 33 & -- & -- & -- & $\cdots$ & -- & 3.2 & & USC \\
\hline 1986 & 3 & 13 & 2 & 29 & 31.6 & 33.23 & 83.23 & 5.0 & IV & 3.3 & & BOL \\
\hline
\end{tabular}


Table 1. Significant Earthquakes within 300 Kilometers of SRS 1698-1988 (page 6 of 6 )

(Intensity > IV or Magnitude > 3)

\begin{tabular}{|c|c|c|c|c|c|c|c|c|c|c|c|c|}
\hline \multirow{2}{*}{$\begin{array}{l}\text { Date } \\
\text { Year }\end{array}$} & \multirow[b]{2}{*}{ Month } & \multirow[b]{2}{*}{$\begin{array}{l}\text { UTC } \\
\text { Day }\end{array}$} & \multirow[b]{2}{*}{ Hour } & \multicolumn{2}{|c|}{ Time } & \multicolumn{2}{|c|}{ Location } & \multirow{2}{*}{$\begin{array}{l}\text { Depth } \\
\text { KM }\end{array}$} & \multirow{2}{*}{$\begin{array}{l}\text { Inten. } \\
\text { MMI }\end{array}$} & \multirow[t]{2}{*}{ Mag } & \multirow{2}{*}{$\begin{array}{l}\text { Site } \\
\text { Dist. } \\
\text { KM }\end{array}$} & \multirow{2}{*}{$\begin{array}{l}\text { Data } \\
\text { Source }\end{array}$} \\
\hline & & & & Min. & Sec. & DEG $N$ & DEG W & & & & & \\
\hline 1986 & 3 & 26 & 16 & 36 & 23.9 & 37.25 & 80.49 & 11.9 & IV & 3.3 & & $\mathrm{BOL}$ \\
\hline 1986 & 4 & 19 & 7 & 40 & 53.0 & 35.19 & 85.51 & 27.3 & -- & 3.0 & & $\mathrm{BOL}$ \\
\hline 1986 & 7 & 11 & 14 & 26 & 14.8 & 34.94 & 84.99 & 13.0 & VI & 3.7 & & BOL \\
\hline 1986 & 9 & 17 & 9 & 233 & 49.5 & 32.93 & 80.16 & 6.7 & IV & 3.3 & & BOL \\
\hline 1986 & 12 & 3 & 9 & 44 & 21.2 & 37.58 & 77.49 & 1.6 & IV & 3.3 & & $\mathrm{BOL}$ \\
\hline 1986 & 12 & 10 & 11 & 30 & 6.1 & 37.59 & 77.47 & 1.2 & $\mathrm{~V}$ & 3.5 & & $\mathrm{BOL}$ \\
\hline 1986 & 12 & 24 & 17 & 58 & 38.3 & 37.58 & 77.49 & 1.0 & IV & 3.3 & & BOL \\
\hline 1987 & 1 & 13 & 14 & 50 & 40.9 & 37.58 & 77.47 & 2.5 & IV & 3.3 & & $\mathrm{BOL}$ \\
\hline 1987 & 3 & 16 & 13 & 9 & 26.8 & 34.56 & 80.95 & 3.0 & -- & 3.1 & & BOL \\
\hline 1987 & 3 & 27 & 7 & 29 & 30.5 & 35.57 & 84.23 & 18.5 & VI & 4.2 & & BOL \\
\hline 1987 & 5 & 20 & 29 & 47 & 41.9 & 37.79 & 83.39 & 0.7 & -- & 3.0 & & $\mathrm{BOL}$ \\
\hline 1987 & 6 & 4 & 17 & 19 & 23.4 & 37.94 & 85.8 & 7.6 & -- & 3.1 & & $\mathrm{BOL}$ \\
\hline 1987 & 7 & 11 & 0 & 4 & 29.5 & 36.11 & 83.82 & 25.1 & V & 3.9 & & BOL \\
\hline 1987 & 7 & 11 & 2 & 48 & 5.9 & 36.1 & 83.82 & 23.8 & IV & 3.5 & & BOL \\
\hline 1987 & 9 & 1 & 23 & 2 & 49.4 & 35.52 & 84.4 & 21.1 & -- & 3.1 & & BOL \\
\hline 1987 & 9 & 22 & 17 & 23 & 50.1 & 35.62 & 84.31 & 19.4 & V & 3.3 & & BOL \\
\hline 1987 & 11 & 27 & 18 & 58 & 29.3 & 36.85 & 83.11 & 26.8 & V & 3.5 & & BOL \\
\hline 1987 & 12 & 12 & 3 & 53 & -- & -- & -- & -- & -- & 3.1 & & USC \\
\hline 1988 & 1 & 9 & 1 & 7 & 40.6 & 35.28 & 84.2 & 12.2 & IV & 3.2 & & BOL \\
\hline 1988 & 1 & 23 & 1 & 57 & 16.4 & 32.94 & 80.16 & 7.4 & V & 3.3 & & BOL \\
\hline 1988 & 2 & 16 & 15 & 26 & 54.8 & 36.6 & 82.27 & 4.0 & IV & 3.3 & & BOL \\
\hline 1988 & 2 & 18 & & 37 & 45.4 & 35.35 & 83.94 & 2.4 & IV & 3.3 & & BOL \\
\hline 1988 & 8 & 27 & 16 & 52 & 29.5 & 37.72 & 77.78 & 14.3 & IV & 3.3 & & $\mathrm{BOL}$ \\
\hline 1988 & 9 & 7 & 2 & 28 & 8.6 & 38.14 & 83.83 & 10.0 & VI & 4.5 & & BOL \\
\hline 1988 & 9 & 7 & 2 & 30 & 2.9 & 38.17 & 83.76 & 8.0 & -- & 3.8 & & BOL \\
\hline
\end{tabular}

1 Asterisk (*) indicates that the depth has been constrained to enable stable earthquake location solution.

2 Magnitude is given as body wave magnitude ( $\mathrm{mb}$ ), unless otherwise specitied as local magnitude (ML) or surface wave magnitude (Ms). 
Table 2. South Carolina Earthquakes 1986-1989 (page 1 of 2)

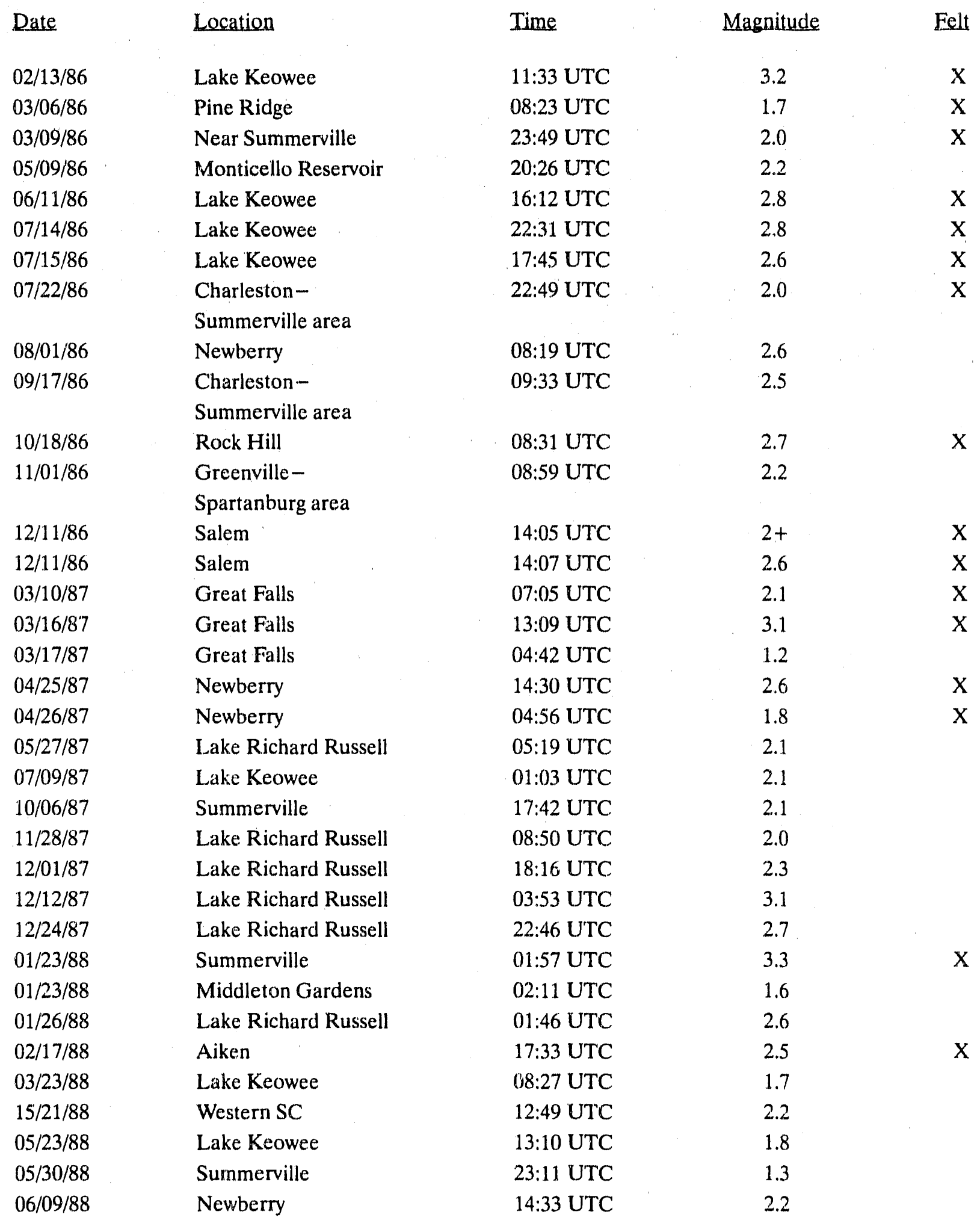


Table 2. South Carolina Earthquakes 1986-1989 (page 2 of 2.)

$\begin{array}{lllc}\text { Date } & \text { Location } & \text { Time } & \text { Magnitude } \\ 06 / 15 / 88 & \text { Western SC } & 14: 46 \text { UTC } & 1.4 \\ 06 / 23 / 88 & \text { Summerville } & 12: 05 \text { UTC } & 2.0 \\ 07 / 19 / 88 & \text { Monticello Reservoir } & 19: 31 \text { UTC } & 2.0 \\ 08 / 05 / 88 & \text { SRS } & 03: 59 \text { UTC } & 2.0 \\ 10 / 27 / 88 & \text { Middleton Gardens } & 03: 47 \text { UTC } & 1.2 \\ 11 / 30 / 88 & \text { Slandsville } & 13: 58 \text { UTC } & 1.2 \\ 12 / 13 / 88 & \text { Charleston } & 03: 00 \text { UTC } & 2.0 \\ 09 / 30 / 88 & \text { Monticello Reservoir } & 17: 46 \text { UTC } & 2.1 \\ 01 / 02 / 89 & \text { Charleston } & 16: 35 \text { UTC } & 1.6 \\ 01 / 04 / 89 & \text { Bluffton-Hilton Head } & 09: 39 \text { UTC } & 2.8 \\ 01 / 21 / 89 & \text { Charleston } & 23: 50 \text { UTC } & 1.6 \\ 04 / 22 / 89 & \text { Charleston } & 09: 29 \text { UTC } & 0.8 \\ 05 / 03 / 89 & \text { Charleston } & 01: 39 \text { UTC } & 1.2 \\ 06 / 02 / 89 & \text { Middleton Gardens } & 05: 04 \text { UTC } & 1.9 \\ 06 / 06 / 89 & \text { Charleston } & 16: 06 \text { UTC } & 1.1 \\ 06 / 08 / 89 & \text { Charleston } & 08: 52 \text { UTC } & 1.6 \\ 10 / 20 / 89 & \text { Charleston } & 05: 55 \text { UTC } & 0.8 \\ 11 / 02 / 89 & \text { Charleston } & 07: 58 \text { UTC } & 1.0\end{array}$


Table 3. Recent Recorded Earthquakes Near SRS

\begin{tabular}{|c|c|c|c|c|}
\hline Date & $\begin{array}{c}\text { Origin Time } \\
\text { UTC }\end{array}$ & $\begin{array}{l}\text { Latitude } \\
\text { (Deg,N) }\end{array}$ & $\begin{array}{l}\text { Longitude } \\
\text { (Deg,W) }\end{array}$ & $\begin{array}{c}\text { Magnitude } \\
\mathrm{M}_{\mathrm{r}}\end{array}$ \\
\hline $08 / 14 / 72$ & 15:05:? & 33.2 & 81.4 & 3.0(USGS) \\
\hline $09 / 15 / 76$ & $05: 15: 35.4$ & 33.14 & 81.41 & $2.5(\mathrm{SRS})$ \\
\hline $06 / 05 / 77$ & $00: 42: 29.73$ & 33.05 & 81.41 & 2.7 (USGS) \\
\hline $01 / 28 / 82$ & $05: 5 ?: 52.1$ & 32.98 & 81.39 & 3.4 (USGS) \\
\hline $06 / 09 / 85$ & $0 \cap: 38: 42.93$ & 33.22 & 81.69 & $2.6(\mathrm{SRS})$ \\
\hline $02 / 17 / 88$ & $17: 33: 33.04$ & 33.61 & 81.72 & 2.6 (USCS) \\
\hline $08 / 05 / 88$ & $03: 59: 21.8$ & 33.22 & 81.66 & $2.0(\mathrm{SRS})$ \\
\hline
\end{tabular}


Table 4. Magnitude Recurrence Relations

Area

Southeastern United States

Valley \& Ridge/Blue Ridge

Giles County, Virginia

Piedmont

Central Virginia

Eastern Tennessee

Coastal Plain

Charleston, South Carolina
Recurrence Relation

$\log N_{l}=3.13-0.84 \mathrm{~m}_{b}(\mathrm{Lg}) \quad 861$

$\log N_{l}=2.67-0.82 m_{b}(\mathrm{Lg}) \quad 395$

$\log \mathrm{N}_{\mathrm{l}}=0.94-0.64 \mathrm{~m}_{\mathrm{b}}(\mathrm{Lg}) \quad 28$

$\log N_{\mathrm{I}}=2.16-0.81 \mathrm{~m}_{\mathrm{b}}(\mathrm{Lg})$

$\log N_{\mathrm{l}}=1.06-0.64 \mathrm{~m}_{\mathrm{b}}(\mathrm{Lg}) \quad 94$

$\log N_{\mathrm{I}}=2.75-0.90 \mathrm{mb}_{\mathrm{b}}(\mathrm{Lg}) \quad 239$

$\log N_{\mathrm{I}}=2.19-0.78 \mathrm{~m}_{\mathrm{b}}(\mathrm{Lg}) \quad 188$

$\log N_{\mathrm{l}}=1.65-0.77 \mathrm{~m}_{\mathrm{b}}(\mathrm{Lg}) \quad 84$

Notes: $\quad N_{l}=$ Number of earthquakes per year in \pm 0.25 magnitude intervals.

$\mathrm{n}=$ Number of earthquakes useds in completeness testing after deletion of aftershocks. 


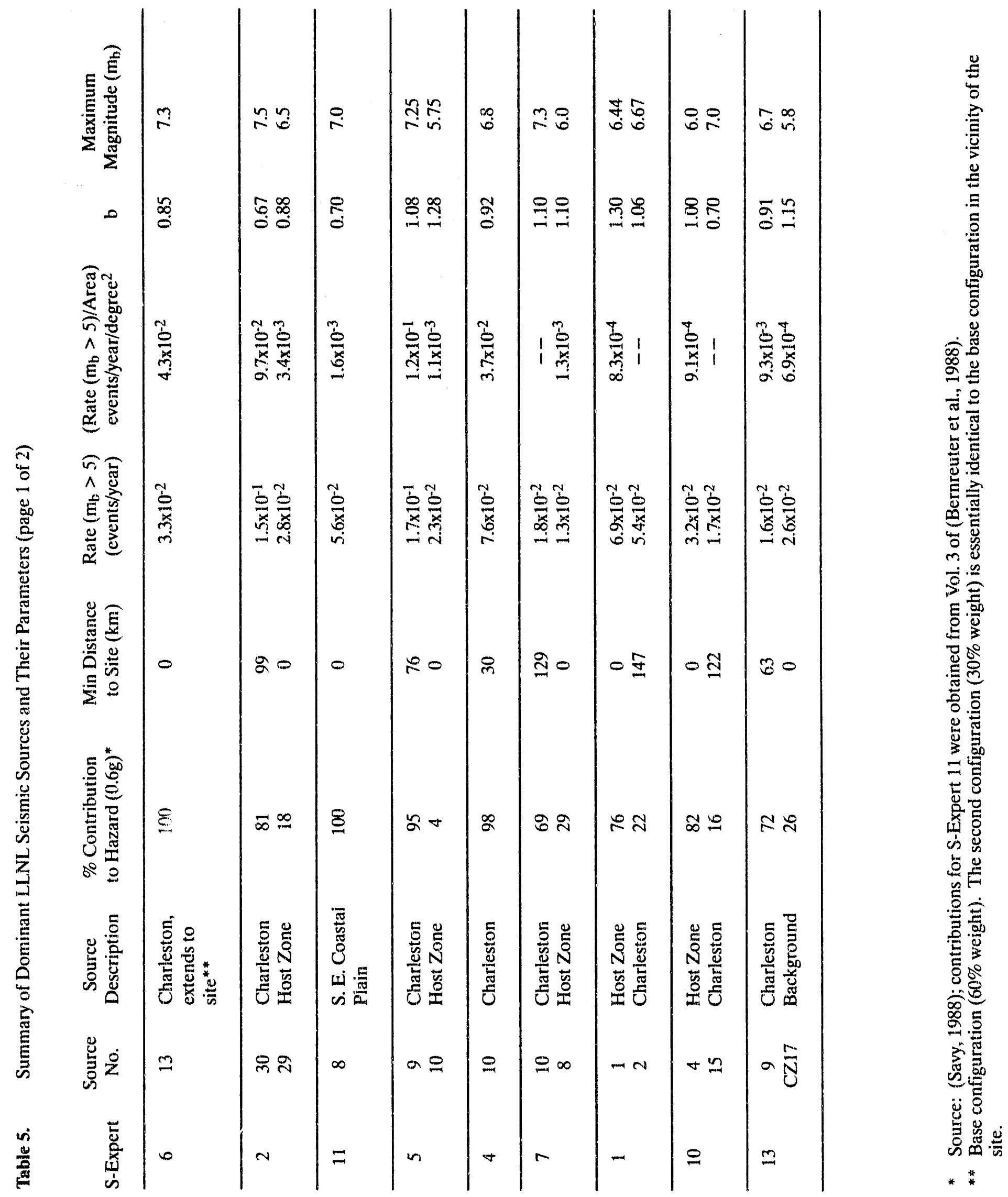




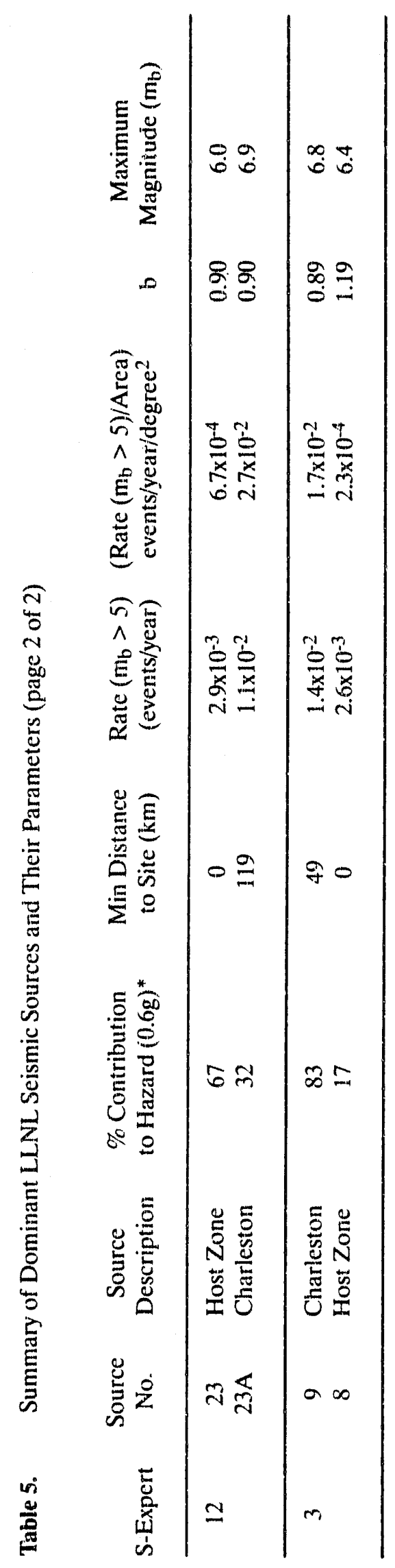




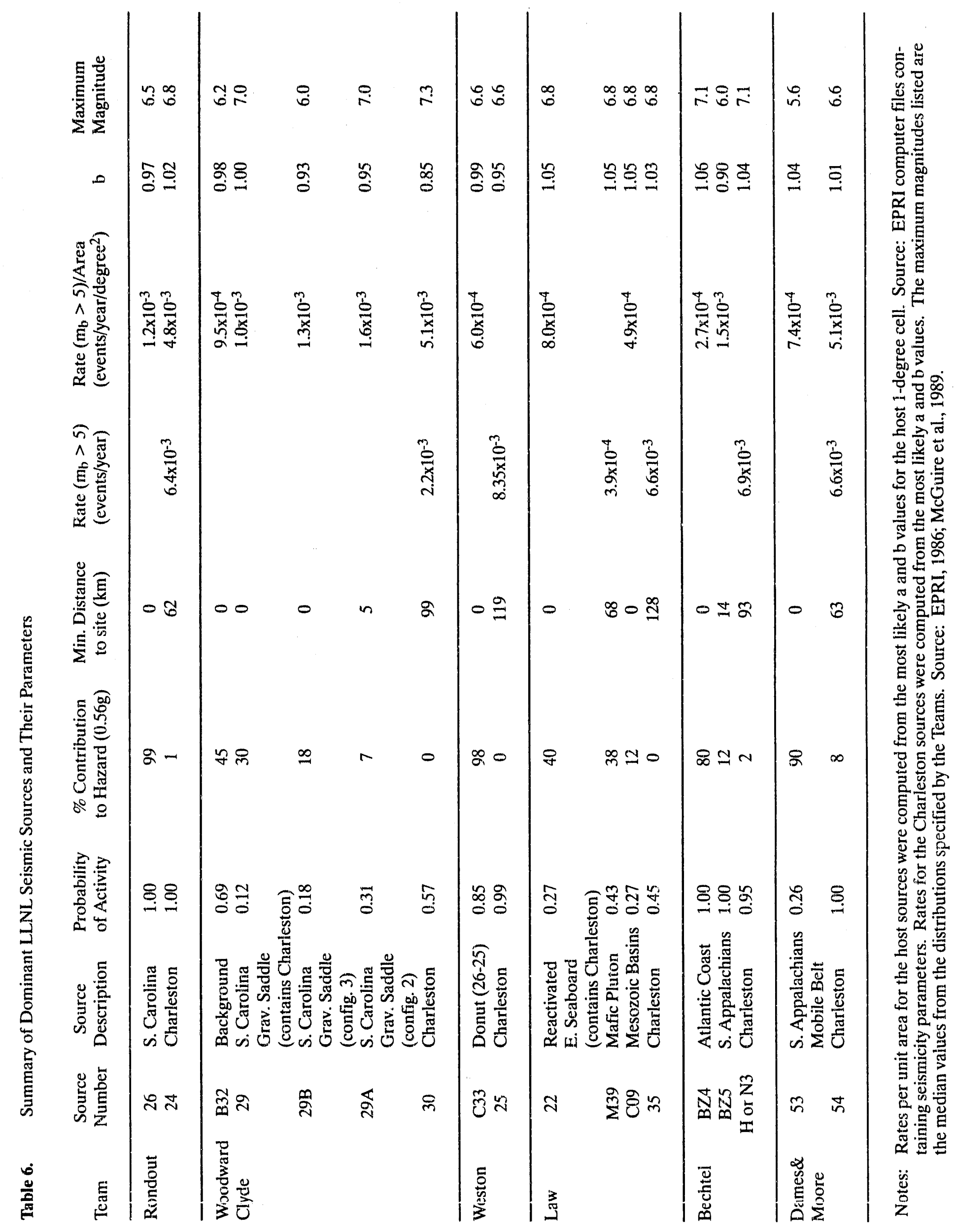


Table 7. Intensity-Based Peak Ground Acceleration Attenuation Models

Model No.

Equation

1

Bollinger (1977)/Murphy-O'Brien (1977)

$\ln (\mathrm{PGA})=-4.644+0.58 \mathrm{I}_{\mathrm{o}}-0.726 \operatorname{In}(\mathrm{R})-0.000302 \mathrm{R}$

$\mathrm{R}^{*}{ }_{\min }-10 \mathrm{~km}$

2

Gupta-Nuttli (1976)/Murphy-O'Brien (1977)

$\operatorname{In}(P G A)=-4.453+0.58 I_{o}-0.679 \operatorname{In}(R)$

$\mathrm{R}_{\min }-10 \mathrm{~km}$

3

Bollinger (1977)/Trifunac (1976)

$\operatorname{In}(P G A)=-5.159+0.67 I_{0}-0.840 \operatorname{In}(R)-0.0008 R$

$\mathrm{R}_{\min }-10 \mathrm{~km}$

4

Bollinger (1977)/Bernreuter (1981)

$\operatorname{In}(P G A)=-4.119+0.13 M_{L}-0.630 I_{0}-0.790 \operatorname{In}(R)-0.0003 R$

$\mathrm{R}_{\min }-10 \mathrm{~km}$

5

Bollinger (1977)/Murphy-O'Brien (1977)

$\operatorname{In}(P G A)=-4.589+0.55 M_{L}-0.32 I_{o}-1.082 \operatorname{In}(R)-0.0002 R$

$R_{\min }-10 \mathrm{~km}$

6

Trifunac-Anderson (1977)

$\operatorname{In}(P G A)=-4.939+0.567 I_{o}-0.789 \operatorname{In}(R)-0.0007 R$

$\mathrm{R}_{\min }-10 \mathrm{~km}$

7

Gupta-Nuttli (1976)/Murphy-O'Brien (1977)

$\operatorname{In}(P G A)=-4.489+0.55 M_{L}-0.32 I_{o}-1.05 \operatorname{In}(R)$

$\mathrm{R}_{\min }-15 \mathrm{~km}$

$\mathrm{R}^{*}{ }_{\min }$ is the minimum distance applicable for the attenuation model.

Models 1, 3, 4, and 5 are based on attenuation of Modified Mercalli Intensity in South Carolina due to the 1886 Charleston earthquake. 
Table 8. Magnitude-Based Models Peak Ground Acceleration Attenuation Models (page 1 of 2)

Model No.

\section{Equation}

1

Nuttli et al., (1983)

$$
\begin{aligned}
& \operatorname{In}(\mathrm{PGA})=-2.994+0.576 \mathrm{~m}_{\mathrm{b}}-0.833 \operatorname{In}\left[\left(\mathrm{R}^{2}+\mathrm{h}^{2}\right)^{1 / 2}\right]-0.000975 \mathrm{R} \\
& \mathrm{m}_{\mathrm{b}}<4.5 \\
& \operatorname{In}(\mathrm{PGA})=-5.577+1.15 \mathrm{~m}_{\mathrm{b}}-0.833 \operatorname{In}\left[\left(\mathrm{R}^{2}+\mathrm{h}^{2}\right)^{1 / 2}\right]-0.000593 \mathrm{R} \\
& \mathrm{m}_{\mathrm{b}} \geq 4.5
\end{aligned}
$$

$\mathrm{h}=$ hypocentral depth

2

Nuitli et al., (1983)

$\operatorname{In}(P G A)=-5.439+1.13 m_{b}-0.95 \operatorname{In}(R)-0.00046 R$

$R_{\min }-10 \mathrm{~km}$

3

Campbell (1982)

$$
\begin{aligned}
& \operatorname{In}(P G A)=-4.289+0.777 m_{b}-0.797 \operatorname{In}[R+0.012 \exp (0.898 M)]-R \\
& R=\text { closest distance to fault rupture } \\
& \quad=\text { frequency-dependent absorption coefficient }
\end{aligned}
$$

4

Nuttli et al., (1983)

$$
\begin{aligned}
& \operatorname{In}(\mathrm{PGA})=-5.231+1.128 \mathrm{~m}_{\mathrm{b}}-1.00 \operatorname{In}(\mathrm{R})-0.0003 \mathrm{R} \\
& \mathrm{R}=\left(\mathrm{r}^{2}+\mathrm{h}^{2}\right)^{!} \cdot 2 \\
& \mathrm{r}=\text { epicentral distance } \\
& \mathrm{h}=\text { hypocentral depth }
\end{aligned}
$$


Table 8. Magnitude-Based Models Peak Ground Acceleration

Attenuation Models (page 2 of 2)

Model No.

5

Bernreuter (1984)

Nuttli (Ref. B-9)

$\operatorname{In}($ PGA $)=-2.997+0.576 m_{b}-0.833 \operatorname{In}(R)-0.0027 R$

$\mathrm{m}_{\mathrm{b}} \leq 4.5$

$R=\left(r^{2}+h^{2}\right)^{1 / 2}$

$\mathrm{r}=$ epicentral distance

$\mathrm{h}=64$

$\operatorname{In}(P G A)=-5.576+1.152 m_{b}-0.833 \operatorname{In}(R)-0.0027 R$

$\mathrm{m}_{\mathrm{b}}>4.4$

$h=10\left(-3.46+0.456 m_{b}\right)$

$r$ = epicentral distance

6

Bernreuter et al., (1984)

Nuttli (Ref. B-9)

$\operatorname{In}(P G A)=-2.997+0.576 m_{b}-0.833 \operatorname{In}(R)-0.0028 R$

$\mathrm{m}_{\mathrm{b}} \leq 4.4$

$\operatorname{In}(\mathrm{PGA})=-5.576+1.152 \mathrm{~m}_{\mathrm{b}}-0.833 \operatorname{In}(\mathrm{R})-0.0028 \mathrm{R}$

$\mathrm{m}_{\mathrm{b}}>4.4$

$\mathrm{r}, \mathrm{h}=($ see model 5$)$

7

Nuttli (1979)

$\operatorname{In}(P G A)=-5.408+1.15 m_{b}-0.833 \operatorname{In}(R)-\left(0.0136-0.00172 m_{b}\right) R$

Models 1, 2, and 4 were developed specifically for ground motion attenuation in South Carolina. 
Table 9. Seismic Analysis of SRS Non-Reactor Facilities

Facility

Separations Facilities

DWPF

Waste Tanks

RBOF

RTF (only areas considered critical)

FMF

L. Lake Dam

PAR Pond Dam

NPR (Preliminary Design)
Zero Period Acceleration Used in the Analysis
$0.20 \mathrm{~g}$
$0.20 \mathrm{~g}$
$0.20 \mathrm{~g}$
$0.20 \mathrm{~g}$
$0.20 \mathrm{~g}$
0.12 and $0.18 \mathrm{~g}$
$0.20 \mathrm{~g}$
$0.10-0.12 \mathrm{~g}$
$0.30 \mathrm{~g}$ 


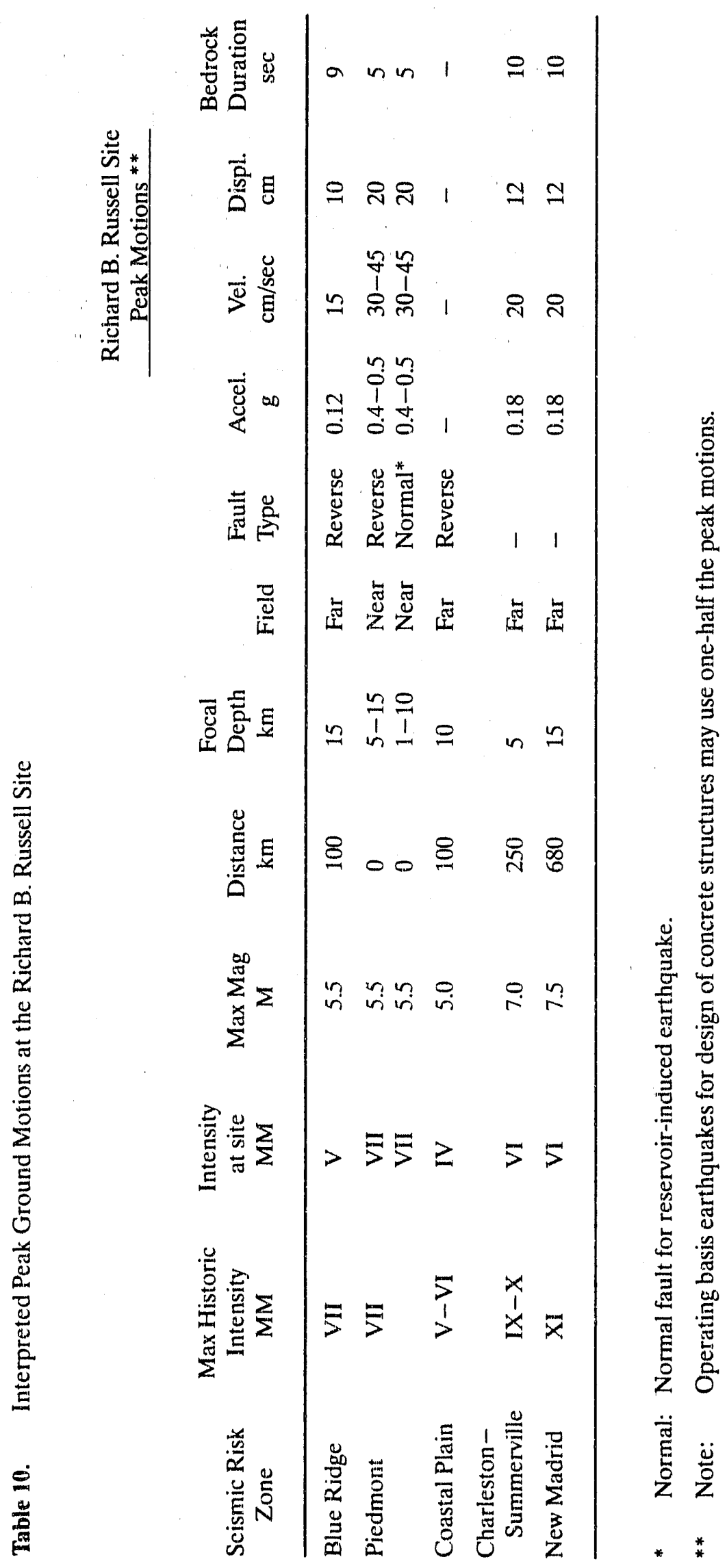



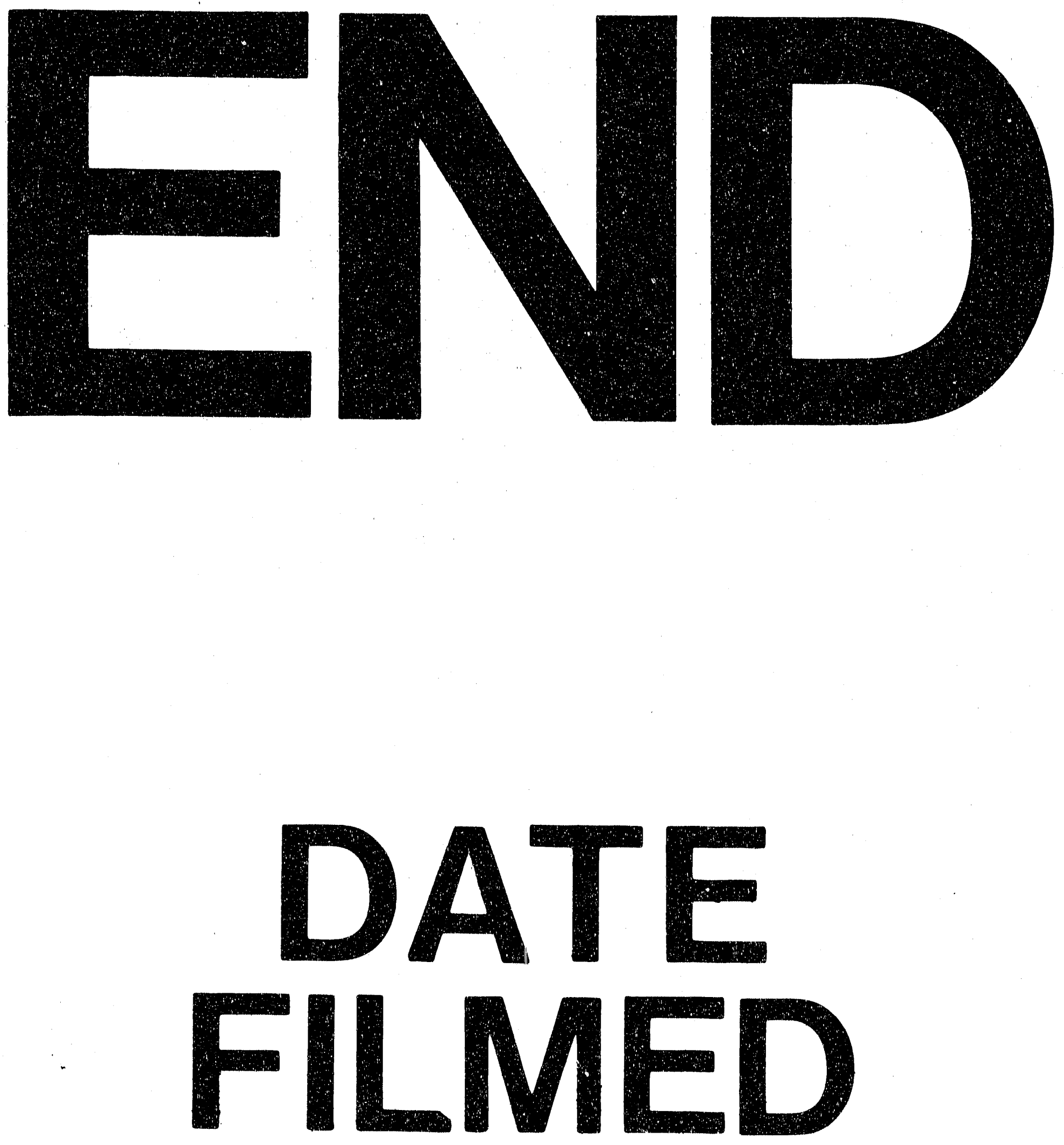

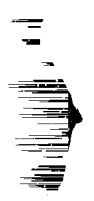

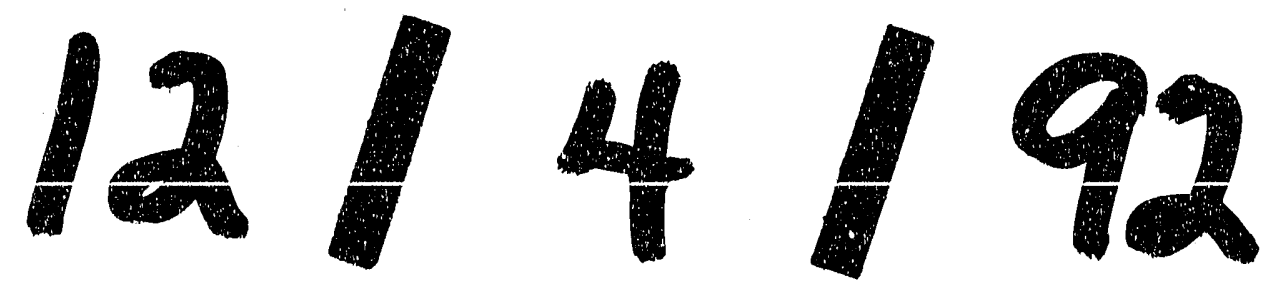


㺼 